Florida International University FIU Digital Commons

3-29-2018

\title{
The Effect of Vitamin D3 Supplementation of Biomarkers of Oxidative Stress and Glycemic Status in Adults with Type 2 Diabetes
}

Sahar Ajabshir

sajab001@fiu.edu

DOI: $10.25148 /$ etd.FIDC006523

Follow this and additional works at: https://digitalcommons.fiu.edu/etd

Part of the Nutrition Commons

\section{Recommended Citation}

Ajabshir, Sahar, "The Effect of Vitamin D3 Supplementation of Biomarkers of Oxidative Stress and Glycemic Status in Adults with Type 2 Diabetes" (2018). FIU Electronic Theses and Dissertations. 3649.

https://digitalcommons.fiu.edu/etd/3649 


\title{
FLORIDA INTERNATIONAL UNIVERSITY
}

Miami, Florida

\section{THE EFFECT OF VITAMIN D3 SUPPLEMENTATION ON BIOMARKERS OF OXIDATIVE STRESS AND GLYCEMIC STATUS IN ADULTS WITH TYPE 2 DIABETES}

\author{
A dissertation submitted in partial fulfillment of \\ the requirements for the degree of \\ DOCTOR OF PHILOSOPHY \\ in \\ DIETETICS AND NUTRITION \\ by
}

Sahar Ajabshir 
To: Dean Tomás R. Guilarte

Robert Stempel College of Public Health and Social Work

This dissertation, written by Sahar Ajabshir, and entitled The Effect of Vitamin D3 Supplementation on Biomarkers of Oxidative Stress and Glycemic Status in Adults with Type 2 Diabetes, have been approved in respect to style and intellectual content, and is referred to you for judgment.

We have read this dissertation and recommend that it be approved.

Adriana Campa

Juan Liuzzi

Tan Li

Fatma G. Huffman, Major Professor

Date of Defense: March 29, 2018

The dissertation of Sahar Ajabshir is approved.

Vice President for Research and Economic Development and Dean of the University Graduate School

Florida International University, 2018 


\section{DEDICATION}

I dedicate this dissertation to my mother Mrs. Homa Naeimiamini, my father Mr. Abbas Ajabshir, my brother Dr. Ramin Ajabshir, and my sister Ms. Sanaz Ajabshir. Because of their unconditional love, support, encouragement, and sacrifices this work became completed.

I dedicated this dissertation to my dearest friends and the rest of my beloved family who have always been there for me during this journey. 


\section{ACKNOWLEDGMENTS}

I would like to express my heartfelt gratitude to my major professor and academic mother, Dr. Fatma Huffman, whose guidance and dedication empowered me to reach my potential. Thank you for believing in me, for cultivating me and for all the opportunities you gave me. I would like to thank Dr. Adriana Campa for her exemplary dedication and investment in supporting younger researchers and for her kind heart. I would like to thank Dr. Juan Liuzzi for all his help, time and encouragement throughout different stages in my journey. I would like to thank Dr. Tan Li for his time, efforts and patience in giving me statistical advices. Special thanks to Dietetics and Nutrition Department and University Graduate School at Florida International University for their financial support. 


\begin{abstract}
OF THE DISSERTATION
THE EFFECT OF VITAMIN D3 SUPPLEMENTATION ON BIOMARKERS OF

OXIDATIVE STRESS AND GLYCEMIC STATUS IN ADULTS WITH TYPE 2

DIABETES

by
\end{abstract}

Sahar Ajabshir

Florida International University, 2018

Miami, Florida

Professor Fatma G. Huffman, Major Professor

The aim of the present study was to assess the effect of $4000 \mathrm{IU}$ and $6000 \mathrm{IU}$ of daily vitamin D3 supplementation for 3 months and 6 months on 8-hydroxy-2`deoxyguanosine $(8-\mathrm{OHdG})$ and glycated albumin (GA\%) among a group of individuals with T2D and hypovitaminosis D. Furthermore, this study investigated the association between dietary inflammatory index (DII), C-reactive protein (CRP), 8-OHdG, hemoglobin A1C (HbA1c), GA\% and insulin. Ninety participants were recruited by community outreach and were screened. Sixty-eight participants met the inclusion criteria were enrolled and completed the study. DII for each individuals was calculated based on the values obtained from a validated food frequency questionnaire. Measurements of variables were conducted at baseline, after 3 months and after 6 months of supplementation. Serum CRP, 8-OHdg, GA\%, HbA1c and insulin were measured by enzymatic immunoassay methods. Mixed model was used to compare treatment groups. Covariates in the adjusted model included age, gender, body mass index (BMI), insulin, HbA1c, years with type 2 diabetes, perceived stress, physical activity, and sun exposure. 
Mean age was $54.94 \pm 7.93$ years. A multivariable linear regression model adjusted for age, gender, waist circumference, and fasting plasma glucose was used to test for the linear trend between DII and CRP, 8-OHdG, GA\% and insulin. The unadjusted model showed no significant associations between quartiles of DII, CRP, HbA1c and GA\%. A significant inverse association was observed between the fourth DII quartile and insulin level $(p=0.030)$. There was a significant association between SBP and DII in Q4 $(p=0.029)$. The unadjusted mean \pm SD for 8 -OHdG levels at baseline, after 3 and 6 months were 8068.94 $\pm 2158.13 \mathrm{pg} / \mathrm{mL}, 9462.22 \pm 2403.89 \mathrm{pg} / \mathrm{mL}$, and $7412.69 \pm 2031.68 \mathrm{pg} / \mathrm{mL}$, respectively. The unadjusted mixed model showed no difference between the 4000 and $6000 \mathrm{IU}$ groups regarding the oxidative stress and GA\%. Interactions between time and treatment were not significant. The model showed a statistically significant difference in 8-OHdG level between baseline and 3 months $(\mathrm{P}<0.001), 3$ months and 6 months $(\mathrm{P}<0.001)$, and baseline and 6 months $(\mathrm{P}=0.016)$. The unadjusted mean $\pm \mathrm{SD}$ for $\mathrm{GA} \%$ at baseline, 3 months and 6 months were $4.69 \pm 1.7,4.13 \pm 1.09$, and $4.42 \pm 1.23$, respectively. Unadjusted pairwise comparisons between GA\% were a statistically significant from baseline to 3 months $(P=0.015)$, and from 3 months to 6 months $(P=0.039)$, but not from baseline to 6 months $(P=0.488)$. The results of the present study showed daily oral supplementation with higher doses of vitamin D for 6 months may have beneficial effects on oxidative stress and glycemic status among a group of individuals with type 2 diabetes and vitamin D deficiency/insufficiency. Furthermore, pro-inflammatory dietary patterns may be associated with increased risk of hyperinsulinemia and hypertension among individuals with T2D and hypovitaminosis D. 


\section{TABLE OF CONTENTS}

CHAPTER PAGE

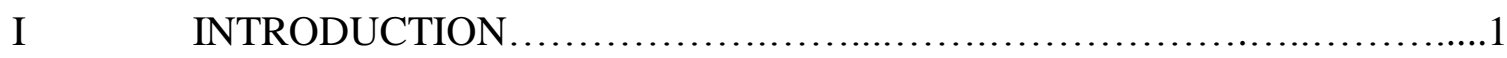

Type 2 diabetes and inflammation.........................................

Dietary inflammatory index.............................................4

Type 2 diabetes and oxidative stress.......................................5

Oxidative stress and vitamin D............................................ 7

Type 2 diabetes and early glycation products.................................... 7

Oxidative stress, inflammation and glycated albumin......................10

Type 2 diabetes and vitamin D........................................ 10

Vitamin D and glycated albumin.......................................... 12

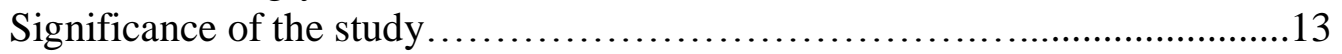

Specific aims and hypothesis.........................................14

REFERENCES..................................................... 16

II ASSOCIATION BETWEEN DIETARY INFLAMMATORY INDEX AND SERUMIN VITAMIN D, OXIDATIVE STRESS, INFLAMMATION, AND GLYCEMIC STATUS IN ADULTS WITH TYPE 2 DIABETES .................................................. 24

Introduction........................................................24

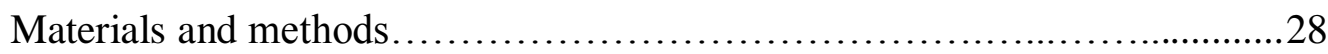

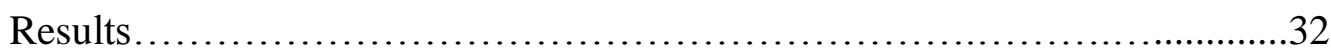

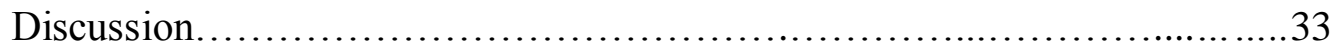

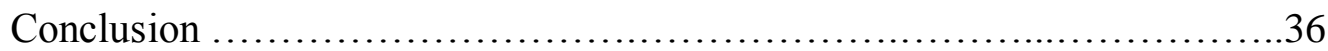

REFERENCES ....................................................... 40

III EFFECT OF VITAMIN D3 SUPPLEMENTATION ON DNA/RNA OXIDATIVE STRESS IN ADULTS WITH TYPE 2 DIABETES

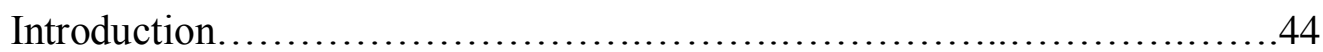

Materials and methods..................................................47

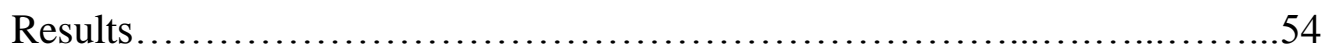

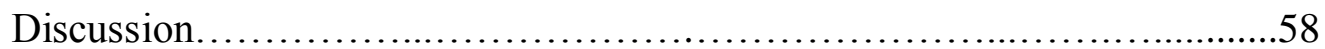

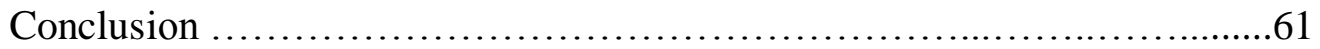

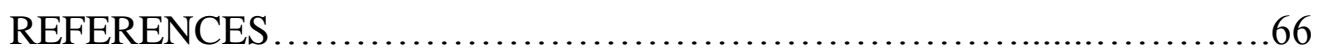

IV EFFECT OF VITAMIN D3 SUPPLEMENTATION ON GLYCATED ALBUMIN IN ADULTS WITH TYPE 2 DIABETES ...................70

Introduction.......................................................... 70

Materials and methods.................................................. 76

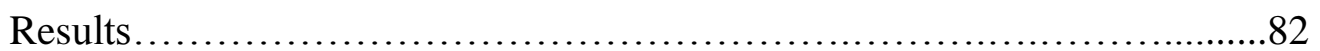

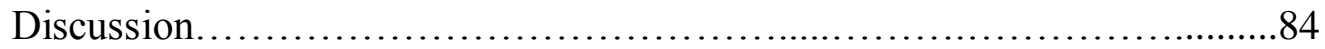

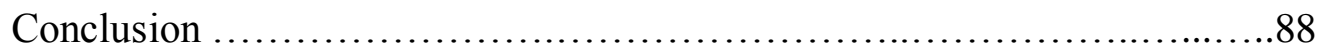


REFERENCES .....................................................92

V SUMMARY AND CONCLUSIONS ..................................97

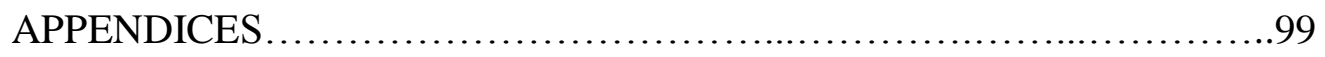

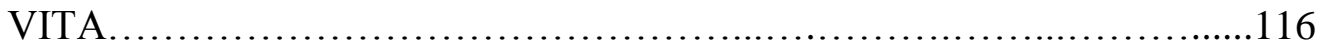




\section{CHAPTER I: INTRODUCTION}

Diabetes mellitus is ranked as the seventh leading cause of death in the United States (1)__According to the 2014 National Diabetes Statistics Report by the Centers for Disease Control and Prevention (CDC), over 29 million individuals (9.3\% of the U.S population) were diagnosed with diabetes while more than 8 million cases were undiagnosed (2). As estimated by the American Diabetes Association in 2013, the total direct and indirect costs of diabetes in the U.S. were \$245 billion in 2012. Individuals with diabetes had 2.3 times more medical expenditures compared to individuals without diabetes (3). Native Americans had the highest rates of diagnosed diabetes (15.9\%) among all race/ethnic groups aged 20 years and older, followed by African Americans (13.2\%) and Hispanics (12.8\%) (3). Type 2 diabetes accounts for $90-95 \%$ of all diagnosed diabetes cases among adults. Insulin resistance and pancreatic Beta cell dysfunction are the major pathophysiological abnormalities that lead to type 2 diabetes pathogenesis and progression (4).

Insulin is a peptide hormone that unlocks the cells to absorb glucose from the bloodstream and inhibits gluconeogenesis by the liver. Pancreatic Beta cells are responsible for insulin production and secretion. Both decline in insulin sensitivity (insulin resistance) and insufficient insulin production result in accumulation of excess

glucose in blood stream and starvation of the cells for glucose, which can lead to several organ or system damages. 


\section{Type 2 diabetes and inflammation}

Insulin resistance and hyperglycemia are linked to systemic inflammation (5). Inflammation is a defense mechanism of the innate immunity. As evidenced by a 9-year case-cohort study of 10,275 adults, systemic inflammation precedes diabetes and low grade inflammation plays a critical intermediary role in diabetogenesis (6). Accumulating evidence suggest that type 2 diabetes is a condition of innate immune system and it may be the result of long-term activation of an acute phase cytokine-mediated response of the innate immune system (7). Although this acute phase reaction of the innate immune system is initially stimulated to maintain homeostasis in response to environmental stressors, it is suggested that the sustained activation of this mechanism may lead to pathogenesis of many chronic inflammatory conditions such as type 2 diabetes (7). In this process stressors, such as age, over-nutrition, physical inactivity, visceral adiposity and oxygen metabolites stimulate the innate immune system such as adipose tissue macrophages and monocytes to produce and release pro-inflammatory cytokines like interleukin (IL)-1, IL-6, IL-18 and tumor necrosis factor-alpha (TNF- $\alpha$ ) (8). Elevated levels of pro-inflammatory cytokines elicit the liver to synthesize the acute phase proteins, such as C-reactive protein (CRP), (8) while inducing dyslipidemia [increased low density lipoproteins (LDL) and decreased high density lipoproteins (HDL)] by hepatocytes (8). In addition, it is suggested that augmented cytokine levels elicit $\beta$-cell apoptosis and result in $\beta$-cell dysfunction (9). Beside their effects on liver and pancreas, pro-inflammatory cytokines stimulate the brain to release adrenocorticotropic hormone which results in increased cortisol level (8). Cortisol is a glucocorticoid and hence is a functional antagonist of insulin. While insulin diminishes hepatic gluconeogenesis, 
cortisol promotes gluconeogenesis and impedes the glucose uptake by insulin (10). Cortisol directly suppresses the insulin release by the pancreatic $\beta$ cells (10). Increased cortisol is linked to insulin resistance, glucose intolerance and central obesity (11).

Systemic inflammation has been linked to oxidative stress (12). Increased ROS production and impaired oxidative balance result in activation of nuclear factor $\mathrm{\kappa B}$ (NF$\kappa \mathrm{B})$ which plays a critical regulatory role in immunity and inflammatory responses (13). $\mathrm{NF}-\mathrm{\kappa B}$ regulates the expression of a variety of genes such as growth factors and proinflammatory cytokines such as IL- $1 \beta$ and TNF- $\alpha$. NF- $\kappa$ B enhances a signaling cascade which leads to sustained production of ROS and causes low grade inflammation (14). As mentioned earlier, continued production of pro-inflammatory cytokines results in an acute phase response by the innate immunity and lead to $\beta$ cell apoptosis and dysfunction. This process diminishes the ability of the pancreas to produce and release insulin and thus contributes to type 2 diabetogenesis.

Nutrition plays a critical role in systemic inflammation regulation (15). It has been shown that dietary patterns affect pro-inflammatory and anti-inflammatory cytokines` balance and therefore enhance the risk of developing inflammatory diseases (16). A comprehensive review of observational and prospective studies along with randomized controlled trials suggested an anti-inflammatory property for Mediterranean dietary pattern (higher consumption of fruits and vegetables, unrefined carbohydrates, and fish, moderate consumption of dairy products and wine, and low consumption of non-fish meat) (17), compared to Western diet (higher consumption of refined carbohydrates, saturated fat, and red meat) (18). Consumption of antioxidant vitamins, such as vitamin $\mathrm{C}, \mathrm{E}$, and $\beta$-Carotene, and polyunsaturated fatty acids (PUFA), such as 
Omega-3 fatty acids, have been linked to lower systemic inflammation (19), while higher intakes of total and saturated fat have been associated with higher systemic inflammation (20-21).

\section{Dietary inflammatory index}

Dietary Inflammatory Index (DII) is a comprehensive literature-derived tool first developed by Caviccia et al. (22) in 2009 to assess the inflammatory potential of each individual's diet. Out of 2700 screened articles published from 1950 to 2007, 929 were considered for developing the algorithm to formulate DII. The objective of this project was to develop a methodology which could quantify dietary intake on a spectrum of maximally anti-inflammatory to maximally pro-inflammatory Caviccia at al. (22) validated the DII scores against CRP. The results of the validation study showed a significant relationship between DII, as a categorical variable, and CRP. Later in 2013, DII was updated by Shivappa et al. (23). The updated DII, is based on 1943 articles , out of 6500 screened, published in 2010-2013 in regards to the effect of diet on 6 inflammatory biomarkers (IL-1 $\beta$, IL-4, IL-6, IL-10, TNF- $\alpha$, and CRP). The updated DII

include forty-five pro-inflammatory and anti-inflammatory food parameters, compared to forty-two in the initial DII. The food parameters include: alcohol, vitamin B12, vitamin B6, $\beta$-Caroten, caffeine, carbohydrate, cholesterol, energy, eugenol, total fat, fibre, folic acid, garlic, ginger, iron, magnesium, monounsaturated fatty acids (MUFA), niacin, n-3 fatty acids, n-6 fatty acids, onion, protein, PUFA, riboflavin, saffron, saturated fat, selenium, thiamin, trans fat, tumeric, vitamin $\mathrm{A}$, vitamin $\mathrm{C}$, vitamin $\mathrm{D}$, vitamin $\mathrm{E}$, zinc, green/black tea, flavan-3-ol, flavones, flavonols, flavonones, anthocyanidins, isoflavones, pepper, thyme/oregano, rosemary. After fitting the DII to eleven dietary intake data sets 
from across the world, the globally adjusted scores ranged from +7.98 (maximally proinflammatory) to -8.87 (maximally anti-inflammatory). High DII values (proinflammatory diet) have been linked to low grade inflammation and insulin resistance (24), metabolic syndrome (25), cardiovascular diseases (26), colorectal cancer (27-28), pancreatic cancer (29), gastric cancer (30), and ovarian cancer (31).

\section{Type 2 diabetes and oxidative stress}

Oxidative stress is caused by an imbalance between oxygen metabolites production and ability of the endogenous and exogenous antioxidant networks to neutralize them (32). Reactive oxygen species (ROS), such as superoxide anion $\left(\mathrm{O}_{2}^{-}\right)$, hydrogen peroxide $\left(\mathrm{H}_{2} \mathrm{O}_{2}\right)$, hydroxyl radical $\left(\mathrm{OH}^{\circ}\right)$ and peroxynitrite $\left(\mathrm{OONO}^{-}\right)$, have one or more unpaired electrons and are highly reactive (33). ROS may attack other molecules to take an electron from them and stabilize (34). They can damage proteins, lipids and DNA. These oxidized biomolecules may trigger further oxidizing chain reactions that may result in production of new free radicals (34-35). Oxidative stress plays a pivotal role in systemic inflammation, type 2 diabetes development and its related complications (36). Although ROS production is one of the primary defense mechanisms, increased ROS production may result in impaired oxidative balance which leads to activation of

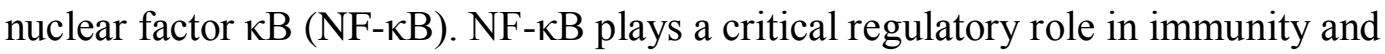
inflammatory responses (35). NF- $\kappa \mathrm{B}$ regulates the expression of a variety of genes such as growth factors and pro-inflammatory cytokines and enhances a signaling cascade which leads to sustained production of ROS and causing low grade inflammation (37). Continued production of pro-inflammatory cytokines results in an acute phase response 
by the innate immunity and lead to pancreatic $\beta$ cell apoptosis and dysfunction. This process diminishes the ability of the pancreas to produce and release insulin and thus causes type 2 diabetes.

ROS induced oxidation of guanine residues of DNA can damage the DNA strands and produce 8-hydroxyguanosine (8-OHdG) (38). Several studies had shown increased 8OHdG levels among individuals with type 2 diabetes (39-40). It has been suggested that 8-OHdG may be a predictive biomarker for early detection of lifestyle related health conditions, such as type 2 diabetes, at population level (41).

Nutrition plays a vital role in maintaining the oxidative balance. The direct effect of nutrition is via providing dietary antioxidants to the exogenous antioxidant network. In addition, nutrition affects the oxidative balance indirectly by providing energy to the endogenous enzymatic antioxidant system and therefore enhances its function (34). On the other hand, over-nutrition and physical inactivity are stressors that contribute to ROS production by inducing hyperglycemia and increased glucose accumulation in the muscle tissue, adipose tissue and pancreatic cells (33). ROS formed by autoxidation of glucose in the muscle tissue, adipose tissue, and pancreatic cells may non-enzymatically react with proteins and result in further production of ROS (42). These pathogenic effects can lead to development of insulin resistance, Beta cell dysfunction and glucose intolerance and thus result in type 2 diabetogenesis. In animal models ROS impaired insulin synthesis via suppression of insulin gene expression in pancreatic Beta cells (37). Antioxidant treatment in diabetic rats resulted in improved insulin secretion (37). It has been suggested that improvement in oxidative stress may have beneficial effects on the health 
of individuals with type 2 diabetes (33), and that antioxidant therapy may be a potential solution to reduce type 2 diabetes-related complications (37).

\section{Oxidative stress and vitamin D}

The antioxidant properties of vitamin D3 in human under diabetes conditions are not clear. One potential anti-oxidative action of vitamin D may be via suppression of intracellular NF- $\kappa \mathrm{B}$ which result in down-regulation of pro-inflammatory cytokines (43). Diminished pro-inflammatory cytokine levels prevent B cell apoptosis and improves B cell survival (36). In addition $1,25(\mathrm{OH})_{2} \mathrm{D} 3$, known as the active form of vitamin $\mathrm{D} 3$, activates the expression of anti-inflammatory cytokines such as IL-4, IL-10 and TGF-B1 (44). Deluca et al. (44) suggested that vitamin D may have an immunosuppressive properties due to its effect on regulation of pro-inflammatory and anti-inflammatory cytokines. Vitamin D supplementation could decrease oxidative stress in human colorectal mucosa as measured by $8-\mathrm{OHdG}(35)$. Furthermore, $1,25(\mathrm{OH})_{2} \mathrm{D} 3$ is proved to have protective properties against UV-induced oxidative DNA damage in skin cells (46).

Sun exposure have been shown to be a critical factor in maintaining serum vitamin D level in human (47). It has been reported that exposed skin areas` color, such as forearm skin color, are significantly associated with serum $25(\mathrm{OH}) \mathrm{D} 3$ and that forearm skin color may be an accurate predictor of serum vitamin D (47). Several studies showed that lighter skin color is associated with higher serum 25(OH)D3 levels (47-50). Considering the antioxidant properties of vitamin $\mathrm{D}$ and the role of sun exposure in maintaining the serum vitamin D level, further investigations are required to assess the 
association between skin color and oxidative stress under hypovitaminosis D and diabetes conditions.

Type 2 diabetes and early glycation products

Persistent hyperglycemia leads to non-enzymatic glycation of proteins, known as Maillard reaction. In this reversible process the carbonyl group of reducing sugars, such as glucose, binds to the amino group on lysine residues of proteins, such as hemoglobin, and form early glycation products known as Schiff-bases and Amadori adducts (51). Early glycation leads to formation of intermediate glycation products (IGPs) such as glycated hemoglobin (HbA1c) and glycated albumin (GA). Continuous elevation in IGP level can lead to their irreversible rearrangement to stable advanced glycation end products (AGEs) (51-52). AGEs accumulation is a measure of carbonyl, metabolic and oxidative stress and serve as a long term metabolic memory, rather than short term glycemic control. In contrast, IGPs are better indicators of glycemic control (52). Amadori adducts, the major form of IGPs, have 2-3 times higher concentrations of glycated products than AGEs (53). HbA1c is currently an established gold standard Amadori adduct, reflecting the glycemic control over the period of 8-12 weeks. In addition $\mathrm{HbA1c}$ is associated with the risk of chronic diabetes related complications such as neuropathy, nephropathy, retinopathy and coronary artery disease (53-54). HbA1c level, however, can be affected by several factors such as red blood cells turnover, uremia, erythropoietin treatment, blood transfusion, anemia, renal malfunction, and irondeficiency (53). Based on the twin studies by Sneider et al. (55), HbA1c is strongly inherited and influenced by genetics. Furthermore HbA1c reflects on the glycemic 
control inside the RBCs while serum protein glycation reflects glycemic control in the extracellular space (56).

Albumin is the most abundant protein in plasma and makes more than $50 \%$ of plasma proteins (57). With a half-life of 14-21 days, albumin is known as the main extracellular antioxidant and plays a fundamental role in maintaining the oxidative balance (58). Furthermore, albumin has anti-inflammatory and anti-thrombotic properties and plays a crucial role in transportation of nutrients, metabolites, hormones and drugs while maintaining the osmotic pressure (53). As a protein with 59 lysine residues, albumin is widely involved in extracellular Maillard reactions under hyperglycemic conditions (53). Non-enzymatic glycation of albumin happens 10 times faster and 9 times more than non-enzymatic glycation of hemoglobin in-vivo (59). It is suggested that glycated albumin (GA) may be a more accurate indicator of short term glycemic control among individuals with type 1 and type 2 diabetes (60). GA has been linked to diabetes induced complications including nephropathy, neuropathy and arteriosclerosis (57). Although as compared to hemoglobin, serum albumin is less affected by RBC turnover, erythropoietin treatment, blood transfusion, anemia, and iron-deficiency; albumin turnover, hepatic cirrhosis and renal malfunction can enhance serum albumin level. It is suggested GA/HbA1c ratio may be a better index of glycemic control among individuals with diabetes (60).

Fructosamine is the measure of a combination of circulating glycated proteins, such as glyco-lipoproteins and glyco-globlulins (61-62). Knowing albumin is the most abundant protein in serum, fructosamine is predominately reflecting GA, however, GA\% may provide a more accurate and efficient measure of extracellular glycation status over 
2-3 weeks (62). Furthermore, in case of abnormal albumin levels, fructosamine values must be adjusted to albumin levels (62).

\section{Oxidative stress, inflammation and glycated albumin}

Albumin structure and antioxidant function is greatly suppressed by the Maillard reaction. Amadori GA is in fact a stimulant for oxidative stress by producing oxygen free radicals and lipid peroxides. Non-enzymatic glycation of albumin also suppresses its nutrient/metabolite/drug binding affinity and diminishes its transportation ability (58). In macrophage RAW cells (a commercial murine cell-line), GA induced oxidative stress activated extracellular signal-regulated kinase (ERK), influenced TGF- $\beta 1$ production and activated NF- $\mathrm{KB}$ which plays a critical regulatory role in immunity and inflammatory responses (63). In diabetic human endothelial cells, GA increased oxidative stress and ROS production by up-regulating NADPH oxidase (64). This may help to understand the role of Amadori-adducts in pathogenesis of diabetes-induced vascular complications. Exposure of diabetic mice adipocytes to GA resulted in increased oxidative stress, accumulation of ROS in these cells and oxidation of proteins inside them (65). GAderived glycation end products (AGEs) may lead to adipocytes dysfunction and insulin resistance in adipose tissue.

\section{Type 2 diabetes and vitamin $\mathrm{D}$}

It has been shown that both, vitamin D deficiency and type 2 diabetes, have several risk factors in common: aging, being overweight, having a sedentary lifestyle, and being African-American or Hispanic (66). In addition, seasonal variations have been observed for both serum vitamin D [25(OH)D3] levels and insulin concentrations 
suggesting a potential relationship between serum 25(OH)D3 and development of type 2 diabetes (67-69). Vitamin D directly affects insulin sensitivity, Beta cell function, insulin secretion and hence mediates glucose homeostasis (66). Several studies reported an association between lower serum vitamin D levels and increased risk of developing type 2 diabetes (70-72). In addition, a high prevalence of hypovitaminosis D has been observed among individuals diagnosed with type 2 diabetes, compared to individuals without type 2 diabetes (73). Beside its effect on Beta cell function and insulin sensitivity, vitamin D also regulates calcium homeostasis which plays an important role in regulating insulin secretion (74).

An extensive review with a meta-analyses, proposed that the direct role of vitamin D on glucose homeostasis is mediated via binding of its metabolically active form, $1,25(\mathrm{OH}) 2 \mathrm{D} 3$, to the vitamin $\mathrm{D}$ receptors (VDR) in pancreatic B-cells, activation of $25(\mathrm{OH}) \mathrm{D} 3$ to $1,25(\mathrm{OH}) 2 \mathrm{D} 3$ by the enzyme 1- $\alpha$-hydroxylase (expressed in B-cells) within B-cells, stimulating the insulin receptor gene transcription, enhancing the expression of insulin receptor and hence affecting the insulin-mediated glucose transport (68). VDRs also exist in skeletal muscle and adipose tissues which are insulin targets and are responsible for peripheral insulin sensitivity. VDR expression in human skeletal muscle tissue, which declines with age, stimulates regulation of protein synthesis and results in diminished insulin sensitivity among older adults (75). In addition, animal studies showed impaired insulin secretion in mice with inactive VDRs (76).

The indirect role of vitamin D in glucose homeostasis is determined by its effect on regulation of extracellular calcium and calcium flux in the pancreatic B-cells (68). Imbalance between the extracellular and intracellular calcium pools influences the ability 
of B-cells to release insulin. Serum vitamin D concentration is inversely associated with Parathyroid hormone (PTH) level, which regulates intracellular calcium (77). In animal and in-vitro study, hypovitaminosis D was found to cause augmented PTH levels, which resulted in elevated intracellular calcium levels (78). In adipose tissue (an insulin target tissue), sustained augmentation in cytosolic calcium level was associated with increased insulin resistance (78). The insulin mediated glucose uptake was decreased by $30 \%$ among PTH injected rats (68). This could be due to increased phosphorylation of GLUT4 (an insulin-regulated glucose transporter in adipose and muscle tissue) in the presence of elevated cytosolic calcium levels. Cross-sectional studies reported an inverse relation between serum vitamin D level and insulin sensitivity (79-81). In addition, vitamin D and calcium supplementation attenuated insulin resistance among non-diabetic older adults with impaired fasting plasma glucose (FPG) (82).

\section{Vitamin D and glycated albumin}

The relationship between vitamin D and GA is yet to be studied. Furthermore, to our knowledge no studies have yet investigated the effectiveness of vitamin D3 supplementation on GA, as a biomarker of short-term glycemic control, among individuals with or without diabetes. Despite lack of evidence on the relationship between GA and vitamin D, HbA1c have been negatively linked to serum 25(OH)D level (83-85). Clinical trials on vitamin D supplementation and its impact on glycemic improvement (specifically on HbA1c) among individuals with type 2 diabetes, however, could not consistently support the effectiveness of vitamin D supplementation on glycemic control (86). It is not clear whether improvement in serum vitamin D may improve Amadori formation of GA. We assume vitamin D may improve GA level via its 
antioxidant properties. Furthermore, since vitamin D has a high binding affinity for adipose tissue, it may prevent the GA-induced oxidative stress in adipocytes via its antioxidant capabilities. Albumin is a transporter of vitamin D; therefore, binding of vitamin D to serum albumin may affect its affinity to glucose under non-enzymatic conditions. In that case, vitamin D may be effective in prevention of GA-derived AGEs production.

\section{Significance of the study}

Effectiveness of vitamin D3 supplementation on DNA/RNA oxidative stress under type 2 diabetes condition in human is not clear. Trials among human subjects are needed to investigate and quantify the potential beneficial impact of vitamin D3 supplementation at different dosages among individuals with vitamin D deficiency. Therefore the aim of this study was to investigate the effect of 4000 IU and 6000 IU daily supplementation of vitamin D3 for 3 and 6 months on biomarkers of DNA/RNA oxidative stress, 8-OHdG, in individuals with type 2 diabetes and serum vitamin D [25(OH)D3] insufficiency or deficiency. In addition, we investigated the relationship between skin exposure score, as a measure of sun exposure, and oxidative stress in individuals with type 2 diabetes and 25(OH)D3 deficiency or insufficiency. We hypothesized that daily supplementation with 4000 and $6000 \mathrm{IU}$ of vitamin D3 for 6 months will decrease serum 8-OHdG level in individuals with type 2 diabetes and vitamin D insufficiency or deficiency, compared to baseline. To our knowledge, this is the first study investigating the effects of vitamin D3 supplementation on 8-OHdG among human subjects with type 2 diabetes. Furthermore, we hypothesized individuals with lighter forearm skin color will have lower 8-OHdG levels compared to those with darker 
forearm skin color, at baseline and that individuals with higher skin exposure scores, as measured by the difference between exposed and unexposed skin colors, will have lower 8-OHdG levels.

To our knowledge, there is currently no studies that assessed the possible effects of vitamin D3 supplementation on serum GA levels among individuals with or without type 2 diabetes. While GA is a relatively new biomarker for type 2 diabetes management, almost all the current studies on vitamin D supplementation in type 2 diabetes have been targeting fasting plasma glucose and HbA1c as the markers of glycemic control. The findings of this study will help to fill the gap on the possible beneficial effects of vitamin D3 on GA, as the most abundant Amadori-protein in human serum. Therefore, the aim of this study was to investigate the effectiveness of daily supplementation with $4000 \mathrm{IU}$ and 6000 IU vitamin D3 for 3 months and 6 months on GA.

Furthermore, this study was aimed to assess the relationship between DII and biomarker of inflammation (CRP), oxidative stress (8-OHdG), glycemic status [glycated hemoglobin (HbA1c) and glycated albumin (GA)] and insulin level among individuals with type 2 diabetes and vitamin D deficiency/insufficiency. To our knowledge this is the first study assessing the relationship between DII, 8-OHdG, HbA1c, GA and insulin among individuals with type 2 diabetes and vitamin D deficiency/insufficiency.

$\underline{\text { Specific aims and hypothesis }}$

Specific aim 1:

To investigate the association between dietary inflammatory biomarker (DII) and biomarker of inflammation (CRP), oxidative stress (8-OHdG), glycemic status [glycated 
hemoglobin (HbA1c) and glycated albumin (GA)] and insulin level among individuals with type 2 diabetes and vitamin D deficiency/insufficiency.

Hypothesis: DII is positively associated with serum CRP, 8-OHdG, GA\%, HbA1c and inversely associated with insulin level.

Specific aim 2:

To investigate the effect of 4000 and 6000 IU/day of vitamin D3 supplementation for 6 months on biomarker of oxidative stress (8-hydroxy-2-deoxyguanosine) in individuals with type 2 diabetes and serum vitamin D insufficiency/deficiency.

Hypothesis: Daily supplementation with 4000 and 6000 IU of vitamin D3 for 6 months will decrease serum 8-OHdG level in individuals with type 2 diabetes and vitamin D insufficiency/deficiency, compared to baseline.

Specific aim 3:

To investigate the effect of 4000 and 6000 IU/day of vitamin D3 supplementation for 6 months on biomarker of glycemic status [glycated albumin (GA\%)] in individuals with type 2 diabetes and serum vitamin D insufficiency/deficiency.

Hypothesis: Daily supplementation with 4000 and 6000 IU of vitamin D3 for 6 months will decrease serum GA\% in individuals with type 2 diabetes and vitamin D insufficiency/deficiency, compared to baseline. 


\section{REFERENCES:}

1. Xu, J., Murphy, S.L., Kochanek, K.D., \& Bastian, B.A. (2016). Deaths: Final data for 2013. National vital statistics reports, 64(2), 1-118.

2. Centers for Disease Control and Prevention. (2014). National Diabetes Statistics Report: Estimates of Diabetes and Its Burden in the United States. U.S. Department of Health and Human Services.

3. Economic costs of diabetes in the U.S. In 2012 (2013). Diabetes Care, 36(4), 1033-1046. doi:10.2337/dc12-2625.

4. Halban, P. A., Polonsky, K. S., Bowden, D. W., Hawkins, M. A., Ling, C., Mather, K. J., Weir, G. C. (2014). B-cell failure in type 2 diabetes: Postulated mechanisms and prospects for prevention and treatment. Diabetes Care, 37(6), 17511758. doi:10.2337/dc14-0396.

5. Pradhan, A. D., Manson, J.E., Rifai, N., Buring, J. E., Ridker, P.M. (2001). CReactive protein, Interleukin 6, and risk of developing type 2 diabetes Mellitus. JAMA, 286(3), 327. doi:10.1001/jama.286.3.327.

6. Duncan, B. B., Schmidt, M. I., Pankow, J. S., Ballantyne, C. M., Couper, D., Vigo, A., Heiss, G. (2003). Low-grade systemic inflammation and the development of type 2 diabetes: The Atherosclerosis risk in communities study. Diabetes, 52(7), 17991805. doi:10.2337/diabetes.52.7.1799.

7. Pickup, J. C., \& Crook, M. A. (1998). Is type II diabetes mellitus a disease of the innate immune system? Diabetologia, 41(10), 1241-1248. doi:10.1007/s001250051058.

8. Kushner, I. (1993). Regulation of the acute phase response by Cytokines. Perspectives in Biology and Medicine, 36(4), 611-622. doi:10.1353/pbm.1993.0004.

9. Pittas, A. G., Lau, J., Hu, F. B., \& Dawson-Hughes, B. (2007). The role of vitamin $\mathrm{D}$ and calcium in type 2 diabetes. A systematic review and Meta-Analysis. The Journal of Clinical Endocrinology \& Metabolism, 92(6), 2017-2029. doi:10.1210/jc.2007-0298.

10. Stulnig, T. M., \& Waldhäusl, W. (2004). 11B-Hydroxysteroid dehydrogenase type 1 in obesity and type 2 diabetes. Diabetologia, 47(1), 1-11. doi:10.1007/s00125003-1284-4.

11. Liebman, T. (2010). The Role of Cortisol and Abdominal Obesity in the Epidemic of Type 2 Diabetes. Undergraduate Research Journal for the Human Sciences, 9(1).

12. Garcia-Bailo, B., El-Sohemy, A., Haddad, P. S., Arora, P., BenZaied, F., Karmali, M., \& Badawi, A. (2011). Vitamins D, C, and E in the prevention of type 2 
diabetes mellitus: modulation of inflammation and oxidative stress.Biologics : Targets \& Therapy, 5, 7-19. doi:10.2147/BTT.S14417.

13. Evans, J. L., Goldfine, I. D., Maddux, B. A., \& Grodsky, G. M. (2002). Oxidative stress and stress-activated signaling pathways: A unifying hypothesis of type 2 diabetes.Endocrine Reviews, 23(5), 599-622. doi:10.1210/er.2001-0039.

14. Kajimoto, Y., \& Kaneto, H. (2004). Role of Oxidative stress in Pancreatic $\beta$ cell dysfunction. Annals of the New York Academy of Sciences, 1011(1), 168-176. doi:10.1196/annals.1293.017.

15. Wirth M.D., Sevoyan M., Hofseth L., Shivappa N., Hurley T.G., Hébert J.R. (2017). The Dietary Inflammatory Index is associated with elevated white blood cell counts in the National Health and Nutrition Examination Survey. Brain Behav Immun. pii: S0889-1591(17)30527-5. doi: 10.1016/j.bbi.2017.12.003.

16. Calder P.C., Ahluwalia N., Brouns F., Buetler T., Clement K., Cunningham K., Esposito K., Jönsson L.S., Kolb H., Lansink M., Marcos A., Margioris A., Matusheski N., Nordmann H., O'Brien J., Pugliese G., Rizkalla S., Schalkwijk C., Tuomilehto J., Wärnberg J., Watzl B., Winklhofer-Roob B.M. (2011). Dietary factors and low-grade inflammation in relation to overweight and obesity. Br J Nutr. 106 Suppl 3:S578. doi: 10.1017/S0007114511005460.

17. Godman H. (2013). Adopt a Mediterranean diet now for better health later. Harvard Health Letter. https://www.health.harvard.edu/blog/adopt-a-mediterranean-dietnow-for-better-health-later-201311066846.

18. Ahluwalia N., Andreevaa V.A., Kesse-Guyota E., Hercbergab S. (2012). Dietary patterns, inflammation and the metabolic syndrome. Diabetes Metab. 39(2):99110. doi: 10.1016/j.diabet.2012.08.007.

19. Del Mar Bibiloni M., Maffeis C., Llompart I., Pons A., Tur J.A. (2013). Dietary factors associated with subclinical inflammation among girls. Eur J Clin Nutr. 67(12):1264-1270. doi: 10.1038/ejcn.2013.196.

20. Aeberli I., Molinari L., Spinas G., Lehmann R., l'Allemand D., Zimmermann M.B. (2006). Dietary intakes of fat and antioxidant vitamins are predictors of subclinical inflammation in overweight Swiss children. Am J Clin Nutr. 84(4):748-755.

21. Almeida-de-Souza J., Santos R., Barros R., Abreu S., Moreira C., Lopes L., Mota J., Moreira P. (2017). Dietary inflammatory index and inflammatory biomarkers in adolescents from LabMed physical activity study. European Journal of Clinical Nutrition. doi:10.1038/s41430-017-0013-X.

22. Cavicchia P.P., Steck S.E., Hurley T.G., Hussey J.R., Ma Y., Ockene I.S., Hébert J.R. (2009). A new dietary inflammatory index predicts interval changes in serum high-sensitivity C-reactive protein. J Nutr. 139(12):2365-2372. doi: 10.3945/jn.109.114025. 
23. Shivappa N., Steck S.E., Hurley T.G., Hussey J.R., Hébert J.R. (2014). Designing and developing a literature-derived, population-based dietary inflammatory index. Public Health Nutr. 17(8):1689-1696. doi: 10.1017/S1368980013002115.

24. van Woudenbergh G.J., Theofylaktopoulou D., Kuijsten A., Ferreira I., van Greevenbroek M.M., van der Kallen C.J., Schalkwijk C.G., Stehouwer C.D., Ocké M.C., Nijpels G., Dekker J.M., Blaak E.E., Feskens E.J. (2013). Adapted dietary inflammatory index and its association with a summary score for low-grade inflammation and markers of glucose metabolism: the Cohort study on Diabetes and Atherosclerosis Maastricht (CODAM) and the Hoorn study. Am J Clin Nutr. 98(6):1533-1542. doi: 10.3945/ajen.112.056333.

25. Wirth M., Burch J., Shivappa N., Violanti, J. M., Burchfiel, C.M., Fekedulegn D., Andrew M.E., Hartley T.A., Miller D.B., Mnatsakanova A., Charles L.E., Steck S.E. Hurley T.G., Vena J.E., Hébert J.R. (2014). Association of a Dietary Inflammatory Index with Inflammatory Indices and the Metabolic Syndrome among Police Officers. J Occup Environ 56(9): 986-989. doi: 10.1097/JOM.0000000000000213.

26. Ruiz-Canela M., Bes-Rastrollo M., Martínez-González M.A. (2016). The Role of Dietary Inflammatory Index in Cardiovascular Disease, Metabolic Syndrome and Mortality. Int J Mol Sci. 3:17(8). pii: E1265. doi: 10.3390/ijms17081265.

27. Tabung F.K., Steck S.E., Ma Y., Liese A.D., Zhang J., Caan B., Hou L., Johnson K.C., Mossavar-Rahmani Y., Shivappa N., Wactawski-Wende J., Ockene J.K., Hebert J.R. (2015). The association between dietary inflammatory index and risk of colorectal cancer among postmenopausal women: results from the Women's Health Initiative. Cancer Causes Control. 26(3):399-408. doi: 10.1007/s10552-014-0515-y.

28. Harmon B.E., Wirth M.D., Boushey C.J., Wilkens L.R., Draluck E., Shivappa N., Steck S.E., Hofseth L., Haiman C.A., Le Marchand L., Hébert J.R. (2017) The Dietary Inflammatory Index Is Associated with Colorectal Cancer Risk in the Multiethnic Cohort. J Nutr. 147(3):430-438. doi: 10.3945/jn.116.242529.

29. Shivappa N., Bosetti C., Zucchetto A., Serraino D., La Vecchia C., Hébert J.R. (2015). Dietary inflammatory index and risk of pancreatic cancer in an Italian casecontrol study. Br J Nutr. 28;113(2):292-298. doi: 10.1017/S0007114514003626.

30. Lee S., Lee J., Choi I.J., Kim Y.W., Ryu K.W., Kim Y.I., Oh J.K., Tran B.T., Kim J. (2017). Dietary inflammatory index and the risk of gastric cancer in a Korean population. Oncotarget. 7;8(49):85452-85462. doi: 10.18632/oncotarget.20008.

31. Shivappa N., Hébert J.R., Paddock L.E., Rodriguez-Rodriguez L., Olson S.H., Bandera E.V. (2018). Dietary inflammatory index and ovarian cancer risk in a New Jersey case-control study. Nutrition. 46:78-82. doi: 10.1016/j.nut.2017.08.011.

32. Stephens, J. W., Khanolkar, M. P., Bain, S. C. (2009). The biological relevance and measurement of plasma markers of oxidative stress in diabetes and cardiovascular disease. Atherosclerosis, 202(2); 321-329.

doi:10.1016/j.atherosclerosis.2008.06.006. 
33. Wright, E., Scism-Bacon, J. L., Glass, L. C. (2006). Oxidative stress in type 2 diabetes: The role of fasting and postprandial glycaemia. Int J of Clin Pract. 60(3): 308314. doi:10.1111/j.1368-5031.2006.00825.

34. Nikooyeh B., Neyestani T.R. (2015). Oxidative stress, type 2 diabetes and vitamin D: past, present and future. Diabetes Metab Res Rev, 32(3): 260-7. doi: 10.1002/dmrr.2718.

35. Evans, J. L., Goldfine, I. D., Maddux, B. A., Grodsky, G. M. (2002). Oxidative stress and stress-activated signaling pathways: A unifying hypothesis of type 2 diabetes. Endocrine Reviews, 23(5): 599-622. doi:10.1210/er.2001-0039.

36. Garcia-Bailo, B., El-Sohemy, A., Haddad, P. S., Arora, P., BenZaied, F., Karmali, M., Badawi, A. (2011). Vitamins D, C, and E in the prevention of type 2 diabetes mellitus: modulation of inflammation and oxidative stress. Biologics : Targets \& Therapy, 5: 7-19. doi:10.2147/BTT.S1441739.

37. Kajimoto, Y., Kaneto, H. (2004). Role of Oxidative stress in Pancreatic $\beta$-cell dysfunction. Annals of the New York Academy of Sciences, 1011(1): 168-176. doi:10.1196/annals.1293.017.

38. Pan H. Z., Zhang L., Guo M. Y., Sui H., Li H., Wu W. H. , Qu N. Q., Liang M. H., Chang D. (2010). The oxidative stress status in diabetes mellitus and diabetic nephropathy. Acta Diabetol. 47 Suppl 1: 71-76. doi: 10.1007/s00592-009-0128-1.

39. Leinonen J., Lehtimäki T., Toyokuni S., Okada K., Tanaka T., Hiai H., Ochi H., Laippala P., Rantalaiho V., Wirta O., Pasternack A., Alho H. (1997). New biomarker evidence of oxidative DNA damage in patients with non-insulin-dependent diabetes mellitus. FEBS Lett. 417(1): 150-152.

40. Dandona P., Thusu K., Cook S., Snyder B., Makowski J., Armstrong D., Nicotera T. (1996). Oxidative damage to DNA in diabetes mellitus. Lancet. 17;347(8999): 444-445.

41. Sakano N., Wang D. H. Takahashi N., Wang B., Sauriasari R., Kanbara S., Sato Y., Takigawa T., Takaki J., Ogino1 K. (2009). Oxidative Stress Biomarkers and Lifestyles in Japanese Healthy People. J Clin Biochem Nutr. 44(2): 185-195. doi: 10.3164/jcbn.08-252.

42. Johansen J. S., Harris A. K., Rychly D. J., Ergul A. (2005). Cardiovasc Diabetol. 4: 5. doi: 10.1186/1475-2840-4-5

43. Etten, E. van, \& Mathieu, C. (2005). Immunoregulation by 1,25dihydroxyvitamin D3: Basic concepts. The Journal of Steroid Biochemistry and Molecular Biology, 97(1-2): 93-101. doi:10.1016/j.jsbmb.2005.06.002

44. Deluca, H. F., \& Cantorna, M. (2001). Vitamin D: Its role and uses in immunology. The FASEB Journal, 15(14): 2579-2585. doi:10.1096/fj.01-0433rev 
45. Fedirko, V., Bostick, R. M., Long, Q., Flanders, W. D., McCullough, M. L., Sidelnikov, E., Shaukat, A. (2010). Effects of supplemental vitamin D and calcium on Oxidative DNA damage marker in normal Colorectal mucosa: A Randomized clinical trial. Cancer Epidemiol Biomarkers Prev, 19(1): 280-291. doi:10.1158/1055-9965.epi09-0448

46. Gordon-Thomson, C., Gupta, R., Tongkao-on, W., Ryan, A., Halliday, G. M., Mason, R. S. (2012). 1 $\alpha, 25$ Dihydroxyvitamin D3 enhances cellular defences against UV-induced oxidative and other forms of DNA damage in skin. Photochemical \& Photobiological Sciences, 11(12): 1837-1847. doi:10.1039/c2pp25202c

47. Ajabshir, S., Exebio, J., Zarini, G., Nayer, A., McLean, M., Shaban, L., Huffman, F. (2014). Skin color and self-reported sun exposure scores are associated with serum 25-Hydroxyvitamin D concentrations in a multi-ethnic population living in south Florida. British Journal of Medicine and Medical Research, 4(34): 5312-5323. doi:10.9734/bjmmr/2014/10551.

48. Armas L.A., Dowell S., Akhter M., Duthuluru S., Huerter C., Hollis B.W., Lund R., Heaney R.P. (2007). Ultraviolet-B radiation increases serum 25-hydroxyvitamin D levels: The effect of UVB dose and skin color. J Am Acad Dermatol. 57(4): 588-593.

49. Harris S.S., Dawson-Hughes B. (1998). Seasonal changes in plasma 25hydroxyvitamin D concentrations of young American black and white women. Am J Clin Nutr. 67: 1232-1236.

50. Nesby-O'Dell S., Scanlon K.S., Cogswell M.E., Gillespie C., Hollis B.W., Looker A.C., Allen C., Doughertly C., Gunter E.W., Bowman B.A. (2002). Hypovitaminosis D prevalence and determinants among African American and white women of reproductive age: Third national health and nutrition examination survey, 1988-1994. Am J Clin Nutr. 76(1): 187-192.

51. Zhang, Q., Ames, J. M., Smith, R. D., Baynes, J. W., Metz, T. O. (2009). A perspective on the Maillard reaction and the analysis of protein Glycation by mass Spectrometry: Probing the pathogenesis of chronic disease. Journal of Proteome Research. 8(2): 754-769. doi:10.1021/pr800858h.

52. Meerwaldt, R., Links, T., Zeebregts, C., Tio, R., Hillebrands, J.-L., Smit, A. (2008). The clinical relevance of assessing advanced glycation endproducts accumulation in diabetes. Cardiovascular Diabetology. 7(1): 29. doi:10.1186/1475-2840-7-29.

53. Ahmad, J., \& Neelofar, K. (2015). Amadori albumin in diabetic nephropathy. Indian Journal of Endocrinology and Metabolism. 19(1), 39. doi:10.4103/22308210.146863.

54. Takahashi, S., Uchino, H., Shimizu, T., Kanazawa, A., Tamura, Y., Sakai, K., Tanaka, Y. (2007). Comparison of Glycated albumin (GA) and Glycated hemoglobin (HbA1c) in type 2 diabetic patients: Usefulness of GA for evaluation of short-term changes in Glycemic control. Endocrine Journal. 54(1): 139-144. 
55. Snieder, H., Sawtell, P. A., Ross, L., Walker, J., Spector, T. D., Leslie, R. D. G. (2001). HbA1c levels are genetically determined even in type 1 diabetes: Evidence from healthy and diabetic twins. Diabetes. 50(12): 2858-2863.

doi:10.2337/diabetes.50.12.2858.

56. Leslie, R. D. G., Cohen, R. M. (2009). Biologic variability in plasma glucose, hemoglobin A1c, and advanced Glycation end products associated with diabetes complications. Journal of Diabetes Science and Technology, 3(4): 635-643. doi:10.1177/193229680900300403.

57. Arasteh, A., Farahi, S., Habibi-Rezaei, M., Moosavi-Movahedi, A. A. (2014). Glycated albumin: an overview of the In Vitro models of an In Vivo potential disease marker. Journal of Diabetes and Metabolic Disorders. 13: 49. http://doi.org/10.1186/2251-6581-13-49

58. Roche M.1., Rondeau P., Singh N.R., Tarnus E., Bourdon E. (2008). FEBS Lett. 11;582(13): 1783-7. doi: 10.1016/j.febslet.2008.04.057.

59. Iberg, N., Flückiger, R. (1986). Nonenzymatic glycosylation of albumin in vivo. Identification of multiple glycosylated sites. The Journal of biological chemistry. 261(29): 13542-13545.

60. Yoshiuchi, K., Matsuhisa, M., Katakami, N., Nakatani, Y., Sakamoto, K., Matsuoka, T., Hori, M. (2008). Glycated albumin is a better indicator for glucose excursion than Glycated hemoglobin in type 1 and type 2 diabetes. Endocrine Journal. 55(3): 503-507. doi:10.1507/endocrj.k07e-089.

61. Danese E., Montagnana M., Nouvenne A., Lippi G. (2015). Advantages and Pitfalls of Fructosamine and Glycated Albumin in the Diagnosis and Treatment of Diabetes. J Diabetes Sci Technol. 2015 Mar; 9(2): 169-176. doi: $10.1177 / 1932296814567227$.

62. Lee J. E. (2015). Alternative biomarkers for assessing glycemic control in diabetes: fructosamine, glycated albumin, and 1,5-anhydroglucitol. Ann Pediatr Endocrinol Metab. 20(2): 74-78. doi: 10.6065/apem.2015.20.2.74.

63. Cohen, M. P., Shea, E., Chen, S., \& Shearman, C. W. (2003). Glycated albumin increases oxidative stress, activates $\mathrm{NF}-\kappa \mathrm{B}$ and extracellular signal-regulated kinase (ERK), and stimulates ERK-dependent transforming growth factor- $\beta 1$ production in macrophage RAW cells. Journal of Laboratory and Clinical Medicine . 141(4): 242249. doi:10.1067/mlc.2003.27.

64. Rodiño-Janeiro, B. K., González-Peteiro, M., Ucieda-Somoza, R., GonzálezJuanatey, J. R., Álvarez, E. (2010). Glycated albumin, a precursor of advanced glycation end-products, up-regulates NADPH oxidase and enhances oxidative stress in human endothelial cells: Molecular correlate of diabetic vasculopathy. Diabetes/Metabolism Research and Reviews. 26(7): 550-558. doi:10.1002/dmrr.1117. 
65. Boyer, F., Diotel, N., Girard, D., Rondeau, P., Essop, M. F.,Bourdon, E. (2016). Enhanced oxidative stress in adipose tissue from diabetic mice, possible contribution of glycated albumin. Biochemical and Biophysical Research Communications. 473(1): 154-160. doi:10.1016/j.bbrc.2016.03.068.

66. Alvarez, J. A., Ashraf, A. (2010). Role of vitamin D in insulin secretion and insulin sensitivity for glucose Homeostasis. International Journal of Endocrinology. 118. doi:10.1155/2010/351385.

67. de Souza, C. J., \& Meier, A. H. (1987). Circadian and seasonal variations of plasma insulin and Cortisol concentrations in the Syrian Hamster, Mesocricetus Auratus.Chronobiology International. 4(2): 141-151. doi:10.3109/07420528709078520.

68. Pittas, A. G., Lau, J., Hu, F. B., Dawson-Hughes, B. (2007). The role of vitamin $\mathrm{D}$ and calcium in type 2 diabetes. A systematic review and Meta-Analysis. The Journal of Clinical Endocrinology \& Metabolism. 92(6): 2017-2029. doi:10.1210/jc.2007-0298.

69. Harinarayan, C., Arvind, S., Joshi, S., Thennarasu, K., Vedavyas, V., Baindur, A. (2014). Improvement in Pancreatic $\beta$-cell function with vitamin D and calcium Supplementation in vitamin d-deficient Nondiabetic subjects. Endocrine Practice. 20(2): 129-138. doi:10.4158/ep13273.or.

70. Mitri, J., Dawson-Hughes, B., Hu, F. B., Pittas, A. G. (2011). Effects of vitamin D and calcium supplementation on pancreatic cell function, insulin sensitivity, and glycemia in adults at high risk of diabetes: The calcium and vitamin D for diabetes Mellitus (CaDDM) randomized controlled trial. American Journal of Clinical Nutrition. 94(2): 486-494. doi:10.3945/ajen.111.011684..

71. Khan, H., Kunutsor, S., Franco, O. H., Chowdhury, R. (2012). Vitamin D, type 2 diabetes and other metabolic outcomes: A systematic review and meta-analysis of prospective studies. Proceedings of the Nutrition Society. 72(01): 89-97. doi:10.1017/s0029665112002765.

72. Song, Y., Wang, L., Pittas, A. G., Del Gobbo, L. C., Zhang, C., Manson, J. E., \& Hu, F. B. (2013). Blood 25-Hydroxy vitamin D levels and incident type 2 diabetes: A meta-analysis of prospective studies. Diabetes Care. 36(5): 1422-1428. doi:10.2337/dc12-0962

73. Pittas, A., Chung, M., Trikalinos, T., Mitri, J., Brendel, M., Patel, K., Balk, E. (2010). Systematic review: Vitamin D and cardiometabolic outcomes. Annals of internal medicine. 152(5): 307-314.

74. Baz-Hecht M., Goldfine A.B. (2010). The impact of vitamin D deficiency on diabetes and cardiovascular risk. Curr Opin Endocrinol Diabetes Obes. 17(2): 113-9. doi: 10.1097/MED.0b013e3283372859.

75. Bischoff-Ferrari, H., Borchers, M., Gudat, F., Dürmüller, U., Stähelin, H., Dick, W. (2004). Vitamin D receptor expression in human muscle tissue decreases with 
age.Journal of Bone and Mineral Research. 19(2): 265-269.

doi:10.1359/jbmr.2004.19.2.265.

76. Zeitz, U., Weber K., Soegiarto, D.S., Wolf, E., Balling, R., Erben, R.G. (2003). Impaired insulin secretory capacity in mice lacking a functional vitamin D receptor. The FASEB Journal. 17(3): 509-11 doi:10.1096/fj.02-0424fje.

77. Holick, M. F. (2007). Vitamin D deficiency. New England Journal of Medicine. 357(3): 266-281. doi:10.1056/nejmra070553

78. Reusch, J. E. ., Begum, N., Sussman, K. E., Draznin, B. (1991). Regulation of GLUT-4 Phosphorylation by Intracellular calcium in Adipocytes. Endocrinology. 129(6): 3269-3273. doi:10.1210/endo-129-6-3269.

79. Borissova, A.M., Tankova, T., Kirilov, G., Dakovska, L., Kovacheva, R. (2003). The effect of vitamin D3 on insulin secretion and peripheral insulin sensitivity in type 2 diabetic patients. Int J Clin Pract. 57(4): 258-261.

80. Baynes, K. C. R., Boucher, B. J., Feskens, E. J. M., Kromhout, D. (1997). Vitamin D, glucose tolerance and insulinaemia in elderly men. Diabetologia. 40(3): 344 347. doi:10.1007/s001250050685.

81. Scragg, R., Sowers, M., Bell, C. (2004). Serum 25-Hydroxyvitamin D, diabetes, and ethnicity in the Third national health and nutrition examination survey. Diabetes Care. 27(12): 2813-2818. doi:10.2337/diacare.27.12.2813.

82. Pittas, A. G., Harris, S. S., Stark, P. C., Dawson-Hughes, B. (2007). The effects of calcium and vitamin D Supplementation on blood glucose and markers of inflammation in Nondiabetic adults. Diabetes Care. 30(4): 980-986. doi:10.2337/dc061994.

83. Manickam, B., Neagu, V., Kukreja, S., Barengolts, E. (2013). Relationship between Glycated hemoglobin and circulating 25-Hydroxyvitamin D concentration in African American and Caucasian American men. Endocrine Practice. 19(1): 73-80. doi:10.4158/ep12168.or.

84. Coskun, H., Aydin, Y., Kutlucan, A., Yildirim, H., Kudas, O., Kir, S., Turgut, M. (2012). Vitamin D3 deficiency effect on the HbA1c in type 2 diabetic population, Endocrine Abstracts. 29: P733.

85. Shanthi, B., Revathy, C., Devi, A. J. M., Parameshwari, P. J., Stephen, T. (2012). Serum 25(OH)D and Type 2 Diabetes Mellitus. Journal of Clinical and Diagnostic Research. 6(5): 774-776.

86. Madar, A. A., Knutsen, K. V., Stene, L. C., Brekke, M., Meyer, H. E., Lagerløv, P. (2014). Effect of vitamin D3 supplementation on glycated hemoglobin (HbA1c), fructosamine, serum lipids, and body mass index: A randomized, doubleblinded, placebo-controlled trial among healthy immigrants living in Norway. BMJ Open Diabetes Research \& Care. 2(1), e000026. doi:10.1136/bmjdrc-2014-000026. 


\section{CHAPTER II: ASSOCIATION BETWEEN DIETARY INFLAMMATORY INDEX AND SERUM VITAMIN D, OXIDATIVE STRESS, INFLAMMATION, AND GLYCEMIC STATUS IN ADULTS WITH TYPE 2 DIABETES}

Introduction

Diabetes mellitus is ranked as the seventh leading cause of death in the United States (1)._According to the 2014 National Diabetes Statistics Report by the Centers for Disease Control and Prevention (CDC), over 29 million individuals (9.3\% of the U.S population) were diagnosed with diabetes while more than 8 million cases were undiagnosed (2). As estimated by the American Diabetes Association in 2013, total direct and indirect costs of diabetes in the U.S. were \$245 billion in 2012. Individuals with diabetes had 2.3 times more medical expenditures compared to individuals without diabetes (3). Native Americans had the highest rates of diagnosed diabetes (15.9\%) among all race/ethnic groups aged 20 years and older, followed by African Americans (13.2\%) and Hispanics (12.8\%) (3). Type 2 diabetes accounts for $90-95 \%$ of all diagnosed diabetes cases among adults. Insulin resistance and pancreatic Beta cell dysfunction are the major pathophysiological abnormalities that lead to type 2 diabetes pathogenesis and progression (4).

Insulin is a peptide hormone that unlocks the cells to absorb glucose from the bloodstream and inhibits gluconeogenesis by the liver. Pancreatic Beta cells are responsible for insulin production and secretion. Both decline in insulin sensitivity (insulin resistance) and insufficient insulin production result in accumulation of excess 
glucose in blood stream and starvation of the cells for glucose, which can lead to several organ or system damages.

Insulin resistance and hyperglycemia are linked to systemic inflammation (5). Inflammation is a defense mechanism of the innate immunity. As evidenced by a 9-year case-cohort study of 10,275 adults, systemic inflammation precedes diabetes and lowgrade inflammation plays a critical intermediary role in diabetogenesis (6). Accumulating evidence suggest that type 2 diabetes is a condition of innate immune system, and it may be the result of long-term activation of an acute phase cytokine-mediated response of the innate immune system (7). Although this acute-phase reaction of the innate immune system is initially stimulated to maintain homeostasis in response to environmental stressors, it is suggested that the sustained activation of this mechanism may lead to pathogenesis of many chronic inflammatory conditions, including type 2 diabetes (7). In this process, stressors such as age, over-nutrition, physical inactivity, visceral adiposity and oxygen metabolites stimulate the innate immune system comprised of adipose tissue macrophages and monocytes to produce and release pro-inflammatory cytokines such as interleukin (IL)-1, IL-6, IL-18 and tumor necrosis factor-alpha (TNF- $\alpha$ ) (8). Elevated levels of pro-inflammatory cytokines elicit the liver to synthesize the acute phase proteins, such as C-reactive protein (CRP), while inducing dyslipidemia [increased low density lipoproteins (LDL) and decreased high density lipoproteins (HDL)] by hepatocytes (8). In addition, it is suggested that augmented cytokine levels elicit $\beta$-cell apoptosis and result in $\beta$-cell dysfunction (9). Furthermore, pro-inflammatory cytokines stimulate the brain to release adrenocorticotropic hormone, which results in increased cortisol level (8). Cortisol is a glucocorticoid that is a functional antagonist of insulin. 
While insulin diminishes hepatic gluconeogenesis, cortisol promotes gluconeogenesis and impedes the glucose uptake by insulin (10). Cortisol directly suppresses the insulin release by the pancreatic $\beta$ cells (10). Increased cortisol is linked to insulin resistance, glucose intolerance and central obesity (11).

Systemic inflammation has been linked to oxidative stress (12). Increased Reactive Oxygen Species (ROS) production and impaired oxidative balance result in activation of nuclear factor $\kappa \mathrm{B}(\mathrm{NF}-\kappa \mathrm{B})$, which plays a critical regulatory role in immunity and inflammatory responses (13). NF- $\mathrm{B}$ regulates the expression of a variety of genes such as growth factors and pro-inflammatory cytokines such as IL-1 $\beta$ and TNF$\alpha$. NF- $\kappa \mathrm{B}$ enhances a signaling cascade which leads to sustained production of ROS and causes low grade inflammation (14). As mentioned earlier, continued production of proinflammatory cytokines results in an acute phase response by the innate immunity and lead to $\beta$ cell apoptosis and dysfunction. This process diminishes the ability of the pancreas to produce and release insulin and thus contributes to type 2 diabetogenesis.

Nutrition plays a critical role in systemic inflammation regulation (15). It has been shown that dietary patterns affect pro-inflammatory and anti-inflammatory cytokines' balance and therefore enhance the risk of developing inflammatory diseases (16). A comprehensive review of observational and prospective studies, along with randomized controlled trials, suggested an anti-inflammatory property for the Mediterranean dietary pattern (higher consumption of fruits and vegetables, unrefined carbohydrates, and fish, moderate consumption of dairy products and wine, and low consumption of non-fish meat (17), compared to the Western diet (higher consumption of refined carbohydrates, saturated fat, and red meat) (18). Consumption of antioxidant 
vitamins, such as vitamin $\mathrm{C}, \mathrm{E}$, and $\beta$-Carotene, and polyunsaturated fatty acids (PUFA), such as Omega-3 fatty acids, have been linked to lower systemic inflammation (19), while higher intakes of total and saturated fat have been associated with higher systemic inflammation (20-21).

The Dietary Inflammatory Index (DII) is a comprehensive literature-derived tool that was first developed by Caviccia et al. (22) in 2009 to assess the inflammatory potential of each individual's diet. Out of 2700 screened articles published from 1950 to 2007, 929 were considered for the development of the algorithm to formulate DII. The objective of this project was to develop a methodology which could score dietary intakes on a spectrum of maximally anti-inflammatory to maximally pro-inflammatory (22). Caviccia at al. validated the DII scores against CRP. The results of the validation study showed a significant relationship between DII, as a categorical variable, and CRP (22). Later in 2013, DII was updated by Shivappa et al. (23). The updated DII, is based on 1943 articles out of 6500 screened, published in 2010-2013 in regards to the effect of diet on 6 inflammatory biomarkers (IL-1 $\beta$, IL-4, IL-6, IL-10, TNF- $\alpha$, and CRP). The updated DII includes forty-five pro-inflammatory and anti-inflammatory food parameters, compared to forty-two in the initial DII. The food parameters include: alcohol, vitamin $\mathrm{B}_{12}$, vitamin $\mathrm{B}_{6}, \beta$-Carotene, caffeine, carbohydrate, cholesterol, energy, eugenol, total fat, fiber, folic acid, garlic, ginger, iron, magnesium, monounsaturated fatty acids (MUFA), niacin, n-3 fatty acids, n-6 fatty acids, onion, protein, PUFA, riboflavin, saffron, saturated fat, selenium, thiamin, trans fat, turmeric, vitamin A, vitamin C, vitamin D, vitamin E, zinc, green/black tea, flavan-3-ol, flavones, flavonols, flavonones, anthocyanidins, isoflavones, pepper, thyme/oregano, rosemary. After fitting the DII to 
eleven dietary intake data sets from across the world, the globally adjusted scores ranged from +7.98 (maximally pro-inflammatory) to -8.87 (maximally anti-inflammatory). High DII values (pro-inflammatory diet) have been linked to low grade inflammation and insulin resistance (24), metabolic syndrome (25), cardiovascular diseases (26), colorectal cancer (27-28), pancreatic cancer (29), gastric cancer (30), and ovarian cancer (31).

The aim of this study was to assess the relationship between DII and biomarker of inflammation (CRP), oxidative stress [8-hydroxydeoxyguanosine (8-OHdG)], glycemic status [glycated hemoglobin (HbA1c) and glycated albumin (GA)] and insulin level among individuals with type 2 diabetes and vitamin D deficiency/insufficiency. To our knowledge this is the first study assessing the relationship between DII, 8-OHdG, $\mathrm{HbA1c}, \mathrm{GA}$ and insulin among individuals with type 2 diabetes and vitamin D deficiency/insufficiency.

\section{Materials and methods:}

This is an ancillary study of data from the parent study by Huffman et al. (32) that investigated the effects of vitamin D3 supplementation on cardiovascular disease biomarkers. The outcome of this study is explained in detail elsewhere (32).

The study design is described below:

Study participants were recruited from 2 sources: 1) Community areas by distributing flyers that included the purpose of the study, inclusion and exclusion criteria, and the investigators information. 2) The Borinquen Health Care Center and the Clinical Care Medical Center. Weekly visits were conducted to recruit study participants. Interested individuals called the investigators and expressed their willingness to 
participate in the study, and were asked to answer a few eligibility pre-screening questions. Qualified individuals were invited for screening at the Human Nutrition Laboratory, Florida International University. After signing the informed consent form, fasting blood samples were collected, and screening questionnaires were administered to evaluate whether the inclusion criteria were met (33).

The inclusion criteria were being 30-70 years old, being African-American or Hispanic, having Type 2 diabetes, and being vitamin $\mathrm{D}$ insufficient $[25(\mathrm{OH}) \mathrm{D} 3<30$ ng/mL]. Exclusion criteria were being pregnant or lactating, taking vitamin D supplements, injecting insulin, suffering from thyroid, hepatic and/or renal complications, and suffering from HIV and cancer. Participants of the current study were contacted at two-time points:

Screening: During screening the eligibility of the participants to enroll in the study was assessed based on the inclusion and exclusion criteria. Participants signed an informed consent form before the start of data collection. Fasting blood was collected for screening of vitamin D status.

Baseline: All participants who met the inclusion criteria participated in the study. Blood collection, anthropometric measurements, Willett food frequency questionnaire and a socio-demographic questionnaire were administered at baseline.

\section{Measurements of variables:}

a. Socio-demographic questionnaire 
A socio-demographic questionnaire was used to collect information about age, gender, race/ethnicity, years living in the United States and years having type 2 diabetes.

b. Anthropometric measurements

Height and weight measurements were taken by using a SECA balance scale (SECA Corp, Columbia, MD), to the nearest $0.5 \mathrm{~cm}$ and $0.1 \mathrm{~kg}$, respectively. Waist circumference was measured by using a measuring tape to the nearest $0.1 \mathrm{~cm}$. Systolic and diastolic blood pressure were measured in a sitting position by using an automated arm-cuff monitor. All measurements were done twice and the average of two readings was included in the analysis.

c. Dietary intake

A food frequency questionnaire (FFQ) developed by Willett et al. (34) was used to assess dietary intake for each individual. This questionnaire was validated previously among individuals from different racial and ethnic backgrounds (34-37). In a study among Cuban-Americans, Nath et al. (35) validated Willet FFQ against a 3-day food record and reported no significant differences in the nutrient intakes estimated by these two methods. Ethnic food items were added to the questionnaire. This study suggested Willet FFQ may be a reasonable tool for estimating macronutrients and alcohol among Cuban-Americans (35). In the present study participants self-reported their average consumption of 131 food items for the past 12 months. Frequency of intake for each food item was ranged from "never" to "6 times or more daily". Consumption of multivitamin and mineral supplements were also recorded. In order to calculate each individuals' macronutrient and micronutrient intake, the frequency of consumption of 
each food item was multiplied by its nutrient value (Harvard University Food Consumption Data Base, Channing Laboratory, Boston, MA).

d. Calculation of the dietary inflammatory index (DII) score

DII for each individual was calculated based on the values obtained from the Willett FFQ. In this process, thirty-four foods and constituents parameters were included in the analysis (Table 1). To obtain a 'z score' relative to standard global mean, estimated intake of each food parameter for each individual was subtracted from the global standard mean and then divided by the global standard deviation. To prevent possible right skewing, calculated z-scores were converted to a percentile score centered on 0; First a percentile ranking was calculated for each $\mathrm{z}$ score and then each value was multiplied by 2 and subtracted by 1 to obtain values range between -1 and +1 . The calculated centered score for each food item was then multiplied by the respective food parameter's specified inflammatory effect score (23). All the obtained food parameter scores for each participant were summed up to create the overall DII score for each individual. More positive scores reflect more pro-inflammatory dietary intakes.

e. Blood collection and analysis

Fasting venous blood was collected by a certified phlebotomist (15 mL). After coagulation of blood samples in serum separator tubes for 30-45 minutes, samples were centrifuged at 2500 RPM for 30 minutes to obtain the serum. Fasting plasma glucose concentration was measured by hexokinase enzymatic method, glycated hemoglobin A1c (HbA1c) was measured by using DCA2000 + system (BAYER Corporation, Diagnostics Division, N.Y) and 25(OH)D3 concentrations were measured by using an enzymatic immunoassay kit (Immunodiagnostic Systems Scottsdale, AZ). Oxidative stress 
biomarker, 8-hydroxydeoxyguanosine (8-OHdG), was assessed using a human DNA/RNA oxidative damage competitive enzyme-linked immunosorbent assay (Cayman Chemical, Ann Arbor, MI, item No 589320).

\section{Statistical analysis:}

The IBM statistical package for the social sciences (SPSS) version 20 (Chicago, IL, USA) was used for performing the statistical analysis. $P$-value $\leq 0.05$ was considered significant (two-tailed). DII score was categorized into quartiles: Q1 (-5.214, -1.827), Q2 (-1.826, -0.653), Q3 (-0.652, +1.138), Q4 (+1.138, +3.999). Descriptive statistics were conducted for baseline characteristics; for continuous variables means and standard errors (SE) and for categorical variables frequencies/percentages were determined. Pearson correlation analysis was used to assess the correlation between variables within each quartile. Linear regression analysis was used to test the association between DII versus CRP, DII versus 8-OHdG, and DII versus GA\% within each quartile. The multivariable model was later adjusted for confounders.

\section{Results:}

Out of 92 individuals who were screened at baseline, 77 met the inclusion criteria and participated in the interventions. Nine subjects were excluded due to missing values for 8-OHdG and GA\%. Sixty-eight participants, 41 females and 27 males, were included in the current analysis. Baseline characteristics of participants for the entire sample and for each quartile [Q1 (-5.214, -1.827), Q2 (-1.826, -0.653), Q3 (-0.652, +1.138), Q4 $(+1.138,+3.999)]$ are shown in table 2 . There were 17 participants in each quartile. Mean age was $54.94 \pm 7.93$ with $60.3 \%$ of participants being female. Participants in the first 
quartile of DII (the least pro-inflammatory diet) were more likely to be women and had the highest systolic blood pressure (SBP). Participants in the third percentile of DII were more likely to be female, had higher BMI scores and higher CRP, HbA1c and fasting plasma glucose (FPG) levels. Participants in the fourth percentile of DII (more proinflammatory diet) were less likely to be female, had higher 8-OHdG, GA\%, HbA1c, FPG and parathyroid hormone (PTH).

Pearson correlation analysis showed a statistically significant correlation between DII Q1 and BMI $(\mathrm{r}=0.520, p=0.033)$, and PTH $(\mathrm{r}=0.510, p=0.037)$. For DII Q2, there was a significant correlation between DII score and HbA1c $(\mathrm{r}=0.529, p=0.029)$. For DII Q3, there was a significant correlation between DII score and insulin level ( $\mathrm{r}=0.620$, $p=0.008$ ). For DII Q4, there was a significant correlation between DII score and SBP $(\mathrm{r}=0.532, p=0.0 .028)$. Linear regression models assessing the association between quartile DII scores and BMI, PTH, HbA1c, insulin, and SBP were conducted (table 3). The unadjusted model showed no significant associations between DII, HbA1c and PTH (Q1-Q4). There was a marginally significant association between DII Q1 and BMI ( $p=0.057)$. A significant inverse association was observed between DII Q3-Q4 and insulin level ( $p=0.006$ and $p=0.030$, respectively). After adjusting for covariates, age, gender, waist circumference, FPG and 25(OH)D, the model remained significant for both Q3 and Q4 ( $p=0.040$ and $p=0.049$, respectively). There was a significant association between SBP and DII in Q4 ( $p=0.029)$. However, after adjusting the model for the covariates the model lost significance. 


\section{Discussion:}

To our knowledge, this is the first study examining the associations between dietary inflammatory index (DII) and biomarkers of inflammation (CRP), oxidative stress (8-OHdG), and glycemic status [glycated hemoglobin (HbAlc) and glycated albumin (GA\%)] among individuals with type 2 diabetes and vitamin D deficiency/insufficiency. The results of this cross-sectional analysis of data showed no statistically significant relationship between DII, CRP, 8-OHdG, HbA1c and GA\%. This confirms the findings of Almeida et al. (38) who found no significant associations between DII score and CRP level among adolescents from the LabMed physical activity study. Furthermore, in a study among 2,567 postmenopausal women, Tabung et al. (39) found no significant association between DII and CRP. However, Tabung et al. found another biomarker of inflammation, IL-6, to be significantly associated with DII. This is not consistent with the results of Cavicchia et al. (22) and Shivappa et al. (23) who found DII to be a significant predictor of CRP. It may be due to the smaller sample size in the present study $(\mathrm{n}=68$ compared to $\mathrm{n}=600$ in the Cavicchia et al.). Furthermore, DII is a literature-derived tool based on 1,943 articles on the effect of diet on a panel of inflammatory biomarkers (IL$1 \beta$, IL-4, IL-6, IL-10, TNF- $\alpha$, and CRP). It is not clear whether any of these biomarkers of inflammation are more sensitive to DII score across various racial/ethnic groups. In addition, the dietary intakes have been recorded with different methods across the studies. For the example Cavicchia at al. (22) obtained the dietary intakes data for each participant from a randomly selected 24-hour recall. This is while Almeida et al. (38) used a semi-quantitative food frequency questionnaire validated for the Portuguese population. It is worth noting that not all the studies used all forty-five food parameters 
included in the updated DII developed by Shivappa et al. (23). This may be due to unavailability of some dietary information caused by the various methods of dietary data collection. In our study, we included 34 food parameters, based on the availability of the dietary information. Food items such as eugenol, garlic, ginger, onion, saffron, turmeric, green/black tea, Isoflavones, pepper, thyme/oregano, and rosemary were not available and were not included in the present study. This may be a source of variation in DII range in across different studies; The DII range in our study was $(-5.214,+3.999)$, while the range for the global database developed by Shivappa et al. (23) was $(-8.87,+7.98)$.

A significant correlation was found between DII score and HbA1c $(r=0.529$, $p=0.029)$ in the second quartile (Q2) in the present study, and the unadjusted linear model also showed an association between DII and HbA1c. These results were inconsistent with findings of Wouderndergh et al. (40) who did not find an association between adopted DII and HbA1c among 1,024 Dutch participants. The present study found a significant inverse association between DII Q3-Q4 and insulin levels $(p=0.006$ and $p=0.030$, respectively). After adjusting for covariates, age, gender, waist circumference, FPG and 25(OH)D, the model remained significant $(p=0.040$ and $p=0.037$ ). This suggests individuals with higher pro-inflammatory dietary intakes may have lower insulin levels. This means a pro-inflammatory diet may play a role in insulin production and release from $\beta$-cells in pancreas. Moslehi et al. (41) reported no significant association between DII and insulin levels and insulin resistance among 2,975 Iranian adults. This may be due to the health status difference among the participants of this study (without type 2 diabetes), compared to the present study included only individuals with type 2 diabetes. In addition, mean age was lower ( $45 \pm 11.7$ years) in the 
study conducted by Moslehi et al. (41), compared to the present study (54.94 \pm 7.93 years).

There was a significant association between SBP and DII in Q4 $(p=0.029)$. This may suggest more pro-inflammatory dietary patterns can lead to a higher risk of developing blood pressure abnormalities. However, after adjusting the model for the covariates mentioned above, the model lost significance. Consistent with our findings, Vissers et al (42) also found pro-inflammatory diets associated with increased risk of developing hypertension among a cohort of middle-aged Australian woman.

\section{Conclusion:}

A pro-inflammatory diet may be associated with increased risk of hypoinsulinemia and incidence of higher SBP among individuals with type 2 diabetes and vitamin D deficiency/insufficiency. The limitations of this study were the small sample size and the exclusion of individuals with adequate serum $25(\mathrm{OH}) \mathrm{D}$ levels to serve as a base for comparison. Furthermore, due to unavailability of the dietary information, eleven food parameters were not included in the DII calculations. The strengths of the study were its innovation in studying the association between DII and biomarkers of inflammation (CRP), oxidative stress (8-OHdG), and glycemic status (HbA1c and GA\%) among individuals with type 2 diabetes and vitamin D deficiency/insufficiency. The results of this study may serve as a basis for future nutrition interventions to improve anti-inflammatory intakes, developing culturally appropriate anti-inflammatory counseling and improving the health status of individuals with type 2 diabetes. 
Table 1. Thirty-five food parameters obtained from the food frequency questionnaire to calculate the dietary inflammatory index

\begin{tabular}{|c|c|}
\hline Food parameter & Overall inflammatory effect score \\
\hline Alcohol (g) & -0.278 \\
\hline Vitamin B12 $(\mu \mathrm{g})$ & 0.106 \\
\hline Vitamin B6 (mg) & -0.365 \\
\hline$\beta$-Caroten $(\mu \mathrm{g})$ & -0.584 \\
\hline Caffeine (g) & -0.110 \\
\hline Carbohydrate (g) & 0.097 \\
\hline Cholesterol (mg) & 0.110 \\
\hline Energy (kcal) & 0.180 \\
\hline Total fat $(\mathrm{g})$ & 0.298 \\
\hline Fibre $(\mathrm{g})$ & -0.663 \\
\hline Folic acid $(\mu \mathrm{g})$ & -0.190 \\
\hline Iron (mg) & 0.032 \\
\hline Magnesium (mg) & -0.484 \\
\hline MUFA (g) & -0.009 \\
\hline Niacin $(\mathrm{mg})$ & -0.246 \\
\hline n-3 fatty acids (g) & -0.436 \\
\hline n-6 fatty acids (g) & -0.159 \\
\hline Protein $(\mathrm{g})$ & 0.021 \\
\hline PUFA $(g)$ & -0.337 \\
\hline Riboflavin (mg) & -0.068 \\
\hline Saturated fat $(\mathrm{g})$ & 0.373 \\
\hline Selenium $(\mu \mathrm{g})$ & -0.191 \\
\hline Thiamin (mg) & -0.098 \\
\hline Trans fat $(\mathrm{g})$ & 0.229 \\
\hline Vitamin A (RE)* & -0.401 \\
\hline Vitamin C (mg) & -0.424 \\
\hline Vitamin $\mathrm{D}(\mu \mathrm{g})$ & -0.446 \\
\hline Vitamin E (mg) & -0.419 \\
\hline Zinc (mg) & -0.313 \\
\hline Flavan-3-ol (mg) & -0.415 \\
\hline Flavones (mg) & -0.616 \\
\hline Flavonols (mg) & -0.467 \\
\hline Flavonones (mg) & -0.250 \\
\hline Anthocyanidins (mg) & -0.131 \\
\hline
\end{tabular}

Eugenol, garlic, ginger, onion, saffron, turmeric, green/black tea, Isoflavones, pepper, thyme/oregano, and rosemary were not included in the present study. $* \mathrm{RE}=$ retinol equivalent. 
Table 2. Baseline Characteristics

\begin{tabular}{|c|c|c|c|c|c|}
\hline Characteristics & $\begin{array}{c}\text { Total } \\
(\mathrm{N}=68) \\
\text { Mean } \pm \text { SE }\end{array}$ & $\begin{array}{c}\text { Q1* } \\
(n=17) \\
\text { Mean } \pm \text { SE }\end{array}$ & $\begin{array}{c}\mathrm{Q}^{*} \\
(\mathrm{n}=17) \\
\text { Mean } \pm \text { SE }\end{array}$ & $\begin{array}{c}\mathrm{Q3}^{*} \\
(\mathrm{n}=17) \\
\text { Mean } \pm \text { SE }\end{array}$ & $\begin{array}{c}\text { Q4* } \\
(\mathrm{n}=17) \\
\text { Mean } \pm \text { SE }\end{array}$ \\
\hline Age (years) & $54.94 \pm 7.93$ & $54.47 \pm 6.57$ & $56 \pm 9.93$ & $54.06 \pm 6.47$ & $55.24 \pm 8.81$ \\
\hline $\begin{array}{l}\text { Gender (\% } \\
\text { female) }\end{array}$ & 60.3 & 58.8 & 58.8 & 76.5 & 47.1 \\
\hline BMI $\left(\mathrm{kg} / \mathrm{m}^{2}\right)$ & $33.70 \pm 6.59$ & $32.65 \pm 4.08$ & $32.86 \pm 5.91$ & $37.14 \pm 8.72$ & $32.15 \pm 6.10$ \\
\hline SBP & $\begin{array}{c}133.706 \pm \\
22.59\end{array}$ & $\begin{array}{c}136.56 \pm \\
21.25\end{array}$ & $\begin{array}{c}135.59 \pm \\
18.92\end{array}$ & $\begin{array}{c}130.65 \pm \\
25.62\end{array}$ & $\begin{array}{c}132.03 \pm \\
25.18\end{array}$ \\
\hline DBP & $84.97 \pm 12.57$ & $85.47 \pm 9.26$ & $85.29 \pm 10.63$ & $85.94 \pm 17.02$ & $\begin{array}{c}83.18 \pm \\
12.99\end{array}$ \\
\hline $\begin{array}{l}25(\mathrm{OH}) \mathrm{D} \\
(\mathrm{ng} / \mathrm{mL})\end{array}$ & $22.34 \pm 6.68$ & $22.78 \pm 6.34$ & $22.40 \pm 5.93$ & $21.79 \pm 6.41$ & $22.38 \pm 8.31$ \\
\hline CRP & $7.91 \pm 10.60$ & $7.87 \pm 10.87$ & $7.92 \pm 12.56$ & $10.43 \pm 12.50$ & $5.43 \pm 5.01$ \\
\hline $\begin{array}{l}\text { 8-OHdG } \\
(\mathrm{pg} / \mathrm{mL})\end{array}$ & $\begin{array}{c}8068.94 \pm \\
2158.13\end{array}$ & $\begin{array}{c}7787.73 \pm \\
2010.92\end{array}$ & $\begin{array}{c}8174.39 \pm \\
3018.67\end{array}$ & $\begin{array}{c}7572.12 \pm \\
1835.72\end{array}$ & $\begin{array}{c}8741.50 \pm \\
1462.46\end{array}$ \\
\hline GA\% & $5.51 \pm 3.28$ & $5.29 \pm 2.84$ & $6.03 \pm 4.30$ & $4.49 \pm 1.80$ & $6.24 \pm 3.65$ \\
\hline $\mathrm{HbA1c}$ & $8.35 \pm 2.28$ & $8.14 \pm 2.01$ & $7.87 \pm 1.95$ & $9.13 \pm 2.62$ & $8.26 \pm 2.47$ \\
\hline FPG (mg/dL) & $\begin{array}{c}184.26 \pm \\
79.02\end{array}$ & $\begin{array}{c}183.82 \pm \\
71.65\end{array}$ & $\begin{array}{c}173.65 \pm \\
70.92\end{array}$ & $\begin{array}{c}203.12 \pm \\
99.19\end{array}$ & $\begin{array}{c}176.47 \pm \\
74.73\end{array}$ \\
\hline $\begin{array}{l}\text { Insulin } \\
(\mathrm{mIU} / \mathrm{L})\end{array}$ & $12.64 \pm 11.38$ & $11.58 \pm 8.71$ & $17.46 \pm 17.05$ & $11.46 \pm 6.68$ & $10.08 \pm 4.95$ \\
\hline PTH (pg/mL) & $\begin{array}{c}39.52 \pm \\
18.139\end{array}$ & $33.90 \pm 16.40$ & $34.52 \pm 17.76$ & $42.87 \pm 18.19$ & $\begin{array}{c}46.49 \pm \\
17.47\end{array}$ \\
\hline
\end{tabular}

*Quartiles; Q1 (-5.214, -1.827), Q2 (-1.826, -0.653), Q3 (-0.652, +1.138), Q4 (+1.138, +3.999). $\mathrm{BMI}=$ Body mass index. $\mathrm{SBP}=$ systolic blood pressure. $\mathrm{DBP}=$ diastolic blood pressure. $\mathrm{CRP}=$ C-reactive protein. GA\% = Glycated albumin/albumin $* 100 . \mathrm{FPG}=$ fasting plasma glucose, $\mathrm{PTH}$ $=$ parathyroid hormone. 
Table 3. Association between Dietary Inflammatory Index and covariates within each quartile

\begin{tabular}{|c|c|c|c|c|c|c|c|c|}
\hline \multirow[t]{2}{*}{ Parameter* } & \multicolumn{3}{|c|}{ Unadjusted } & \multirow[b]{2}{*}{ P-value } & \multicolumn{4}{|c|}{ Adjusted } \\
\hline & $\beta$ & SE & $\mathrm{T}$ & & $\beta$ & SE & $\mathrm{T}$ & P-value \\
\hline \multicolumn{9}{|l|}{ Insulin (mIU/L) } \\
\hline Q1 & 0.340 & 1.418 & 1.398 & 0.182 & & & & \\
\hline Q2 & 0.088 & 2.104 & 0.342 & 0.737 & & & & \\
\hline Q3 & 0.636 & 0.703 & 3.188 & $0.006 \dagger$ & -0.594 & 0.921 & -2.362 & $0.040 \dagger$ \\
\hline Q4 & -0.526 & 0.505 & -2.398 & $0.030 \dagger$ & -0.619 & 0.635 & -2.246 & $0.049 \dagger$ \\
\hline \multicolumn{9}{|l|}{$\mathrm{SBP}(\mathrm{mmHg})$} \\
\hline Q1 & 0.447 & 3.29 & 1.937 & 0.072 & & & & \\
\hline Q2 & 0.100 & 2.09 & 0.388 & 0.703 & & & & \\
\hline Q3 & -0.400 & 3.32 & -1.692 & 0.111 & & & & \\
\hline Q4 & 0.528 & 2.57 & 2.408 & $0.029 \dagger$ & 0.486 & 0.23 & 1.815 & 0.10 \\
\hline
\end{tabular}

*Other covariates in the multiple regression model were age, gender, waist circumference and fasting plasma glucose and $25(\mathrm{OH}) \mathrm{D}$. $\uparrow$ Statistically significant. $P<0.05$ is considered significant.

REFERENCES: 
1. Xu, J., Murphy, S.L., Kochanek, K.D., \& Bastian, B.A. (2016). Deaths: Final data for 2013. National vital statistics reports, 64(2), 1-118.

2. Centers for Disease Control and Prevention. (2014). National Diabetes Statistics Report: Estimates of Diabetes and Its Burden in the United States. U.S. Department of Health and Human Services.

3. Economic costs of diabetes in the U.S. In 2012 (2013). Diabetes Care, 36(4), 1033-1046. doi:10.2337/dc12-2625.

4. Halban, P. A., Polonsky, K. S., Bowden, D. W., Hawkins, M. A., Ling, C., Mather, K. J., Weir, G. C. (2014). B-cell failure in type 2 diabetes: Postulated mechanisms and prospects for prevention and treatment. Diabetes Care, 37(6), 17511758. doi:10.2337/dc14-0396.

5. Pradhan, A. D., Manson, J.E., Rifai, N., Buring, J. E., Ridker, P.M. (2001). CReactive protein, Interleukin 6, and risk of developing type 2 diabetes Mellitus. JAMA, 286(3), 327. doi:10.1001/jama.286.3.327.

6. Duncan, B. B., Schmidt, M. I., Pankow, J. S., Ballantyne, C. M., Couper, D., Vigo, A., Heiss, G. (2003). Low-grade systemic inflammation and the development of type 2 diabetes: The Atherosclerosis risk in communities study. Diabetes, 52(7), 17991805. doi:10.2337/diabetes.52.7.1799.

7. Pickup, J. C., \& Crook, M. A. (1998). Is type II diabetes mellitus a disease of the innate immune system? Diabetologia, 41(10), 1241-1248. doi:10.1007/s001250051058.

8. Kushner, I. (1993). Regulation of the acute phase response by Cytokines. Perspectives in Biology and Medicine, 36(4), 611-622. doi:10.1353/pbm.1993.0004.

9. Pittas, A. G., Lau, J., Hu, F. B., \& Dawson-Hughes, B. (2007). The role of vitamin $\mathrm{D}$ and calcium in type 2 diabetes. A systematic review and Meta-Analysis. The Journal of Clinical Endocrinology \& Metabolism, 92(6), 2017-2029. doi:10.1210/jc.2007-0298.

10. Stulnig, T. M., \& Waldhäusl, W. (2004). 11B-Hydroxysteroid dehydrogenase type 1 in obesity and type 2 diabetes. Diabetologia, 47(1), 1-11. doi:10.1007/s00125003-1284-4.

11. Liebman, T. (2010). The Role of Cortisol and Abdominal Obesity in the Epidemic of Type 2 Diabetes. Undergraduate Research Journal for the Human Sciences, 9(1).

12. Garcia-Bailo, B., El-Sohemy, A., Haddad, P. S., Arora, P., BenZaied, F., Karmali, M., \& Badawi, A. (2011). Vitamins D, C, and E in the prevention of type 2 diabetes mellitus: modulation of inflammation and oxidative stress.Biologics : Targets \& Therapy, 5, 7-19. doi:10.2147/BTT.S14417. 
13. Evans, J. L., Goldfine, I. D., Maddux, B. A., \& Grodsky, G. M. (2002). Oxidative stress and stress-activated signaling pathways: A unifying hypothesis of type 2 diabetes. Endocrine Reviews, 23(5), 599-622. doi:10.1210/er.2001-0039.

14. Kajimoto, Y., \& Kaneto, H. (2004). Role of Oxidative stress in Pancreatic $\beta$ cell dysfunction. Annals of the New York Academy of Sciences, 1011(1), 168-176. doi:10.1196/annals.1293.017.

15. Wirth M.D., Sevoyan M., Hofseth L., Shivappa N., Hurley T.G., Hébert J.R. (2017). The Dietary Inflammatory Index is associated with elevated white blood cell counts in the National Health and Nutrition Examination Survey. Brain Behav Immun. pii: S0889-1591(17)30527-5. doi: 10.1016/j.bbi.2017.12.003.

16. Calder P.C., Ahluwalia N., Brouns F., Buetler T., Clement K., Cunningham K., Esposito K., Jönsson L.S., Kolb H., Lansink M., Marcos A., Margioris A., Matusheski N., Nordmann H., O'Brien J., Pugliese G., Rizkalla S., Schalkwijk C., Tuomilehto J., Wärnberg J., Watzl B., Winklhofer-Roob B.M. (2011). Dietary factors and low-grade inflammation in relation to overweight and obesity. Br J Nutr. 106 Suppl 3:S578. doi: 10.1017/S0007114511005460.

17. Godman H. (2013). Adopt a Mediterranean diet now for better health later. Harvard Health Letter. https://www.health.harvard.edu/blog/adopt-a-mediterranean-dietnow-for-better-health-later-201311066846.

18. Ahluwalia N., Andreevaa V.A., Kesse-Guyota E., Hercbergab S. (2012). Dietary patterns, inflammation and the metabolic syndrome. Diabetes Metab. 39(2):99110. doi: 10.1016/j.diabet.2012.08.007.

19. Del Mar Bibiloni M., Maffeis C., Llompart I., Pons A., Tur J.A. (2013). Dietary factors associated with subclinical inflammation among girls. Eur J Clin Nutr. 67(12):1264-1270. doi: 10.1038/ejen.2013.196.

20. Aeberli I., Molinari L., Spinas G., Lehmann R., l'Allemand D., Zimmermann M.B. (2006). Dietary intakes of fat and antioxidant vitamins are predictors of subclinical inflammation in overweight Swiss children. Am J Clin Nutr. 84(4):748-755.

21. Almeida-de-Souza J., Santos R., Barros R., Abreu S., Moreira C., Lopes L., Mota J., Moreira P. (2017). Dietary inflammatory index and inflammatory biomarkers in adolescents from LabMed physical activity study. European Journal of Clinical Nutrition. doi:10.1038/s41430-017-0013-x.

22. Cavicchia P.P., Steck S.E., Hurley T.G., Hussey J.R., Ma Y., Ockene I.S., Hébert J.R. (2009). A new dietary inflammatory index predicts interval changes in serum high-sensitivity C-reactive protein. J Nutr. 139(12):2365-2372. doi: 10.3945/jn.109.114025.

23. Shivappa N., Steck S.E., Hurley T.G., Hussey J.R., Hébert J.R. (2014). Designing and developing a literature-derived, population-based dietary inflammatory index. Public Health Nutr. 17(8):1689-1696. doi: 10.1017/S1368980013002115. 
24. van Woudenbergh G.J., Theofylaktopoulou D., Kuijsten A., Ferreira I., van Greevenbroek M.M., van der Kallen C.J., Schalkwijk C.G., Stehouwer C.D., Ocké M.C., Nijpels G., Dekker J.M., Blaak E.E., Feskens E.J. (2013). Adapted dietary inflammatory index and its association with a summary score for low-grade inflammation and markers of glucose metabolism: the Cohort study on Diabetes and Atherosclerosis Maastricht (CODAM) and the Hoorn study. Am J Clin Nutr. 98(6):1533-1542. doi: 10.3945/ajen.112.056333.

25. Wirth M., Burch J., Shivappa N., Violanti, J. M., Burchfiel, C.M., Fekedulegn D., Andrew M.E., Hartley T.A., Miller D.B., Mnatsakanova A., Charles L.E., Steck S.E. Hurley T.G., Vena J.E., Hébert J.R. (2014). Association of a Dietary Inflammatory Index with Inflammatory Indices and the Metabolic Syndrome among Police Officers. J Occup Environ 56(9): 986-989. doi: 10.1097/JOM.0000000000000213.

26. Ruiz-Canela M., Bes-Rastrollo M., Martínez-González M.A. (2016). The Role of Dietary Inflammatory Index in Cardiovascular Disease, Metabolic Syndrome and Mortality. Int J Mol Sci. 3:17(8). pii: E1265. doi: 10.3390/ijms17081265.

27. Tabung F.K., Steck S.E., Ma Y., Liese A.D., Zhang J., Caan B., Hou L., Johnson K.C., Mossavar-Rahmani Y., Shivappa N., Wactawski-Wende J., Ockene J.K., Hebert J.R. (2015). The association between dietary inflammatory index and risk of colorectal cancer among postmenopausal women: results from the Women's Health Initiative. Cancer Causes Control. 26(3):399-408. doi: 10.1007/s10552-014-0515-y.

28. Harmon B.E., Wirth M.D., Boushey C.J., Wilkens L.R., Draluck E., Shivappa N., Steck S.E., Hofseth L., Haiman C.A., Le Marchand L., Hébert J.R. (2017) The Dietary Inflammatory Index Is Associated with Colorectal Cancer Risk in the Multiethnic Cohort. J Nutr. 147(3):430-438. doi: 10.3945/jn.116.242529.

29. Shivappa N., Bosetti C., Zucchetto A., Serraino D., La Vecchia C., Hébert J.R. (2015). Dietary inflammatory index and risk of pancreatic cancer in an Italian casecontrol study. Br J Nutr. 28;113(2):292-298. doi: 10.1017/S0007114514003626.

30. Lee S., Lee J., Choi I.J., Kim Y.W., Ryu K.W., Kim Y.I., Oh J.K., Tran B.T., Kim J. (2017). Dietary inflammatory index and the risk of gastric cancer in a Korean population. Oncotarget. 7;8(49):85452-85462. doi: 10.18632/oncotarget.20008.

31. Shivappa N., Hébert J.R., Paddock L.E., Rodriguez-Rodriguez L., Olson S.H., Bandera E.V. (2018). Dietary inflammatory index and ovarian cancer risk in a New Jersey case-control study. Nutrition. 46:78-82. doi: 10.1016/j.nut.2017.08.011.

32. Exebio, J. C., Zarini, G. G., Ajabshir, S., Antwi, J., Huffman, F. G. (2015). Validation of a sun exposure questionnaire among subjects with type 2 diabetes residing in south Florida. Journal of Immigrant and Minority Health, 18(1): 228-233.

doi:10.1007/s10903-015-0163-7.

33. Pittas, A. G., Harris, S. S., Stark, P. C., \& Dawson-Hughes, B. (2007). The effects of calcium and vitamin D Supplementation on blood glucose and markers of 
inflammation in Nondiabetic adults. Diabetes Care, 30(4), 980-986. doi:10.2337/dc061994.

34. Willett W.C., Sampson L., Stampfer M.J., Rosner B., Bain C., Witschi J., Hennekens C.H., Speizer F.E. (1985). Reproducibility and validity of a semiquantitative food frequency questionnaire. Am J Epidemiol. 122(1):51-65.

35. Nath S.D., Huffman F.G. (2005). Validation of a semiquantitative food frequency questionnaire to assess energy and macronutrient intakes of Cuban Americans. Int J Food Sci Nutr. 56(5):309-314.

36. Hernández-Avila M., Romieu I., Parra S., Hernández-Avila J., Madrigal H., Willett W. (1998). Validity and reproducibility of a food frequency questionnaire to assess dietary intake of women living in Mexico City. Salud Publica Mex. 40(2):133-140.

37. Tucker K.L., Bianchi L.A., Maras J., Bermudez O.I. (1998). Adaptation of a food frequency questionnaire to assess diets of Puerto Rican and non-Hispanic adults. Am J Epidemiol. 1;148(5):507-518.

38. Almeida-de-Souza J., Santos R., Barros R., Abreu S., Moreira C., Lopes L., Mota J., Moreira P. (2017). Dietary inflammatory index and inflammatory biomarkers in adolescents from LabMed physical activity study. Eur J Clin Nutr. doi: 10.1038/s41430017-0013-X.

39. Tabung F.K., Steck S.E., Zhang J., Ma Y., Liese A.D., Agalliu I., Hingle M., Hou L., Hurley T.G., Jiao L., Martin L.W., Millen AE., Park H.L., Rosal M.C., Shikany J.M., Shivappa N., Ockene J.K., Hebert J.R. Construct validation of the dietary inflammatory index among postmenopausal women. Ann Epidemiol. 25(6):398-405. doi: 10.1016/j.annepidem.2015.03.009.

40. van Woudenbergh G.J., Theofylaktopoulou D., Kuijsten A., Ferreira I., van Greevenbroek M.M., van der Kallen C.J., Schalkwijk C.G., Stehouwer C.D., Ocké M.C., Nijpels G., Dekker J.M., Blaak E.E., Feskens E.J. (2013). Adapted dietary inflammatory index and its association with a summary score for low-grade inflammation and markers of glucose metabolism: the Cohort study on Diabetes and Atherosclerosis Maastricht (CODAM) and the Hoorn study. Am J Clin Nutr. 98(6):1533-1542. doi: 10.3945/ajen.112.056333.

41. Moslehi N., Ehsani B., Mirmiran P., Shivappa N., Tohidi M., Hébert J.R. , Azizi F. (2016). Inflammatory Properties of Diet and Glucose-Insulin Homeostasis in a Cohort of Iranian Adults. Nutrients. 18;8(11). pii: E735.

42. Vissers LET1, Waller M2, van der Schouw YT3, Hébert JR4, Shivappa N4, Schoenaker DAJM2, Mishra GD. (2017). A pro-inflammatory diet is associated with increased risk of developing hypertension among middle-aged women. Nutr Metab Cardiovasc Dis. 27(6):564-570. doi: 10.1016/j.numecd.2017.03.005. 


\section{CHAPTER III: EFFECT OF VITAMIN D3 SUPPLEMENTATION ON DNA/RNA OXIDATIVE STRESS IN ADULTS WITH TYPE 2 DIABETES}

\section{$\underline{\text { Introduction }}$}

Oxidative stress is caused by an imbalance between oxygen metabolites production and ability of the endogenous and exogenous antioxidant networks to neutralize them (1). Reactive oxygen species (ROS), such as superoxide anion $\left(\mathrm{O}_{2}{ }^{-}\right)$, hydrogen peroxide $\left(\mathrm{H}_{2} \mathrm{O}_{2}\right)$, hydroxyl radical $\left(\mathrm{OH}^{\circ}\right)$ and peroxynitrite $\left(\mathrm{OONO}^{-}\right)$, have one or more unpaired electrons and are highly reactive (2). ROS may attack other molecules to take an electron from them and stabilize (3). They can damage proteins, lipids and DNA. These oxidized biomolecules may trigger further oxidizing chain reactions that may result in production of new free radicals (3-4). Oxidative stress plays a pivotal role in systemic inflammation, type 2 diabetes development and its related complications (5). Although ROS production is one of the primary defense mechanisms, increased ROS production may result in impaired oxidative balance which leads to activation of nuclear factor $\kappa \mathrm{B}(\mathrm{NF}-\kappa \mathrm{B})$. NF- $\kappa \mathrm{B}$ plays a critical regulatory role in immunity and inflammatory responses (4). $\mathrm{NF}-\kappa \mathrm{B}$ regulates the expression of a variety of genes such as growth factors and pro-inflammatory cytokines and enhances a signaling cascade which leads to sustained production of ROS and causing low grade inflammation (6). Continued production of pro-inflammatory cytokines results in an acute phase response by the innate immunity and lead to pancreatic $\beta$ cell apoptosis and dysfunction. This process diminishes the ability of the pancreas to produce and release insulin and thus causes type 2 diabetes. 
ROS induced oxidation of guanine residues of DNA can damage the DNA strands and produce 8-hydroxydeoxyguanosine (8-OHdG) (7). Several studies had shown increased 8-OHdG levels among individuals with type 2 diabetes (8-9). It has been suggested that 8-OHdG may be a predictive biomarker for early detection of lifestyle related health conditions, such as type 2 diabetes, at population level (10).

Nutrition plays a vital role in maintaining the oxidative balance. The direct effect of nutrition is via providing dietary antioxidants to the exogenous antioxidant network. In addition, nutrition affects the oxidative balance indirectly by providing energy to the endogenous enzymatic antioxidant system and therefore enhances its function (3). On the other hand, over-nutrition and physical inactivity are stressors that contribute to ROS production by inducing hyperglycemia and increased glucose accumulation in the muscle tissue, adipose tissue and pancreatic cells (2). ROS formed by autoxidation of glucose in the muscle tissue, adipose tissue, and pancreatic cells may non-enzymatically react with proteins and result in further production of ROS (11). These pathogenic effects can lead to development of insulin resistance, Beta cell dysfunction and glucose intolerance and thus result in type 2 diabetogenesis. In animal models, ROS impaired insulin synthesis via suppression of insulin gene expression in pancreatic Beta cells (6). Antioxidant treatment in diabetic rats resulted in improved insulin secretion (6). It has been suggested that decreasing oxidative stress may have beneficial effects on the health of individuals with type 2 diabetes (2), and that antioxidant therapy may be a potential solution to reduce type 2 diabetes-related complications (6).

The antioxidant properties of vitamin D3 in human under diabetes conditions are not clear. One potential anti-oxidative action of vitamin D may be via suppression of 
intracellular NF-אB which result in down-regulation of pro-inflammatory cytokines (12). Diminished pro-inflammatory cytokine levels prevent B cell apoptosis and improves B cell survival (5). In addition, $1,25(\mathrm{OH})_{2} \mathrm{D} 3$ known as the active form of vitamin $\mathrm{D} 3$, activates the expression of anti-inflammatory cytokines such as IL-4, IL-10 and TGF-B1 (13). Deluca et al. (13) suggested that vitamin D may have an immunosuppressive property due to its effect on regulation of pro-inflammatory and anti-inflammatory cytokines. Vitamin D supplementation could decrease oxidative stress in human colorectal mucosa as measured by $8-\mathrm{OHdG}(14)$. Furthermore, $1,25(\mathrm{OH})_{2} \mathrm{D} 3$ is proved to have protective properties against UV-induced oxidative DNA damage in skin cells (15).

Sun exposure have been shown to be a critical factor in maintaining serum vitamin D level in human (16). It has been reported that exposed skin areas' color, such as forearm skin color, are significantly associated with serum $25(\mathrm{OH}) \mathrm{D} 3$ and that forearm skin color may be an accurate predictor of serum vitamin D (16). Several studies showed that lighter skin color is associated with higher serum 25(OH)D3 levels (16-19). Considering the antioxidant properties of vitamin D and the role of sun exposure in maintaining the serum vitamin D level, further investigations are required to assess the association between skin color and oxidative stress under hypovitaminosis D and diabetes conditions.

Effectiveness of vitamin D3 supplementation on DNA/RNA oxidative stress under type 2 diabetes condition in human is not clear. Trials among human subjects are needed to investigate and quantify the potential beneficial impact of vitamin D3 supplementation at different dosages among individuals with vitamin D deficiency. Therefore, the aim of this study was to investigate the effect of $4000 \mathrm{IU}$ and $6000 \mathrm{IU}$ 
daily supplementation of vitamin D3 for 3 and 6 months on a biomarker of DNA/RNA oxidative stress, $8-\mathrm{OHdG}$, in individuals with type 2 diabetes and serum vitamin D [25(OH)D3] insufficiency or deficiency. In addition, we investigated the relationship between skin exposure score, as a measure of sun exposure, and oxidative stress in individuals with type 2 diabetes and 25(OH)D3 deficiency or insufficiency. We hypothesized that daily supplementation with 4000 and 6000 IU of vitamin D3 for 6 months will decrease serum 8-OHdG level in individuals with type 2 diabetes and vitamin D insufficiency or deficiency, compared to baseline. To our knowledge, this is the first study investigating the effects of vitamin D3 supplementation on 8-OHdG among human subjects with type 2 diabetes. Furthermore, we hypothesized individuals with lighter forearm skin color will have lower 8-OHdG levels compared to those with darker forearm skin color, at baseline, and that individuals with higher skin exposure scores, as measured by the difference between exposed and unexposed skin colors, will have lower 8-OHdG levels.

\section{Materials and methods:}

This clinical trial, assessed the effect of daily supplementation with 4000 and $6000 \mathrm{IU}$ of vitamin D3 over six months on biomarker of DNA/RNA oxidative stress among adults with type 2 diabetes living in South Florida. The parent study was conducted by Huffman et al. (20) assessing the effect of vitamin D3 supplementation on cardiovascular disease biomarkers. In the present study, serum samples collected at baseline, 3 months and 6 months stored at $-80^{\circ}$ were used to measure DNA/RNA oxidative stress level (8-OHdG). 
Study participants were recruited from 2 sources:

- From community areas by distributing flyers including the purpose of the study, inclusion and exclusion criteria, and the investigators information.

- From 2 clinics: Borinquen Health care center and Clinical Care Medical center. Weekly visits were conducted to recruit study participants.

Interested individuals called the investigators and expressed their willingness to participate in the study and were asked to answer a few pre-screening questions. Qualified individuals were invited for screening at the Human Nutrition Laboratory, Florida International University. After signing the informed consent form, fasting blood samples were collected and screening questionnaires were administered to evaluate whether the inclusion criteria were met (20).

Inclusion criteria was being 30-70 years old, being African-American or Hispanic, having Type 2 diabetes, and being vitamin D insufficient [25(OH)D3 $<30 \mathrm{ng} / \mathrm{mL}]$. Exclusion criteria was being pregnant or lactating, taking vitamin D supplements, injecting insulin, suffering from thyroid, hepatic and/or renal complications, suffering from HIV, or cancer. The duration of the intervention was 6 months and participants were contacted at four-time points:

Time zero (T0): Screening: During screening the eligibility of the participants to enroll in the study was assessed based on the inclusion and exclusion criteria. Participants signed an informed consent form before the data collection. Fasting blood was collected for screening of vitamin D status. 
Time one (T1): Baseline: All participants who met the inclusion criteria participated in the study. Blood collection, anthropometric measurements, skin color measurements, and a socio-demographic questionnaire were administered at baseline and vitamin D supplements (pills) were provided to the participants (4000 and $6000 \mathrm{IU} / \mathrm{p} i l l$ ).

Time two (T2): Blood collection, anthropometric measurements, and skin color measurements were administered after 3 months of supplementation with $4000 \mathrm{IU}$ or 6000 IU vitamin D3 pills. Additional vitamin D3 pills were provided to the participants.

Time three (T3): Blood collection, anthropometric measurements, and skin color measurements were administered after 6 months of supplementation. Study was terminated at this point.

Table 1. Parent Study Timeline

\begin{tabular}{|c|l|}
\hline Time & \multicolumn{1}{c|}{ Assessments } \\
\hline Screening (T0) & $\begin{array}{l}\text { Informed consent form signing, fasting blood collection, screening } \\
\text { questionnaire }\end{array}$ \\
\hline Baseline (T1) & $\begin{array}{l}\text { Fasting blood collection, sociodemographic questionnaire, food frequency } \\
\text { questionnaire, skin color measurement, anthropometric measurement }\end{array}$ \\
\hline 3 months (T2) & Pill count, fasting blood collection, skin color measurement \\
\hline 6 months (T3) & Pill count, fasting blood collection, skin color measurement \\
\hline
\end{tabular}

Measurements of variables:

a. Socio-demographic questionnaire 
A socio-demographic questionnaire was used to collect information about age, gender, race/ethnicity, years living in the United States and years having type 2 diabetes.

b. Anthropometric measurements

Height and weight measurements were taken by using a SECA balance scale (SECA Corp, Columbia, MD), to the nearest $0.5 \mathrm{~cm}$ and $0.1 \mathrm{~kg}$, respectively. Waist circumference was measured by using a measuring tape to the nearest $0.1 \mathrm{~cm}$. Systolic and diastolic blood pressure were measured in a sitting position by using an automated arm-cuff monitor. All measurements were done twice and the average of two readings was considered in the analysis.

c. Skin color measurement

Reflectance colorimetry method was used to determine skin color as an objective measure of skin sun exposure (IMS Smart Probe 400, Millford CT, USA) (20). This instrument uses the International Commission on Illumination Scale and ranges the skin color from 0 (black) to 100 (white). The measurement sites included 3 areas: wrist of the right hand as the most exposed area to sun, inside of the right upper arm and the waist as the least exposed areas to the sun (20). Each measurement was conducted 2 times and the average was considered in the proposed study analysis. This tool is validated by several studies (16, 20-21). Skin sun exposure level was determined by calculating the difference between the wrist of the right-hand skin color (the most exposed) and the inside of the right upper arm (the least exposed). 


\section{d. Food frequency questionnaire}

A validated short vitamin D and calcium questionnaire developed by Blalock (22) was used to assess the dietary calcium and vitamin D intakes. The modified questionnaire added pizza to the 22 existing foods and beverages and asked for serving size and frequency of consumption of each food (16). This tool is validated by several studies (16, 20, 22).

\section{e. Physical activity}

Physical activity was measured using the Modifiable Activity Questionnaire (MAQ), which has been validated for individuals with type 2 diabetes (23-24). This questionnaire by Kriska et al. (25) measures the levels of leisure and occupational physical activity for over the past year in sum of hours per week. After collecting this information, the sum of hours per week were multiplied by the estimated metabolic rate to calculate metabolic equivalents (METs)/hours per week.

\section{f. Perceived stress}

Perceived stress level was measured by using Perceived Stress Scale (PSS-10) (26-27). The response categories in this questionnaire were ranged from 'never' $=0$, 'almost never' $=1$, 'sometimes' $=2$, 'fairly often' $=3$, and 'very often' $=4$. The total score outcome ranges from 0-40 which reflects perceived stress level. This questionnaire has been validated among individuals from different racial and ethnic groups, with and without type 2 diabetes (28). 


\section{g. Blood collection and analysis}

Fasting venous blood was collected by a certified phlebotomist (15 mL). After coagulation of blood samples in serum separator tubes for 30-45 minutes, samples were centrifuged at 2500 RPM for 30 minutes to obtain the serum. Fasting plasma glucose concentration was measured by hexokinase enzymatic method, glycated hemoglobin A1c (HbA1c) was measured by using DCA2000 + system (BAYER Corporation, Diagnostics Division, N.Y) and 25(OH)D3 concentrations were measured by using an enzymatic immunoassay kit (Immunodiagnostic Systems Scottsdale, AZ) (16).

\section{h. Oxidative stress}

Oxidative stress biomarker, 8-hydroxyguanosine (8-OHdG), was assessed using a human DNA/RNA oxidative damage competitive enzyme-linked immunosorbent assay (Cayman Chemical, Ann Arbor, MI, item No 589320); this immunoassay measures the DNA/RNA damage by detecting 8-hydroxy-2`-deoxyguanosine and 8-hydroxyguanosine from DNA and RNA, respectively. In addition, it detects 8-hydroxyguanine from both DNA and RNA which provides more accurate information about biologic products of oxidative stress, compared to other available assays which mostly detect only one of the three biomarkers mentioned (29). As recommended by the assay protocol, initially 15 serum samples were diluted with the assay buffer within the range of 1:25 - 1:100. After analyzing the results, dilution 1:50 was used for this study. Participant`s serum samples were defrosted and diluted with the assay buffer to 1:50. Assay standards were prepared in 8 test tubes by serially diluting the bulk standard from tube 1 to tube 8 . Coated plates with goat polyclonal anti-mouse IgG were prepared with standards and serum samples based the assay protocol. Each standard and sample were run in duplicates. After addition 
of DNA/RNA oxidative damage assay monoclonal antibody, plated were covered and incubated for 18 hours at $4^{\circ} \mathrm{c}$. After completion of the incubation, plates were washed 5 times with the assay wash buffer and were developed in dark with developing reagent for 100 minutes on an orbital shaker. Each plate was read at 405 wavelengths using a plate reader located at Huffman Nutrition Laboratory at Florida International University. Data was plotted and analyzed using a pre-configured analysis tool for Cayman DNA/RNA oxidative damage ELISA kit.

\section{Statistical analysis:}

The IBM statistical package for the social sciences (SPSS) version 20 (Chicago, IL, USA) was used for performing the statistical analysis. Descriptive statistics were conducted for baseline characteristics. Numerical normally distributed data and categorical data were compared using paired t-test and Chi-Squared test, respectively. The main outcome was serum 8-OHdG. Gender and time were input as categorical and the rest of variables were input as continuous in the analysis. G*Power 3.0.10 software was used for post-hoc power analysis. Mixed model was used to compare $4000 \mathrm{IU}$ and 6000 IU treatment groups. In this model, oxidative stress $(8-\mathrm{OHdG})$ was the dependent variable and supplementation time was the independent variable. Covariates were age, gender, BMI, insulin level, HbA1c level, years with type 2 diabetes, perceived stress level, physical activity, and skin exposure score. Factors included gender and treatment groups. To compare the changes from baseline, three months and six months, Bonferroni multiple comparison test was used at the statistical significance of $\mathrm{P}$-value $<0.05$. 


\section{$\underline{\text { Results }}$}

Out of 92 individuals who were screened at baseline, 77 met the inclusion criteria and participated in the interventions. Two subjects were excluded due to missing values for sun exposure. Sixty-eight participants completed the study, females $(n=41)$ and males $(n=27)$, and were included in the present study`s analysis. Descriptive characteristics are featured in Table 2. Mean age was $54.94 \pm 7.93$ years. Mean years with type 2 diabetes was $6.44 \pm 5.23$ years. Oxidative stress $(8-\mathrm{OHdG})$ was measured at baseline, after 3 months and after 6 months. The unadjusted mean \pm SD for $8-O H d G$ levels at baseline, after 3 months and after 6 months were $8068.94 \pm 2158.13 \mathrm{pg} / \mathrm{mL}, 9462.22 \pm 2403.89$ $\mathrm{pg} / \mathrm{mL}$, and $7412.69 \pm 2031.68 \mathrm{pg} / \mathrm{mL}$, respectively (Figure 1). Paired t-test comparisons showed a statistically significant change in $8-\mathrm{OHdG}$ level between baseline and 3 months $(P<0.001), 3$ months and 6 months $(P<0.001)$, and baseline and 6 months $(P=0.013)$ (Figure 3). The unadjusted mean \pm SD for serum 25(OH)D3 at baseline, after 3 months and after 6 months were $22.34 \pm 6.67 \mathrm{ng} / \mathrm{mL}, 40.77 \pm 13.63 \mathrm{ng} / \mathrm{mL}$, and $40.41 \pm 14.50$ ng/mL, respectively (Figure 2). Paired t-test comparisons showed a statistically significant change in 25OHD3 level between baseline and 3 months $(P<0.001)$, and baseline and 6 months $(P<0.001)$. There was no statistically significant difference in serum 25OHD3 between 3 months and 6 months of supplementations (Figure 3). 


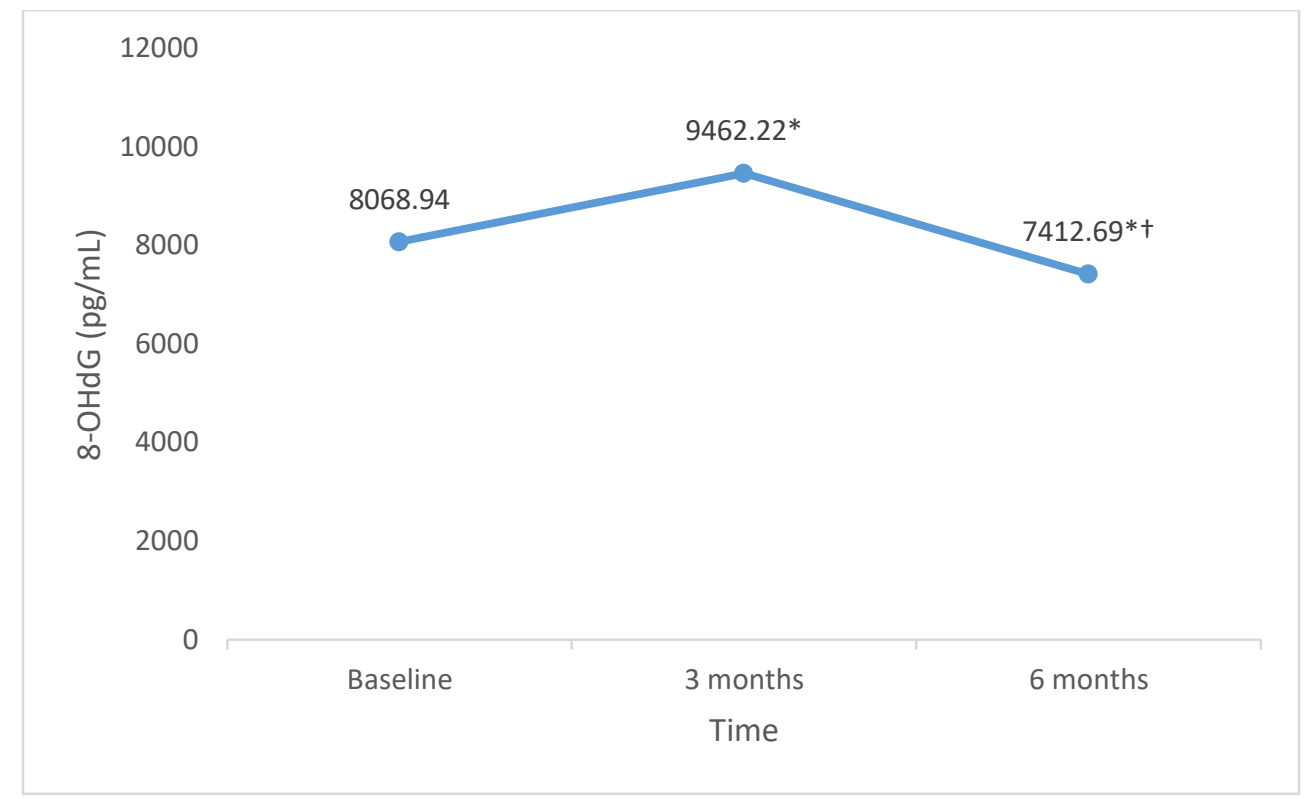

Figure 1. Mean DNA/RNA oxidative stress level (8-OHdG) at baseline, after 3 months, and after 6 months of supplementation with vitamin D3. Serum 8-OHdG level significantly increased after 3 months of supplementation with vitamin D3 and then significantly decreased after from 3 months to 6 months after supplementation with vitamin D3. * Statistically significance from baseline. $\uparrow$ Statistically significant from 3 months. $\mathrm{P}<0.05$ is considered significant. 


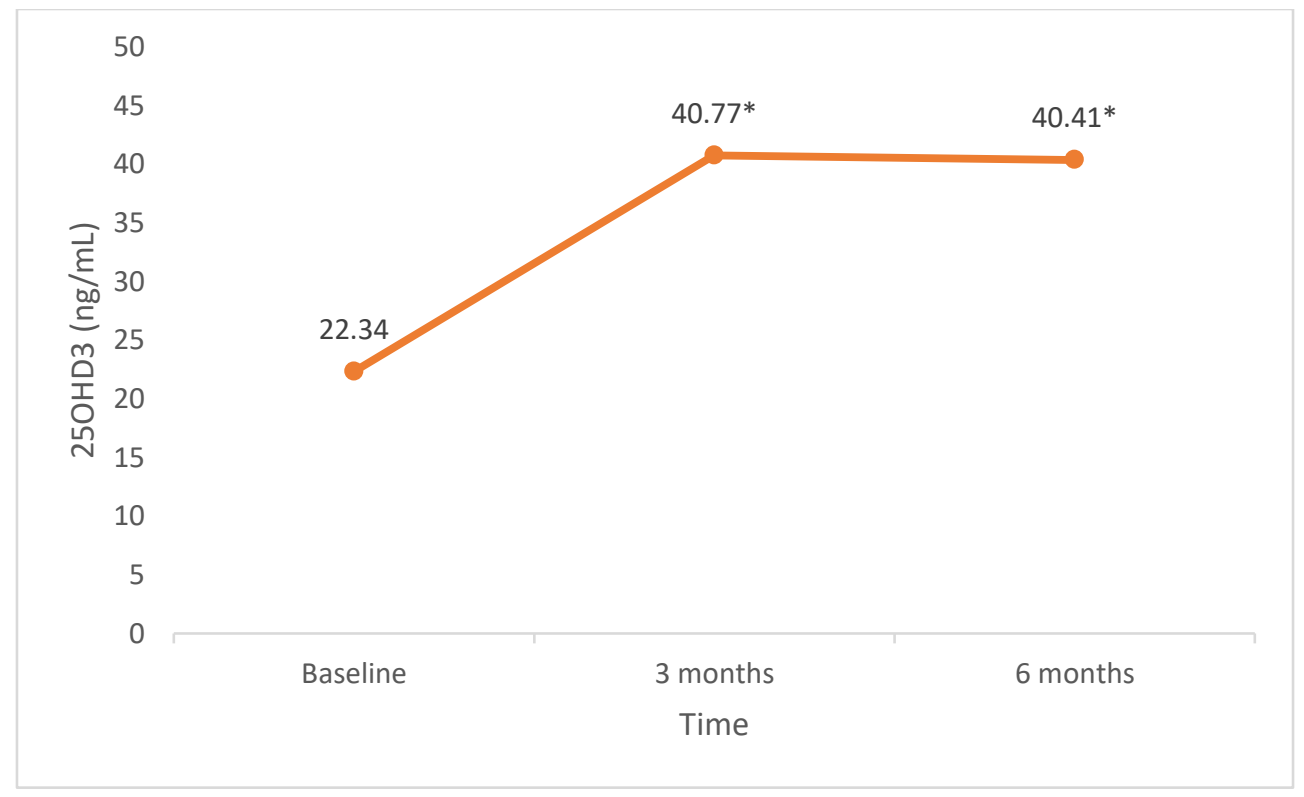

Figure 2. Mean serum vitamin D3 level [25(OH)D3] at baseline, after 3 months, and after 3 months of supplementation with vitamin D3. * Statistically significance from baseline. $\mathrm{P}<0.05$ is considered significant. 


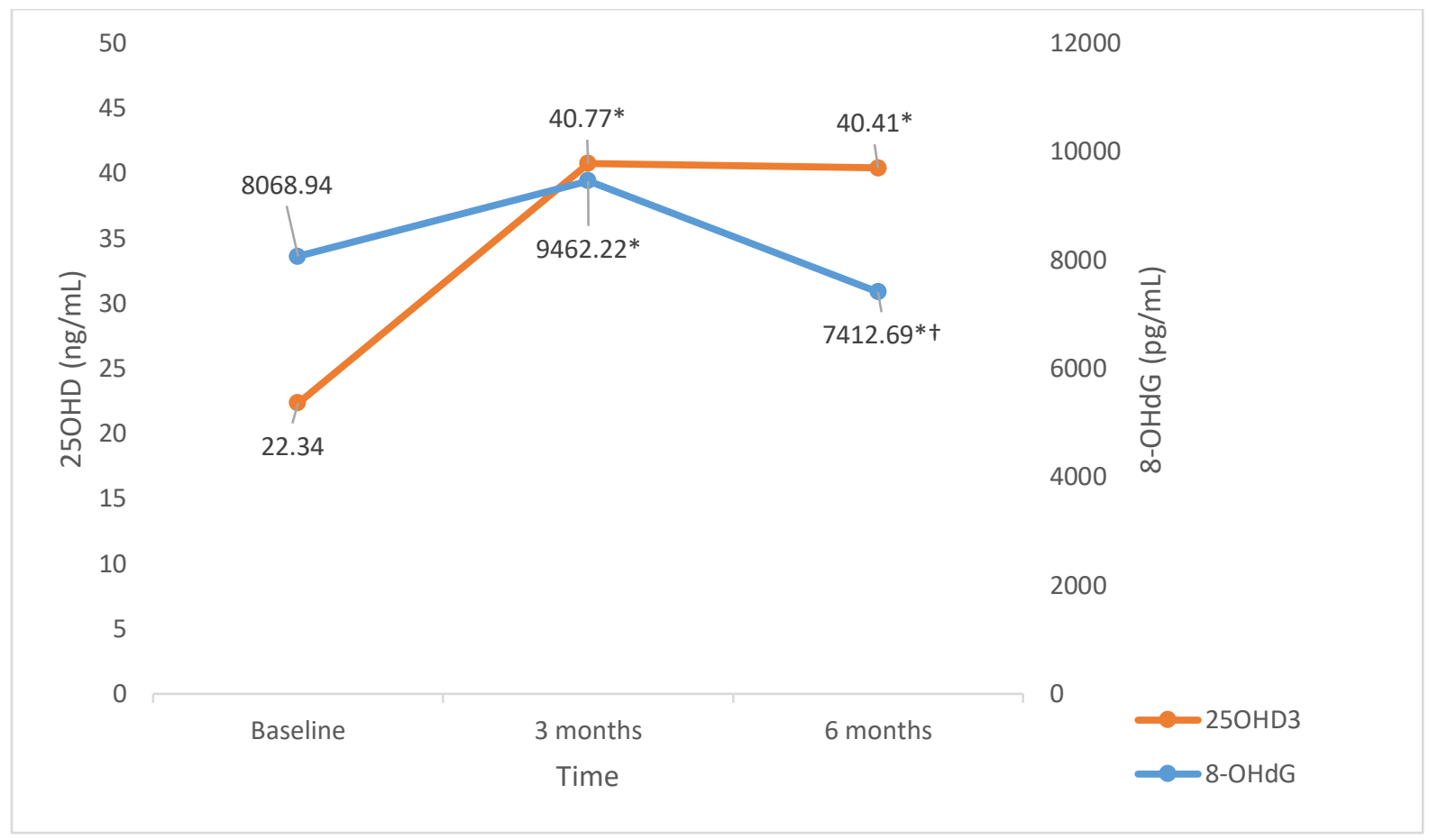

Figure 3. Mean DNA/RNA oxidative stress level (8-OHdG) and mean serum 25(OH)D3 at baseline, after 3 months, and after 6 months of supplementation with vitamin D3. * Statistically significance from baseline. $\uparrow$ Statistically significant from 3 months. $\mathrm{P}<0.05$ is considered significant. 
There were 46 participants in the 4000 IU/day intervention group and 22 participants in the $6000 \mathrm{IU}$ intervention group. The unadjusted mixed model showed no significant differences between the $4000 \mathrm{IU}$ and $6000 \mathrm{IU}$ groups regarding the oxidative stress level and the interactions between time and treatment were not significant. The model showed a statistically significant increase in $8-\mathrm{OHdG}$ level between baseline and 3 months $(\mathrm{P}<0.001)$, but a significant decrease between 3 months and 6 months $(\mathrm{P}<0.001)$, and baseline and 6 months $(\mathrm{P}=0.016)$ (Table 3).

After adjusting for age, gender, BMI, insulin level, HbA1c level, years with type 2 diabetes, perceived stress, physical activity, and skin sun exposure level, the model remained statistically significant; Pairwise comparisons showed significant changes in 8OHdG level between baseline and 3 months $(\mathrm{P}<0.001)$, between 3 months and 6 months $(\mathrm{P}<0.001)$, and between baseline and 6 months $(\mathrm{P}=0.020)$ (Table 4).

There were no significant correlations between exposed and unexposed skin color (forearm, upper-arm, and stomach) and the oxidative stress level at baseline, 3 months and 6 months. In addition, no statistically significant relations were found between skin sun exposure (difference between the exposed and unexposed skin color) and oxidative stress level at baseline, 3 months and 6 months. No adverse events associated with supplementation were reported by any of the study arms during the 6-month period of participation.

\section{Discussion}

To our knowledge this was the first interventional study among human subjects with type 2 diabetes investigated the effect of long-term supplementation of different 
dosages of vitamin D3 on the biomarker of DNA/RNA oxidative stress, 8-OHdG. The results of the present study suggest daily supplementation with vitamin D3, both $4000 \mathrm{IU}$ and $6000 \mathrm{IU}$, for 6 months may improve the DNA/RNA oxidative stress status among a group of individuals with type 2 diabetes and vitamin D deficiency/insufficiency. The improvement remained significant after adjusting for age, gender, BMI, insulin level, hemoglobin A1C level, years with type 2 diabetes, perceived stress level, physical activity, and skin exposure score.

In contrast with our study, Nikooyeh et al. (30) reported that daily intake of vitamin D fortified yogurt drink for 12 weeks decreased biomarkers of oxidative stress among 90 of individuals with type 2 diabetes. Different from our study, the daily vitamin D3 supplementation for this study was significantly lower (500 IU vs 4000/6000 IU), and the baseline serum vitamin D level among their participants was $44.8 \pm 28.7 \mathrm{ng} / \mathrm{mL}$, which was above the sufficient level of $30 \mathrm{ng} / \mathrm{mL}(30)$.

The dissimilarities in design between the two studies may explain why we could not detect improvement in oxidative stress status for the first 3 months of the study. As evidenced by our results, decrease in oxidative stress level occurred only after study subjects reached the sufficient serum 25(OH)D3 level (>30 ng/mL). Therefore, although oxidative stress was increasing from baseline to 3 months, we observed a significant decrease in oxidative stress between 3 months and 6 months with daily supplementation of vitamin D3. In fact, the mean 8-OHdG at 6 months was significantly lower than the mean $8-\mathrm{OHdG}$ at both baseline $[8068.94 \pm 2158.13 \mathrm{pg} / \mathrm{mL}$ to $7412.69 \pm 2031.68 \mathrm{pg} / \mathrm{mL}$ $(\mathrm{P}=0.013)]$ and 3 months $[9462.22 \pm 2403.89 \mathrm{pg} / \mathrm{mL}$ to $7412.69 \pm 2031.68 \mathrm{pg} / \mathrm{mL}$ $(\mathrm{P}<0.001)]$. This may suggest the beneficial effects of vitamin D3 supplementation on 
oxidative stress under diabetes conditions may be observed after the replenishment of serum vitamin D. Therefore, our findings suggest that longer duration of vitamin D3 supplementation is needed among individuals with type 2 diabetes and vitamin $\mathrm{D}$ deficiency/insufficiency.

The outcome of another longitudinal study among 103 patients with type 2 diabetes and vitamin D deficiency, which aimed to evaluate the effect of vitamin D3 supplementation on oxidative stress (31) showed weekly supplementation with $60,000 \mathrm{IU}$ of vitamin D3 for 8 weeks could improve oxidative stress level among individuals with type 2 diabetes and vitamin D deficiency. Participants consumed 4 sachets of cholecalciferol with $120 \mathrm{ml}$ of milk every week for 4 weeks. The mean serum 25(OH)D at baseline was $14.6 \mathrm{ng} / \mathrm{mL}$ and was significantly increased to $42.33 \mathrm{ng} / \mathrm{mL}(P<0.001)$ after the 8 weeks of intervention with this larger doses. Although both studies are in agreement that vitamin D3 supplementation significantly improves the oxidative status among individuals with type 2 diabetes and vitamin D deficiency, in our study we could find improvement in oxidative stress status only after 6 months of intervention. This may be due to significantly higher dosage of supplementation (equivalent to 8571/day IU) in the Anansabaskar et al. (31) compared with our daily supplementation of $4000 \mathrm{IU}$ or $6000 \mathrm{IU}$ of vitamin D in our study.

Several other studies among human subjects also revealed that vitamin D supplementation may have beneficial effects on oxidative stress status $(32,33)$. In a randomized double-blind placebo-controlled trial among 104 female subjects with vitamin D deficiency and polycystic ovary syndrome, weekly supplementation with 50,000 IU of vitamin D for 8 weeks improved the biomarkers of oxidative stress (32). In 
another study among 53 adults with non-alcoholic fatty liver disease, Sharifi et al. (33) reported oral supplementation with 50,000 IU of vitamin D3 every 14 days for 4 months improved serum 25(OH)D3 status as well as biomarkers of oxidative stress. The present study did not find a significant association between serum $25(\mathrm{OH}) \mathrm{D} 3$ and $8 \mathrm{OHdG}$. This may be due to small sample size of the current study and low power.

Animal studies suggest an antioxidant role for vitamin D. Konko et al. (34) showed that vitamin $\mathrm{D}$ analog could reduce oxidative stress in non-obese type 2 diabetic rats as measured by $8-\mathrm{OHdG}$. It has been suggested that vitamin D induced decrease in oxidative stress determines the vasoprotective properties of vitamin D. Administration of paricalcitol, a vitamin D receptor antagonist, could improve pancreatic oxidative stress in type 2 diabetic rats (35). It has been concluded that vitamin D may protect B cells from damages caused by ROS and therefore may prevent B cell dysfunction and apoptosis (35). In rats with alloxan-induced diabetes, vitamin D administration could increase the antioxidant activities of enzymes and decrease oxidative stress, especially in the pancreatic tissue (36). This study suggested a therapeutic role for vitamin D in diabetes condition.

\section{$\underline{\text { Conclusion }}$}

The results of the present study implied daily oral supplementation with higher doses of vitamin D, 4000 IU and 6000 IU/day, for 6 months may improve oxidative stress status among a group of individuals with type 2 diabetes and vitamin D deficiency/insufficiency. It also showed that there were no significant differences between the lower and higher doses on the effect on oxidative stress. Neither arm 
reported adverse effects of supplementation during the six months of participation, therefore, both doses were considered safe. Furthermore, 8 -OHdG may be a predictive biomarker of DNA/RNA damage among individuals with type 2 diabetes. The limitations of this study included lack of a control group, small samples size, and exclusion of participants with sufficient serum vitamin D levels. The strengths of the study were the ability to compare 2 different dosages of vitamin D3 supplementation, the longevity of study and measurement of sun exposure. We did not find significant changes in sun exposure during the 6-month period of this study. Further interventional studies among human subjects with larger sample sizes and longer observation timelines are required to confirm the antioxidants effects of vitamin D on RNA/DNA oxidative stress. 
Table 2. Participants characteristics at baseline $(\mathrm{N}=68)$

\begin{tabular}{lc}
\hline Variable & Mean \pm SD \\
& $\mathrm{N}=68$ \\
\hline Age (years) & $54.94 \pm 7.93$ \\
Gender n (\%) & $41(60)$ \\
Female & $27(40)$ \\
$\quad$ Male & \\
Dosage $\mathrm{n}(\%)$ & $46(68)$ \\
$\quad 4000 \mathrm{IU}$ & $22(32)$ \\
$6000 \mathrm{IU}$ & $33.7 \pm 6.59$ \\
BMI $\left(\mathrm{Kg} / \mathrm{m}^{2}\right)$ & $6.44 \pm 5.23$ \\
Years with T2DM & $55.29 \pm 7.49$ \\
Forearm skin color & $59.87 \pm 8.66$ \\
Upper-arm skin color & $4.58 \pm 4.27$ \\
Skin exposure score & $14.65 \pm 25.68$ \\
Physical activity (METs/hour/week) &
\end{tabular}

Data are $\%$ or mean \pm standard deviation (SD). IU = International Unit. BMI = Body mass index. Sun exposure is defined by calculating the difference between quantitative measures of forearm skin color and upper-arm skin color. METs $=$ Metabolic equivalents. 
Table 3. Mixed model comparisons of repeated measures at baseline, after 3 months and after 6 months without adjustment for covariates.

\begin{tabular}{|c|c|c|}
\hline Variable & $\begin{array}{c}\text { Mean } \pm \mathbf{S E} \\
(\mathbf{N}=\mathbf{6 8})\end{array}$ & $\boldsymbol{P}$-value \\
\hline 8-OHdG (pg/mL) & $8014.86 \pm 277.19$ & $* 0.001$ \\
Baseline & $9649.95 \pm 302.467$ & $* 0.016, \uparrow 0.001$ \\
3 months & $7338.26 \pm 260.12$ & \\
6 months & & $* 0.001$ \\
\hline 25(OH)D (ng/mL) & $22.41 \pm 0.87$ & $* 0.001$ \\
Baseline & $42.35 \pm 1.67$ & \\
6 months & $41.14 \pm 1.87$ & \\
\hline
\end{tabular}

Data represented by mean \pm standard error. $*$ Statistically significance from baseline.

$\dagger$ Statistically significant from 3 months. $P$-values are from multiple comparisons with Bonferroni correction. $P<0.05$ is considered significant. Time and dosage interactions were not significant for any of the variables. 
Table 4. Mixed model comparisons of repeated measures at baseline, after 3 months and after 6 months with adjustment for covariates $(\mathrm{N}=68)$.

\begin{tabular}{ccc}
\hline & $\begin{array}{c}\text { Mean } \pm \mathrm{SD} \\
(\mathrm{N}=68)\end{array}$ & $* P$-value \\
\hline $8-\mathrm{OHdG}(\mathrm{pg} / \mathrm{mL})$ & & \\
Baseline & $8064.905 \pm 266.12$ & $* 0.001$ \\
3 months & $9677.06 \pm 278.45$ & $* 0.020, \dagger 0.001$ \\
6 months & $7395.60 \pm 253.64$ & $* 0.004$ \\
\hline
\end{tabular}

Data represented by mean \pm standard error. * Statistically significance from baseline.

$\dagger$ Statistically significant from 3 months. $P$-values are from multiple comparisons with Bonferroni correction. $P<0.05$ is considered significant. Time and dosage interactions were not significant for $8-\mathrm{OHdG}$. Mixed model analysis was adjusted for age, gender, BMI, insulin level, HbA1C level, years with type 2 diabetes, perceived stress level, physical activity, and skin exposure score. 


\section{REFERENCES:}

(1) Stephens, J. W., Khanolkar, M. P., Bain, S. C. (2009). The biological relevance and measurement of plasma markers of oxidative stress in diabetes and cardiovascular disease. Atherosclerosis, 202(2); 321-329. doi:10.1016/j.atherosclerosis.2008.06.006.

(2) Wright, E., Scism-Bacon, J. L., Glass, L. C. (2006). Oxidative stress in type 2 diabetes: The role of fasting and postprandial glycaemia. International Journal of Clinical Practice, 60(3): 308-314. doi:10.1111/j.1368-5031.2006.00825.

(3) Nikooyeh B., Neyestani T.R. (2015). Oxidative stress, type 2 diabetes and vitamin D: past, present and future. Diabetes Metab Res Rev, 32(3): 260-7. doi: 10.1002/dmrr.2718.

(4) Evans, J. L., Goldfine, I. D., Maddux, B. A., Grodsky, G. M. (2002). Oxidative stress and stress-activated signaling pathways: A unifying hypothesis of type 2 diabetes.Endocrine Reviews, 23(5): 599-622. doi:10.1210/er.2001-0039.

(5) Garcia-Bailo, B., El-Sohemy, A., Haddad, P. S., Arora, P., BenZaied, F., Karmali, M., Badawi, A. (2011). Vitamins D, C, and E in the prevention of type 2 diabetes mellitus: modulation of inflammation and oxidative stress.Biologics : Targets \& Therapy, 5: 7-19. doi:10.2147/BTT.S1441739.

(6) Kajimoto, Y., Kaneto, H. (2004). Role of Oxidative stress in Pancreatic $\beta$-cell dysfunction. Annals of the New York Academy of Sciences, 1011(1): 168-176. doi:10.1196/annals.1293.017.

(7) Pan H. Z., Zhang L., Guo M. Y., Sui H., Li H., Wu W. H., Qu N. Q., Liang M. H., Chang D. (2010). The oxidative stress status in diabetes mellitus and diabetic nephropathy. Acta Diabetol. 47 Suppl 1: 71-76. doi: 10.1007/s00592-009-0128-1.

(8) Leinonen J., Lehtimäki T., Toyokuni S., Okada K., Tanaka T., Hiai H., Ochi H., Laippala P., Rantalaiho V., Wirta O., Pasternack A., Alho H. (1997). New biomarker evidence of oxidative DNA damage in patients with non-insulin-dependent diabetes mellitus. FEBS Lett. 417(1): 150-152.

(9) Dandona P., Thusu K., Cook S., Snyder B., Makowski J., Armstrong D., Nicotera T. (1996). Oxidative damage to DNA in diabetes mellitus. Lancet. 17;347(8999): 444-445.

(10) Sakano N., Wang D. H. Takahashi N., Wang B., Sauriasari R., Kanbara S., Sato Y., Takigawa T., Takaki J., Ogino1 K. (2009). Oxidative Stress Biomarkers and Lifestyles in Japanese Healthy People. J Clin Biochem Nutr. 44(2): 185-195. doi: 10.3164/jcbn.08-252.

(11) Johansen J. S., Harris A. K., Rychly D. J., Ergul A. (2005). Cardiovasc Diabetol. 4: 5. doi: 10.1186/1475-2840-4-5 
(12) Etten, E. van, \& Mathieu, C. (2005). Immunoregulation by 1,25dihydroxyvitamin D3: Basic concepts. The Journal of Steroid Biochemistry and Molecular Biology, 97(1-2): 93-101. doi:10.1016/j.jsbmb.2005.06.002

(13) Deluca, H. F., \& Cantorna, M. (2001). Vitamin D: Its role and uses in immunology.The FASEB Journal, 15(14): 2579-2585. doi:10.1096/fj.01-0433rev

(14) Fedirko, V., Bostick, R. M., Long, Q., Flanders, W. D., McCullough, M. L., Sidelnikov, E., Shaukat, A. (2010). Effects of supplemental vitamin D and calcium on Oxidative DNA damage marker in normal Colorectal mucosa: A Randomized clinical trial. Cancer Epidemiology Biomarkers \& Prevention, 19(1): 280-291. doi:10.1158/1055-9965.epi-09-0448

(15) Gordon-Thomson, C., Gupta, R., Tongkao-on, W., Ryan, A., Halliday, G. M., Mason, R. S. (2012). 1 1,25 Dihydroxyvitamin D3 enhances cellular defences against UV-induced oxidative and other forms of DNA damage in skin. Photochemical \& Photobiological Sciences, 11(12): 1837-1847. doi:10.1039/c2pp25202c

(16) Ajabshir, S., Exebio, J., Zarini, G., Nayer, A., McLean, M., Shaban, L., Huffman, F. (2014). Skin color and self-reported sun exposure scores are associated with serum 25-Hydroxyvitamin D concentrations in a multi-ethnic population living in south Florida.British Journal of Medicine and Medical Research, 4(34): 5312-5323. doi:10.9734/bjmmr/2014/10551.

(17) Armas L.A., Dowell S., Akhter M., Duthuluru S., Huerter C., Hollis B.W., Lund R., Heaney R.P. (2007). Ultraviolet-B radiation increases serum 25-hydroxyvitamin D levels: The effect of UVB dose and skin color. J Am Acad Dermatol. 57(4): 588-593.

(18) Harris S.S., Dawson-Hughes B. (1998). Seasonal changes in plasma 25hydroxyvitamin D concentrations of young American black and white women. Am J Clin Nutr. 67: 1232-1236.

(19) Nesby-O'Dell S., Scanlon K.S., Cogswell M.E., Gillespie C., Hollis B.W., Looker A.C., Allen C., Doughertly C., Gunter E.W., Bowman B.A. (2002). Hypovitaminosis D prevalence and determinants among African American and white women of reproductive age: Third national health and nutrition examination survey, 1988-1994. Am J Clin Nutr. 76(1): 187-192.

(20) Exebio, J. C., Zarini, G. G., Ajabshir, S., Antwi, J., Huffman, F. G. (2015). Validation of a sun exposure questionnaire among subjects with type 2 diabetes residing in south Florida. Journal of Immigrant and Minority Health, 18(1): 228-233. doi:10.1007/s10903-015-0163-7

(21) Hanwell, H. E. C., Vieth, R., Cole, D. E. C., Scillitani, A., Modoni, S., Frusciante, V., Carnevale, V. (2010).Sun exposure questionnaire predicts circulating 25hydroxyvitamin D concentrations in Caucasian hospital workers in southern Italy. The Journal of Steroid Biochemistry and Molecular Biology, 121(1-2): 334-337. doi:10.1016/j.jsbmb.2010.03.023 
(22) Blalock, S. J., Norton, L. L., Patel, R. A., Cabral, K., Thomas, C. L. (2003). Development and assessment of a short instrument for assessing dietary Intakes of calcium and vitamin D. Journal of the American Pharmacists Association, 43(6): 685693. doi: 10.1331/154434503322642615.

(23) Kriska A.M., LaPorte R.E., Pettitt D.J., Charles M.A., Nelson R.G., Kuller L.H., Bennett P.H., Knowler W.C. (1993). The association of physical activity with obesity, fat distribution and glucose intolerance in Pima Indians. Diabetologia. 36(9): 863-869.

(24) Kriska A.M., Pereira M.A., Hanson R.L., de Courten M.P., Zimmet P.Z., Alberti K.G., Chitson P., Bennett P.H., Narayan K.M., Knowler W.C. (2001). Association of physical activity and serum insulin concentrations in two populations at high risk for type 2 diabetes but differing by BMI. Diabetes Care. 24(7): 1175-1180.

(25) Kriska A.M., Pereira M.A., Fitzgerald S.J., Gregg E.W. (1997). Modifiable activity questionnaire. In: A collection of physical activity questionnaires for healthrelated research. Med Sci Sports Exerc. 29: S73-78.

(26) Cohen S., Kamarck T., Mermelstein R. A global measure of perceived stress. (1983). J Health Soc Behav. 24: 385-396.

(27) Cohen S., Williamson G. Perceived stress in a probability sample of the U.S. (1988) In: Spacapam S, Oskamp S, editors. The social psychology of health: Claremont Symposium on Applied Social Psychology. California: Newbury Park CA: Sage; pp. 99125.

(28) Huffman F. G., Vaccaro J. A., Ajabshir S., Zarini G. G., Exebio J., Dixon Z. (2013). Perceived stress and self-rated health of Haitian and African Americans with and without Type 2 diabetes. J Res Med Sci. 18(3): 198-204.

(29) DNA/RNA Oxidative damage ELISA kit. Retrieved July 27, 2016, from https://www.caymanchem.com/product/589320.

(30) Nikooyeh B., Neyestani T.R., Tayebinejad N., Alavi-Majd H., Shariatzadeh N., Kalayi A., Zahedirad M., Heravifard S., Salekzamani S. (2014). Daily intake of vitamin D- or calcium-vitamin D-fortified Persian yogurt drink (doogh) attenuates diabetes-induced oxidative stress: evidence for antioxidative properties of vitamin D. $J$ Hum Nutr Diet. 27 Suppl 2: 276-283. doi: 10.1111/jhn.12142.

(31) Anandabaskar N., Selvarajan S., Dkhar S. A., Kamalanathan S. K., Tamilarasu K., Bobby Z. (2017). Effect of Vitamin D Supplementation on Vascular Functions and Oxidative Stress in Type 2 Diabetic Patients with Vitamin D Deficiency. Indian J Endocrinol Metab. 21(4): 555-563. doi: 10.4103/ijem.IJEM_140_17.

(32) Foroozanfard F., Jamilian M., Bahmani F., Talaee R., Talaee N., Hashemi T., Nasri K., Asemi Z., Esmaillzadeh A. (2015). Calcium plus vitamin D supplementation influences biomarkers of inflammation and oxidative stress in overweight and vitamin D- 
deficient women with polycystic ovary syndrome: a randomized double-blind placebocontrolled clinical trial. Clin Endocrinol (Oxf). 83(6): 888-894. doi: 10.1111/cen.12840.

(33) Sharifi N., Amani R., Hajiani E., Cheraghian B. (2014). Does vitamin D improve liver enzymes, oxidative stress, and inflammatory biomarkers in adults with non-alcoholic fatty liver disease? A randomized clinical trial. Endocrine. 47(1): 70-80. doi: 10.1007/s12020-014-0336-5.

(34) Kono K., Fujii H., Nakai K., Goto S., Kitazawa R., Kitazawa S., Shinohara M., Hirata M., Fukagawa M., Nishi S. (2013). Anti-oxidative effect of vitamin D analog on incipient vascular lesion in non-obese type 2 diabetic rats. Am J Nephrol. 37(2): 16774. doi: 10.1159/000346808.

(35) Ali T.M., El Esawy B., Elaskary A. (2017). Effect of paricalcitol on pancreatic oxidative stress, inflammatory markers, and glycemic status in diabetic rats. Ir J Med Sci. doi: 10.1007/s11845-017-1635-7.

(36) Iqbal S., Khan S., Naseem I. (2017). Antioxidant Role of Vitamin D in mice with Alloxan-Induced Diabetes. Can J Diabetes. pii: S1499-2671(16)30590-1. doi: 10.1016/j.jcjd.2017.10.032 


\section{CHAPTER IV: EFFECT OF VITAMIN D3 SUPPLEMENTATION ON GLYCATED ALBUMIN IN ADULTS WITH TYPE 2 DIABETES}

\section{$\underline{\text { Introduction }}$}

Diabetes mellitus is ranked as the seventh leading cause of death in the United States (1)._According to the 2014 National Diabetes Statistics Report by the Centers for Disease Control and Prevention (CDC), over 29 million individuals (9.3\% of the U.S population) were diagnosed with diabetes while more than 8 million cases remained undiagnosed (2). Type 2 diabetes accounts for $90-95 \%$ of all diagnosed diabetes cases among adults.

\section{Type 2 diabetes and early glycation products}

Persistent hyperglycemia leads to non-enzymatic glycation of proteins, known as Maillard reaction. In this reversible process, the carbonyl group of reducing sugars, such as glucose, binds to the amino group on lysine residues of proteins, such as hemoglobin, and form early glycation products known as Schiff-bases and Amadori adducts (3). Early glycation leads to formation of intermediate glycation products (IGPs) such as glycated hemoglobin (HbA1c) and glycated albumin (GA). Continuous elevation in IGP levels can lead to their irreversible rearrangement to stable advanced glycation end products (AGEs) (3-4). AGEs accumulation is a measure of carbonyl, metabolic and oxidative stress and serve as a long term metabolic memory, rather than short term glycemic control. In contrast, IGPs are better indicators of glycemic control (4). Amadori adducts, the major form of IGPs, have 2-3 times higher concentrations of glycated products than AGEs (5). HbA1c is currently an established gold standard Amadori adduct, reflecting the glycemic 
control over the period of 8-12 weeks. In addition, HbA1c is associated with the risk of chronic diabetes related complications such as neuropathy, nephropathy, retinopathy and coronary artery disease (5-6). HbA1c level, however, can be affected by several factors such as red blood cells turnover, uremia, erythropoietin treatment, blood transfusion, anemia, renal malfunction, and iron-deficiency (5). Based on the twin studies by Sneider et al. (7), HbA1c is strongly inherited and influenced by genetics. Furthermore, HbA1c reflects on the glycemic control inside the RBCs while serum protein glycation reflects glycemic control in the extracellular space (8).

Albumin is the most abundant protein in plasma and makes more than $50 \%$ of plasma proteins (9). With a half-life of 14-21 days, albumin is known as the main extracellular antioxidant and plays a fundamental role in maintaining oxidative balance (10). Furthermore, albumin has anti-inflammatory and anti-thrombotic properties and plays a crucial role in transportation of nutrients, metabolites, hormones and drugs while maintaining the osmotic pressure (5). As a lysine rich protein with 59 lysine residues, albumin is widely involved in extracellular Maillard reactions under hyperglycemic conditions (5). Non-enzymatic glycation of albumin happens 10 times faster and 9 times more than non-enzymatic glycation of hemoglobin in-vivo (11). It is suggested that glycated albumin (GA) may be a more accurate indicator of short term glycemic control among individuals with type 1 and type 2 diabetes (12). GA have been linked to diabetes induced complications including nephropathy, neuropathy and arteriosclerosis (9). Although as compared to hemoglobin, serum albumin is less affected by RBC turnover, erythropoietin treatment, blood transfusion, anemia, and iron-deficiency; albumin turnover, hepatic cirrhosis and renal malfunction can enhance serum albumin level. It is 
suggested GA/HbA1c ratio may be a better index of glycemic control among individuals with diabetes (12).

Fructosamine is the measure of a combination of circulating glycated proteins, such as glyco-lipoproteins and glyco-globlulins (13-14). Knowing that albumin is the most abundant protein in serum, fructosamine is predominately reflecting GA, however, GA\% may provide a more accurate and efficient measure of extracellular glycation status over 2-3 weeks (14). Furthermore, in case of abnormal albumin levels, fructosamine values must be adjusted to albumin levels (14).

\section{Oxidative Stress, Inflammation and Glycated Albumin}

Albumin structure and antioxidant function is greatly suppressed by the Maillard reaction. Amadori GA is in fact a stimulant for oxidative stress by producing oxygen free radicals and lipid peroxides. Non-enzymatic glycation of albumin also suppresses its nutrient/metabolite/drug binding affinity and diminishes its transportation ability (10). In macrophage RAW 246.7 cells (a commercial murine cell-line), GA induced oxidative stress activated extracellular signal-regulated kinase (ERK), influenced TGF- $\beta 1$ production and activated $\mathrm{NF}-\kappa \mathrm{B}$ which plays a critical regulatory role in immunity and inflammatory responses (15). In diabetic human endothelial cells, GA increased oxidative stress and Reactive Oxygen Species (ROS) production by up-regulating nicotinamide adenine dinucleotide phosphate (NADPH) oxidase (16). This may help to understand the role of Amadori-adducts in pathogenesis of diabetes-induced vascular complications. Exposure of diabetic mice adipocytes to GA resulted in increased oxidative stress, accumulation of ROS in these cells and oxidation of proteins inside them (17). GA- 
derived glycation end products (AGEs) may lead to adipocytes dysfunction and insulin resistance in adipose tissue.

\section{Type 2 diabetes and Vitamin D}

It has been shown that both, vitamin D deficiency and type 2 diabetes, have several risk factors in common: aging, being overweight, having a sedentary lifestyle, and being African-American or Hispanic (18). In addition, seasonal variations have been observed for both serum vitamin D [25(OH)D3] levels and insulin concentrations suggesting a potential relationship between serum 25(OH)D3 and development of type 2 diabetes (19-21). Vitamin D directly affects insulin sensitivity, Beta cell function, insulin secretion and hence mediates glucose homeostasis (18). Several studies reported an association between lower serum vitamin D levels and increased risk of developing type 2 diabetes (22-24). In addition, a high prevalence of hypovitaminosis D has been observed among individuals diagnosed with type 2 diabetes, compared to individuals without type 2 diabetes (25). Beside its effect on Beta cell function and insulin sensitivity, vitamin D also regulates calcium homeostasis which plays an important role in regulating insulin secretion (26).

An extensive review with a meta-analyses, proposed that the direct role of vitamin D on glucose homeostasis is mediated via binding of its metabolically active form, $1,25(\mathrm{OH}) 2 \mathrm{D} 3$, to the vitamin D receptors (VDR) in pancreatic B-cells, activation of $25(\mathrm{OH}) \mathrm{D} 3$ to $1,25(\mathrm{OH}) 2 \mathrm{D} 3$ by the enzyme 1- $\alpha$-hydroxylase (expressed in B-cells) within B-cells, stimulating the insulin receptor gene transcription, enhancing the expression of insulin receptor and hence affecting the insulin-mediated glucose transport (20). VDRs 
also exist in skeletal muscle and adipose tissues which are insulin targets and are responsible for peripheral insulin sensitivity. VDR expression in human skeletal muscle tissue, which declines with age, stimulates regulation of protein synthesis and results in diminished insulin sensitivity among older adults (27). In addition, animal studies showed impaired insulin secretion in mice with inactive VDRs (28).

The indirect role of vitamin D in glucose homeostasis is determined by its effect on regulation of extracellular calcium and calcium flux in the pancreatic B-cells (20). Imbalance between the extracellular and intracellular calcium pools influences the ability of B-cells to release insulin. Serum vitamin D concentration is inversely associated with Parathyroid hormone (PTH) level, which regulates intracellular calcium (29). In animal and in-vitro study, hypovitaminosis D was found to cause augmented PTH levels, which resulted in elevated intracellular calcium levels (30). In adipose tissue (an insulin target tissue), sustained augmentation in cytosolic calcium level was associated with increased insulin resistance (30). The insulin mediated glucose uptake was decreased by $30 \%$ among PTH injected rats (30). This could be due to increased phosphorylation of GLUT4 (an insulin-regulated glucose transporter in adipose and muscle tissue) in the presence of elevated cytosolic calcium levels. Cross-sectional studies reported an inverse relation between serum vitamin D level and insulin sensitivity (31-33). In addition, vitamin D and calcium supplementation attenuated insulin resistance among non-diabetic older adults with impaired fasting plasma glucose (FPG) (34). 


\section{Vitamin D and Glycated Albumin}

The relationship between vitamin D and GA is yet to be studied. Furthermore, to our knowledge no studies have yet investigated the effectiveness of vitamin D3 supplementation on GA, as a biomarker of short-term glycemic control, among individuals with or without diabetes. Despite lack of evidence on the relationship between GA and vitamin D, HbA1c have been negatively linked to serum 25(OH)D level (35-37). Clinical trials on vitamin D supplementation and its impact on glycemic improvement (specifically on HbA1c) among individuals with type 2 diabetes, however, could not consistently support the effectiveness of vitamin D supplementation on glycemic control (38). It is not clear whether improvement in serum vitamin D may improve Amadori formation of GA. We assume vitamin D may improve GA level via its antioxidant properties. Furthermore, since vitamin D has a high binding affinity for adipose tissue, it may prevent the GA-induced oxidative stress in adipocytes via its antioxidant capabilities. Albumin is a transporter of vitamin D; therefore, binding of vitamin D to serum albumin may affect its affinity to glucose under non-enzymatic conditions. In that case, vitamin D may be effective in prevention of GA-derived AGEs production.

\section{Significance of the current study}

To our knowledge, there is currently no studies that assessed the possible effects of vitamin D3 supplementation on serum GA levels among individuals with or without type 2 diabetes. While GA is a relatively new biomarker for type 2 diabetes management, almost all the current studies on vitamin D supplementation in type 2 diabetes have been 
targeting fasting plasma glucose and HbA1c as the markers of glycemic control. The findings from this study will help to fill the gap on the possible beneficial effects of vitamin D3 on GA, as the most abundant Amadori-protein in human serum. Therefore, the aim of this is study was to investigate and compare the effectiveness of daily supplementation with 4000 IU and 6000 IU vitamin D3 for 3 months and 6 months on GA.

\section{Materials and methods:}

In this clinical trial, we assessed the effect of daily supplementation with 4000 and 6000 IU of vitamin D3 over six months on glycated albumin (GA), albumin (ALB) and GA\% (GA to ALB ratio * 100) among adults with type 2 diabetes living in South Florida. The parent study was conducted by Huffman et al. (39) assessing the effect of vitamin D3 supplementation on cardiovascular disease biomarkers. In the present study, serum samples were collected at baseline, 3 months and 6 months stored at $-80^{\circ}$ were used for measuring GA, ALB and GA\%.

Study participants were recruited from 2 sources:

- From community areas by distributing flyers including the purpose of the study, inclusion and exclusion criteria, and the investigators information.

- From 2 clinics: Borinquen Health care center and Clinical Care Medical center. Weekly visits were conducted to recruit study participants.

Interested individuals called the investigators and expressed their willingness to participate in the study and were asked to answer a few pre-screening questions. 
Qualified individuals were invited for screening at the Human Nutrition Laboratory, Florida International University. After signing the informed consent form, fasting blood samples were collected and screening questionnaires were administered to evaluate whether the inclusion criteria were met (39).

Inclusion criteria were being 30-70 years old, being African-American or Hispanic, having Type 2 diabetes, being vitamin D insufficient $[25(\mathrm{OH}) \mathrm{D} 3<30 \mathrm{ng} / \mathrm{mL}]$. Exclusion criteria was being pregnant or lactating, taking vitamin D supplements, injecting insulin, suffering from thyroid, hepatic and/or renal complications, suffering from HIV, cancer. The duration of the intervention was 6 months and participants were contacted at four time points:

Time zero (T0): Screening: During screening the eligibility of the participants to enroll in the study was assessed based on the inclusion and exclusion criteria. Participants signed an informed consent form before the data collection. Fasting blood was collected for screening of vitamin D status.

Time one (T1): Baseline: All participants who met the inclusion criteria participated in the study. Blood collection, anthropometric measurements, skin color measurements, and a socio-demographic questionnaire were administered at baseline and vitamin D supplements (pills) were provided to the participants (4000 and 6000 IU pills).

Time two (T2): Blood collection, anthropometric measurements, and skin color measurements were administered after 3 months of supplementation with $4000 \mathrm{IU}$ or 6000 IU vitamin D3 pills. Additional vitamin D3 pills were provided to the participants. 
Time three (T3): Blood collection, anthropometric measurements, and skin color measurements were administered after 6 months of supplementation. Study was terminated at this point.

\section{Measurements of variables:}

a. Socio-demographic questionnaire

A socio-demographic questionnaire was used to collect information about age, gender, race/ethnicity, years living in the United States and years having type 2 diabetes.

\section{b. Anthropometric measurements}

Height and weight measurements were taken by using a SECA balance scale (SECA Corp, Columbia, MD), to the nearest $0.5 \mathrm{~cm}$ and $0.1 \mathrm{~kg}$, respectively. Waist circumference was measured by using a measuring tape to the nearest $0.1 \mathrm{~cm}$. All measurements were done twice and the average of two readings was considered in the analysis.

c. Skin exposure measurement

Reflectance colorimetry method was used to determine skin color as an objective measure of skin sun exposure (IMS Smart Probe 400, Millford CT, USA) (39). This instrument uses the International Commission on Illumination Scale and ranges the skin color from 0 (black) to 100 (white). The measurement sites included 3 areas: wrist of the right hand as the most exposed area to sun, inside of the right upper arm and the waist as the least exposed areas to the sun (39). Each measurement was conducted 2 times and the average was considered in the proposed study analysis. This tool is validated by several 
studies (39-40). Skin sun exposure level was determined by calculating the difference between the wrist of the right hand skin color (the most exposed) and the inside of the right upper arm (the least exposed).

\section{d. Blood collection and analysis}

Fasting venous blood was collected by a certified phlebotomist (15 mL). After coagulation of blood samples in serum separator tubes for 30-45 minutes, samples were centrifuged at 2500 RPM for 30 minutes to obtain the serum. Fasting plasma glucose concentration was measured by hexokinase enzymatic method, glycated hemoglobin A1c (HbA1c) was measured by using DCA2000 + system (BAYER Corporation, Diagnostics Division, N.Y) and 25(OH)D3 concentrations were measured by using an enzymatic immunoassay kit (Immunodiagnostic Systems Scottsdale, AZ) (16). C-reactive protein (CRP) was measured Immulite (Diagnostic Products Corporation, Los Angeles, CA). Insulin was determined by an enzymatic immunoassay kit (Millipore, St Charles, MZ).

\section{e. Glycated albumin, albumin and GA\%}

Serum GA, ALB and GA\% were measured by using GLYCABEN assay (Exocell Inc., Philadelphia, PA, item No 1003). In this sandwich based enzyme linked immunosorbent assay, glycated albumin is quantitatively determined by capturing the binding of a specific immobilized monoclonal antibody, A717, to glycated albumin (4142). In this process, $100 \mu \mathrm{L}$ of participants's serum samples were mixed with $100 \mu \mathrm{L}$ Charcoal Extraction Buffer overnight (18-hours) at room temperature. After centrifuging the mixture at $14 \mathrm{~K}$ for 10 minutes, $100 \mu \mathrm{L}$ of the supernatant were collected. To neutralize the extracted serum samples, $100 \mu \mathrm{L}$ Glycated Albumin Neutralizing Buffer 
were added to the collected samples and mixed. Samples were centrifuged at $14 \mathrm{~K}$ for 1 minute.

To measure GA, the precoated Glycated Albumin Assay Plate was washed 8 times with wash buffer. Assay standards were prepared as instructed in the GLYCABEN protocol. Then $50 \mu \mathrm{L}$ Glycated Albumin Reaction Buffer was added to all the wells. After adding $50 \mu \mathrm{L}$ Glycated Albumin Diluent to the blank wells, $50 \mu \mathrm{L}$ of assay standards and assay control were added to the designated wells. Later, $50 \mu \mathrm{L}$ of the extracted and neutralized serum samples were added to the plate. Plate was incubated in an incubation chamber at room temperature for 60 minutes. The plate was washed 8 times and $100 \mu \mathrm{L}$ of TMB color developer was added to all the wells. After 10 minutes of incubation at room temperature, $100 \mu \mathrm{L}$ Acid Color Stopper was added to the wells. The absorbance was determined at $450 \mathrm{~nm}$ by a plate reader located at Huffman Nutrition Laboratory at Florida International University. Regression analysis was used to determine the glycated albumin in each sample. Concentrations were expressed as $\mathrm{mg} / \mathrm{mL}$.

To measure total albumin (ALB), serial dilution of total albumin standards were prepared as instructed in the GLYCABEN protocol. A non-coated plate was used for this colorimetric assay. After adding $10 \mu \mathrm{L}$ of purified water in the blank wells, $10 \mu \mathrm{L}$ of the standards were added to the standard well. Later, $10 \mu \mathrm{L}$ of the extracted and neutralized serum samples were added to the designated wells followed by $200 \mu \mathrm{L}$ of Total Albumin Reagent to all the wells. After 5 minutes incubation in the room temperature, the absorbance was determined at $630 \mathrm{~nm}$ by a plate reader. Regression analysis was used to determine the albumin levels. Concentrations were expressed as $\mathrm{mg} / \mathrm{mL}$. 
GA\% was calculated by dividing the absolute concentration of $\mathrm{GA}(\mathrm{mg} / \mathrm{mL})$ to the total albumin concentration $(\mathrm{mg} / \mathrm{mL})$ multiplied by 100 :

$$
\mathrm{GA} \%=\mathrm{GA} / \mathrm{ALB} \times 100 \%
$$

Expected values measured by Glycaben for GA\% for non-diabetic individuals is estimated between $0.4 \%$ to $2.4 \%$. For individuals with uncontrolled diabetes, GA\% will be $>2.5 \%$.

\section{Statistical analysis:}

The IBM statistical package for the social sciences (SPSS) version 20 (Chicago, IL, USA) was used for performing the statistical analysis. Descriptive statistics were conducted for baseline characteristics. Numerical normally distributed data and categorical data were compared using paired t-test and Chi-Squared test, respectively. The main outcome was GA\%. Gender and time were input as categorical and the rest of variables were input as continuous in the analysis. $G *$ Power 3.0.10 software was used for post-hoc power analysis. Mixed models were used to compare $4000 \mathrm{IU}$ and $6000 \mathrm{IU} / \mathrm{day}$ treatment groups. In this model, GA\% was the dependent variable and supplementation time was the independent variable. Covariates were age, BMI, sun exposure, fasting plasma glucose, insulin and CRP. Factors included gender and treatment groups. To compare the changes from baseline, three months and six months, Bonferroni multiple comparison test was used at the statistical significance of P-value $<0.05$. 


\section{$\underline{\text { Results }}$}

Seventy-seven out of 92 subject who were initially screened for this study, met the inclusion criteria. Two participants were excluded due to missing values for sun exposure. Sixty-eight participants completed the study. Values were tested for normal distribution. Three subjects with outlier values for GA and ALB were excluded. A sample of 65 participants, females $(n=40)$ and males $(n=25)$, were included in the present study`s analysis. There were 44 participants in 4000 IU intervention group and 21 participants in the $6000 \mathrm{IU}$ intervention group. Mean age was $54.52 \pm 7.86$ years. Mean FPG at baseline, 3 months and 6 months were $186.478 \pm 79.93,184.52 \pm 72.55$, and $172.8 \pm 71.4 \mathrm{mg} / \mathrm{dL}$. There were no statistically significant differences in FPG from baseline to 3 months $(\mathrm{P}=0.756), 3$ months to 6 months $(\mathrm{P}=0.084)$ and baseline to 6 months $(\mathrm{P}=0.142)$. Mean HbA1c at baseline, 3 months and 6 months were $8.41 \pm 2.31$, $8.37 \pm 2.03$, and $8.30 \pm 2.06 \mathrm{mg} / \mathrm{dL}$. There were no statistically significant differences in HbA1c from baseline to 3 months $(\mathrm{P}=0.806), 3$ months to 6 months $(\mathrm{P}=0.701)$ and baseline to 6 months $(\mathrm{P}=0.635)$. Mean insulin levels at baseline, 3 months and 6 months were $12.63 \pm 11.56,11.64 \pm 7.17$, and $11.3 \pm 7.35 \mathrm{mg} / \mathrm{dL}$. There were no statistically significant differences in insulin levels from baseline to 3 months $(\mathrm{P}=0.474), 3$ months to 6 months $(\mathrm{P}=0.687)$ and baseline to 6 months $(\mathrm{P}=0.256)$. Mean CRP at baseline, 3 months and 6 months were $8.07 \pm 10.81,6.81 \pm 7.3$, and $7.13 \pm 6.91 \mathrm{mg} / \mathrm{dL}$. There were no statistically significant differences in CRP from baseline to 3 months $(\mathrm{P}=0.271), 3$ months to 6 months $(\mathrm{P}=0.701)$ and baseline to 6 months $(\mathrm{P}=0.425)$.

Unadjusted mean \pm SD for serum 25(OH)D3 at baseline, 3 months and 6 months were $22.4 \pm 6.77,40.4 \pm 13.68$, and $40.57 \pm 14.55$, respectively. Paired t-test analysis 
showed a statistically significant increase in $25(\mathrm{OH}) \mathrm{D} 3$ from baseline to 3 months $(\mathrm{P}<0.001)$, and from baseline to 6 months $(\mathrm{P}<0.001)$. There were no significant differences between 25(OH)D3 levels at 3 months and 6 months $(P=0.886)$. Mixed model analysis did not show significant interactions between 2 intervention groups and study time points regarding 25(OH)D3. Unadjusted mean \pm SD for GA at baseline, 3 months and 6 months were $1.51 \pm 0.44,1.47 \pm 0.72$, and $1.54 \pm 0.34$, respectively (Table 1 ). Paired t-test analysis showed no statistically significant differences between GA levels at baseline and 3 months $(\mathrm{P}=0.418), 3$ months and 6 months $(\mathrm{P}=0.112)$, and baseline and 6 months $(\mathrm{P}=0.619)$. Mixed model analysis controlling for interactions between $4000 \mathrm{IU}$ and $6000 \mathrm{IU} /$ day doses and outcome variables showed no differences between the two treatment groups. Unadjusted mean \pm SD for ALB at baseline, 3 months and 6 months were $32.84 \pm 05.69,36.34 \pm 7.36$, and $35.66 \pm 6.7$, respectively (Table 1). Paired t-test analysis showed statistically significant differences between ALB levels at baseline and 3 months $(\mathrm{P}=0.002)$, and at baseline and 6 months $(\mathrm{P}=0.009)$. There were no significant differences between ALB levels at 3 months and 6 months $(\mathrm{P}=0.521)$. Mixed model analysis controlling for interactions between 4000 IU and 6000 IU doses and outcome variables showed no differences between the two treatment groups. Unadjusted pairwise comparisons between ALB levels showed a statistically significant increase from baseline to 3 months $(\mathrm{P}=0.003)$, and a statistically significant increase from baseline to 6 months $(\mathrm{P}=0.031)$. After adjusting for covariates, including age, gender, BMI, sun exposure, fasting plasma glucose, insulin and CRP, the model remained statistically significant for baseline and 3 months $(\mathrm{P}=0.004)$ and baseline and 6 months $(\mathrm{P}=0.046)$. 
Unadjusted mean \pm SD for GA\% at baseline, 3 months and 6 months were $4.69 \pm$ $1.7,4.13 \pm 1.09$, and $4.42 \pm 1.23$, respectively. Paired t-test analysis showed statistically significant differences between GA\% at baseline and 3 months $(\mathrm{P}=0.005)$. This difference was not statistically significant for GA\% at 3 months and 6 months $(\mathrm{P}=0.068)$ and GA\% at baseline and 6 months $(\mathrm{P}=0.208)$. Mixed model analysis controlling for interactions between $4000 \mathrm{IU}$ and $6000 \mathrm{IU} /$ day doses and outcome variables showed no differences between the two treatment groups. Unadjusted pairwise comparisons between GA\% were statistically significant from baseline to 3 months ( $\mathrm{P}=0.015)$, and from 3 months to 6 months $(\mathrm{P}=0.039)$, but not from baseline to 6 months $(\mathrm{P}=0.488)$. After adjusting for covariates, including age, gender, BMI, sun exposure, fasting plasma glucose, insulin and CRP, the change remained statistically significant for baseline and 3 months $(\mathrm{P}=0.018)$ but not for 3 months to 6 month $(\mathrm{P}=0.069)$, nor for baseline and 6 months $(\mathrm{P}=0.471)$.

\section{$\underline{\text { Discussion }}$}

To our knowledge the present study is the first to assess the effects of vitamin D3 supplementation on serum glycated albumin (GA\%) among human subjects with or without type 2 diabetes. Most of the previous studies investigated the effects of vitamin D3 on HbA1c $(38,43-51)$. The results of the present study showed that daily supplementation with $4000 \mathrm{IU}$ and $6000 \mathrm{IU}$ of vitamin D3 to individuals with type 2 diabetes could significantly increase serum 25(OH)D3 after 3 months $(P<0.001)$. However, after reaching the sufficient level of vitamin D level $(>20 \mathrm{ng} / \mathrm{mL})$ in 3 months, the same dose of supplementation could not significantly change serum 25(OH)D3 from 3 months to 6 months. We observed the same change pattern for GA\%. GA\% is a 
relatively new biomarker of glycemic control and oxidative stress. GA half-life is shorter than HbA1c (2-3 weeks for GA\% compared to 2-3 months for HbA1c) and it is believed to be a more sensitive biomarker of glycemic status compared to HbA1c. Our results showed a statistically significant decrease in GA\% after 3 months of supplementation with vitamin D3, with both 4000 IU and 6000 IU/day dosages. However, from 3 months to 6 months, there was a significant increase in GA\%. Furthermore, the present study did not find a significant association between serum 25(OH)D3 and GA\%. This may be due to small sample size of the current study and low power.

Overall, we could not detect a significant change in GA\% from baseline to 6 months. This is consistent with our findings regarding HbAlc; we could not find a statistically significant change in HbA1c with vitamin D3 supplementation over 6 months (nor for 3 months). Madar et al (38) also reported no significant improvements in HbA1c and fructosamine after 16 week of vitamin D3 supplementation to healthy individuals with insufficient vitamin D levels. In this randomized double-blinded placebo-controlled study in Norway, 251 immigrants aged 18-50 years were assigned to receive $400 \mathrm{IU}$ (n= 85), 1000 IU $(n=84)$, or placebo $(n=82)$. Although we found similar results with HbA1c and GA\% over 6 months of oral supplementation with higher doses of vitamin D3, we found significant decrease in GA\% from baseline to 3 months. There were several differences in design between our study and Madar et al. (38). Madar's did not measure fructosamine levels after 3 months of supplementation with vitamin D. This trial was conducted among a younger group of individuals without type 2 diabetes. Comparing GA\% with fructosamine, it is believed that GA\% is a more sensitive diagnostic tool than fructosamine (13). Furthermore, knowing fructosamine is predominantly a measure of 
GA, adjustment for abnormal albumin levels should be considered to obtain accurate measures of nonenzymatic glycation of extracellular proteins.

A recent systematic review of 12 interventional and 7 observational studies on the effect of vitamin D on type 2 diabetes reported that there is not sufficient evidence supporting the beneficial effects of vitamin D supplementation on glycemic control among patients with type 2 diabetes (43), this conclusion was reached despite cumulative evidence on the direct and indirect role of vitamin D in glucose metabolism and the established association between serum vitamin D status and glycemic status. More specifically, the systematic review concluded that daily supplementation with lower than 6000 IU/day vitamin D $(38,44-45)$, supplementation with 400-5600 IU/day vitamin D for less than 6 months $(38,46)$, and supplementation with vitamin D among individuals with well-managed type 2 diabetes or sufficient serum vitamin D levels did not improve biomarkers of glucose metabolism (43). In contrast; we found significant improvement in GA\% in the first phase of study (baseline to 3 months), when participants had hypovitaminosis D. When participants reached the sufficiency level (> $20 \mathrm{ng} / \mathrm{mL})$ at 3 months, there were no further improvements in GA\% from 3 months to 6 months.

It has been suggested that supplementation with more than $4000 \mathrm{IU}$ of vitamin D may have beneficial effects on serum FPG, HbAlc and insulin resistance among individuals with type 2 diabetes (47). In a recent meta-analysis of 24 controlled trials, Mirhosseini et al. (47) indicated insufficient evidence regarding the improvement in glycemic control with vitamin D supplementation might be due to insufficient dose of vitamin D (< 4000 IU/day), short duration of supplementation, high BMI and small study sample size (47). Obesity has inverse effects on serum $25(\mathrm{OH}) \mathrm{D}(48)$. As vitamin D is a 
fat-soluble vitamin, it can get trapped in the fat tissue and become less biologically available to the body. Vimaleswaran et al. (49) reported a $1.15 \%$ decrease in serum $25(\mathrm{OH}) \mathrm{D} 3$ for each $\mathrm{kg} / \mathrm{m}^{2}$ increase in BMI. It is suggested that obese people with insufficient vitamin D level should take 2-3 times higher doses of vitamin D to replenish.

A recent prospective observational cohort study found a significant decrease in HbA1c with vitamin D3 supplementation for 9 months (50). This study was conducted among 1000 individuals with type 1 and type 2 diabetes. The supplementation dosage in this study was not revealed in the article (50). Although we cannot compare this study with ours based on the vitamin D supplementation dosage, their extended study duration may suggest vitamin D supplementation for longer periods than 6 months may have beneficial effects on glycemic control outcomes in individuals with diabetes.

In a community-based longitudinal study among 1018 individuals without type 2 diabetes, the effect of vitamin D supplementation alone, and vitamin supplementation in combination with other nutrients on glycemic status was assessed (51). First group (n $=223$ ) received daily supplementation of 1000-20,000 IU/day vitamin D3, as needed to achieve the target serum 25(OH)D3 level, and group $2(\mathrm{n}=790)$ was assigned to 1000 20,000 IU/day with vitamin D3 and additional supplements (omega-3 fatty acids, vitamin C, magnesium, caprylic acid, PolyGlycopleX and probiotics). The results of this study showed significant increase in serum 25(OH)D3 in both groups over the period of 12 months. HbA1c and CRP were significantly reduced only among group 2, after 12 months of supplementation. Larger decrease in $\mathrm{HbA} 1 \mathrm{c}$ and CRP levels were associated with higher $25(\mathrm{OH}) \mathrm{D} 3$ level after 12 months. The results of this study suggested that participants in group 2 were less likely to develop prediabetes/diabetes, compared to 
participants in group 1 ( $8 \%$ vs. 16\%). Furthermore, $44 \%$ of subjects with prediabetes in group 2 improved to normoglycemic after 12 months, compared to $8 \%$ in group 1 . This study concluded that vitamin D supplementation in combination with other nutrients may have beneficial effects on glycemic control and reduce the risk of diabetogenesis (51).

\section{$\underline{\text { Conclusion }}$}

Daily supplementation with higher doses of vitamin D3 (>4000 IU) may have beneficial effects on health status of individuals with type 2 diabetes. GA\% may be a more sensitive biomarker for oxidative/glycemic changes in individuals with type 2

diabetes and hypovitaminosis D. The limitations of the study included small sample size, lack of a control group, shorter duration of the study, and utilization of frozen serum samples to measure GA. The strengths of the study were its novelty to assess the effect of vitamin D3 supplementation on less studied biomarkers of glycemic/oxidative status and the ability to compare two different doses of vitamin D3 supplementation. Larger studies with longer durations among different racial and ethnic groups with and without diabetes may help to confirm the benefits of vitamin D3 supplementation on oxidative and glycemic health outcomes. 
Table 1. Participants`s characteristics at baseline

\begin{tabular}{lc}
\hline Variable & $\begin{array}{c}\text { Mean } \pm \mathrm{SD} \\
(\mathrm{N}=65)\end{array}$ \\
\hline Age (years) & $54.52 \pm 7.86$ \\
Gender n $(\%)$ & \\
$\quad$ Female & $40(62)$ \\
$\quad$ Male & $25(38)$ \\
Dosage n $(\%)$ & \\
4000 IU & $44(68)$ \\
6000 IU & $21(32)$ \\
BMI $\left(\mathrm{kg} / \mathrm{m}^{2}\right)$ & $33.57 \pm 6.5$ \\
Skin sun exposure score & $4.2 \pm 4.02$ \\
25(OH)D3 (ng/mL) & $22.4 \pm 6.77$ \\
FPG (mg/dL) & $186.478 \pm 79.93$ \\
HbA1c $(\%)$ & $8.41 \pm 2.31$ \\
Insulin $(\mathrm{mg} / \mathrm{dL})$ & $12.63 \pm 11.56$ \\
CRP $(\mathrm{mg} / \mathrm{dL})$ & $8.06 \pm 10.81$ \\
GA $(\mathrm{mg} / \mathrm{mL})$ & $1.51 \pm 0.44$ \\
ALB $(\mathrm{mg} / \mathrm{mL})$ & $32.84 \pm 05.69$ \\
GA\% & $4.69 \pm 1.7$ \\
\hline
\end{tabular}

Data are mean $\pm(\mathrm{SD})$ or \%. BMI $=$ Body mass index. HbA1c $=$ glycated hemoglobin. $\mathrm{CRP}=\mathrm{C}$-reactive protein. $\mathrm{GA}=$ glycated albumin. $\mathrm{ALB}=$ serum total albumin. GA\% $=(\mathrm{GA} / \mathrm{ALB}) \%$. 
Table 2. Mixed model comparisons of repeated measures at baseline, after 3 months and after 6 months without adjustment for covariates.

\begin{tabular}{|c|c|c|}
\hline Variable & $\begin{array}{c}\text { Mean } \pm \mathbf{S E} \\
(\mathbf{N}=\mathbf{6 5})\end{array}$ & $\boldsymbol{P}$-value \\
\hline ALB $(\mathrm{mg} / \mathrm{mL})$ & $33.08 \pm 0.74$ & $* 0.003$ \\
Baseline & $36.67 \pm 0.96$ & $* 0.031$ \\
3 months & $35.52 \pm 0.89$ & \\
6 months & & $* 0.015$ \\
GA\% & $4.58 \pm 0.19$ & $* 0.039$ \\
Baseline & $4.07 \pm 0.14$ & \\
3 months & $4.43 \pm 0.16$ & $*<0.001$ \\
6 months & & $*<0.001$ \\
\hline 25(OH)D3 (ng/mL) & $22.49 \pm 0.897$ & \\
Baseline & $41.96 \pm 1.71$ & \\
3 months & $41.46 \pm 1.91$ & \\
6 months & & \\
& & \\
\hline
\end{tabular}

Data represented by mean \pm standard error. $* P$-values are from multiple comparisons with Bonferroni correction. Statistically significance from baseline. $P<0.05$ is considered significant. Time and dosage interactions were not significant for any of the variables included in table 2. GA=glycated albumin. GA\% $=(\mathrm{GA} / \mathrm{ALB}) \%$. 
Table 3. Mixed model comparisons of repeated measures at baseline, after 3 months and after 6 months with adjustment for covariates.

\begin{tabular}{|c|c|c|}
\hline & $\begin{array}{c}\text { Mean } \pm S D \\
(N=65)\end{array}$ & $P$-value \\
\hline \multicolumn{3}{|l|}{$\operatorname{ALB}(\mathrm{mg} / \mathrm{mL})$} \\
\hline Baseline & $33.02 \pm 0.74$ & \\
\hline 3 months & $36.51 \pm 0.96$ & $0.004 *$ \\
\hline 6 months & $35.42 \pm 0.87$ & $0.046^{*}$ \\
\hline \multicolumn{3}{|l|}{ GA\% } \\
\hline Baseline & $4.58 \pm 0.19$ & \\
\hline 3 months & $4.09 \pm 0.141$ & $0.018 *$ \\
\hline 6 months & $4.41 \pm 0.173$ & 0.471 \\
\hline
\end{tabular}

Data represented by mean \pm standard error. ${ }^{*} P$-values are from multiple comparisons with Bonferroni correction. Statistically significance from baseline. $P<0.05$ is considered significant. $\mathrm{GA}=$ glycated albumin. $\mathrm{ALB}=$ serum total albumin. $\mathrm{GA} \%=(\mathrm{GA} / \mathrm{ALB}) \%$. Time and dosage interactions were not significant for ALB and GA\%. Mixed model analysis was adjusted for age, gender, BMI, sun exposure, fasting plasma glucose, insulin and CRP. 


\section{REFERENCES:}

(1) Xu, J., Murphy, S.L., Kochanek, K.D., \& Bastian, B.A. (2016). Deaths: Final data for 2013. National vital statistics reports. 64(2): 1-118.

(2) Centers for Disease Control and Prevention. (2014). National Diabetes Statistics Report: Estimates of Diabetes and Its Burden in the United States. U.S. Department of Health and Human Services. P. 1-11.

(3) Zhang, Q., Ames, J. M., Smith, R. D., Baynes, J. W., Metz, T. O. (2009). A perspective on the Maillard reaction and the analysis of protein Glycation by mass Spectrometry: Probing the pathogenesis of chronic disease. Journal of Proteome Research. 8(2): 754-769. doi:10.1021/pr800858h.

(4) Meerwaldt, R., Links, T., Zeebregts, C., Tio, R., Hillebrands, J.-L., Smit, A. (2008). The clinical relevance of assessing advanced glycation endproducts accumulation in diabetes. Cardiovascular Diabetology. 7(1): 29. doi:10.1186/1475-2840-7-29.

(5) Ahmad, J., \& Neelofar, K. (2015). Amadori albumin in diabetic nephropathy. Indian Journal of Endocrinology and Metabolism . 19(1), 39. doi:10.4103/22308210.146863.

(6) Takahashi, S., Uchino, H., Shimizu, T., Kanazawa, A., Tamura, Y., Sakai, K., Tanaka, Y. (2007). Comparison of Glycated albumin (GA) and Glycated hemoglobin (HbA1c) in type 2 diabetic patients: Usefulness of GA for evaluation of short-term changes in Glycemic control. Endocrine Journal. 54(1): 139-144.

(7) Snieder, H., Sawtell, P. A., Ross, L., Walker, J., Spector, T. D., Leslie, R. D. G. (2001). HbA1c levels are genetically determined even in type 1 diabetes: Evidence from healthy and diabetic twins. Diabetes. 50(12): 2858-2863.

doi:10.2337/diabetes.50.12.2858.

(8) Leslie, R. D. G., Cohen, R. M. (2009). Biologic variability in plasma glucose, hemoglobin A1c, and advanced Glycation end products associated with diabetes complications. Journal of Diabetes Science and Technology, 3(4): 635-643. doi:10.1177/193229680900300403.

(9) Arasteh, A., Farahi, S., Habibi-Rezaei, M., Moosavi-Movahedi, A. A. (2014). Glycated albumin: an overview of the In Vitro models of an In Vivo potential disease marker. Journal of Diabetes and Metabolic Disorders. 13: 49. http://doi.org/10.1186/2251-6581-13-49

(10) Roche M.1., Rondeau P., Singh N.R., Tarnus E., Bourdon E. (2008). FEBS Lett. 11;582(13): 1783-7. doi: 10.1016/j.febslet.2008.04.057.

(11) Iberg, N., Flückiger, R. (1986). Nonenzymatic glycosylation of albumin in vivo. Identification of multiple glycosylated sites. The Journal of biological chemistry. 261(29): 13542-13545. 
(12) Yoshiuchi, K., Matsuhisa, M., Katakami, N., Nakatani, Y., Sakamoto, K., Matsuoka, T., Hori, M. (2008). Glycated albumin is a better indicator for glucose excursion than Glycated hemoglobin in type 1 and type 2 diabetes. Endocrine Journal. 55(3): 503-507. doi:10.1507/endocrj.k07e-089.

(13) Danese E., Montagnana M., Nouvenne A., Lippi G. (2015). Advantages and Pitfalls of Fructosamine and Glycated Albumin in the Diagnosis and Treatment of Diabetes. J Diabetes Sci Technol. 2015 Mar; 9(2): 169-176. doi: $10.1177 / 1932296814567227$.

(14) Lee J. E. (2015). Alternative biomarkers for assessing glycemic control in diabetes: fructosamine, glycated albumin, and 1,5-anhydroglucitol. Ann Pediatr Endocrinol Metab. 20(2): 74-78. doi: 10.6065/apem.2015.20.2.74.

(15) Cohen, M. P., Shea, E., Chen, S., \& Shearman, C. W. (2003). Glycated albumin increases oxidative stress, activates $N F-\kappa B$ and extracellular signal-regulated kinase (ERK), and stimulates ERK-dependent transforming growth factor- $\beta 1$ production in macrophage RAW cells. Journal of Laboratory and Clinical Medicine. 141(4): 242249. doi:10.1067/mlc.2003.27.

(16) Rodiño-Janeiro, B. K., González-Peteiro, M., Ucieda-Somoza, R., GonzálezJuanatey, J. R., Álvarez, E. (2010). Glycated albumin, a precursor of advanced glycation end-products, up-regulates NADPH oxidase and enhances oxidative stress in human endothelial cells: Molecular correlate of diabetic vasculopathy. Diabetes/Metabolism Research and Reviews. 26(7): 550-558. doi:10.1002/dmrr.1117.

(17) Boyer, F., Diotel, N., Girard, D., Rondeau, P., Essop, M. F.,Bourdon, E. (2016). Enhanced oxidative stress in adipose tissue from diabetic mice, possible contribution of glycated albumin. Biochemical and Biophysical Research Communications. 473(1): 154-160. doi:10.1016/j.bbrc.2016.03.068.

(18) Alvarez, J. A., Ashraf, A. (2010). Role of vitamin D in insulin secretion and insulin sensitivity for glucose Homeostasis. International Journal of Endocrinology. 118. doi:10.1155/2010/351385.

(19) de Souza, C. J., \& Meier, A. H. (1987). Circadian and seasonal variations of plasma insulin and Cortisol concentrations in the Syrian Hamster, Mesocricetus Auratus.Chronobiology International. 4(2): 141-151. doi:10.3109/07420528709078520.

(20) Pittas, A. G., Lau, J., Hu, F. B., Dawson-Hughes, B. (2007). The role of vitamin $\mathrm{D}$ and calcium in type 2 diabetes. A systematic review and Meta-Analysis. The Journal of Clinical Endocrinology \& Metabolism. 92(6): 2017-2029. doi:10.1210/jc.2007-0298.

(21) Harinarayan, C., Arvind, S., Joshi, S., Thennarasu, K., Vedavyas, V., Baindur, A. (2014). Improvement in Pancreatic $\beta$-cell function with vitamin D and calcium Supplementation in vitamin d-deficient Nondiabetic subjects. Endocrine Practice. 20(2): 129-138. doi:10.4158/ep13273.or. 
(22) Mitri, J., Dawson-Hughes, B., Hu, F. B., Pittas, A. G. (2011). Effects of vitamin D and calcium supplementation on pancreatic cell function, insulin sensitivity, and glycemia in adults at high risk of diabetes: The calcium and vitamin D for diabetes Mellitus (CaDDM) randomized controlled trial. American Journal of Clinical Nutrition. 94(2): 486-494. doi:10.3945/ajcn.111.011684..

(23) Khan, H., Kunutsor, S., Franco, O. H., Chowdhury, R. (2012). Vitamin D, type 2 diabetes and other metabolic outcomes: A systematic review and meta-analysis of prospective studies. Proceedings of the Nutrition Society. 72(01): 89-97. doi:10.1017/s0029665112002765.

(24) Song, Y., Wang, L., Pittas, A. G., Del Gobbo, L. C., Zhang, C., Manson, J. E., \& Hu, F. B. (2013). Blood 25-Hydroxy vitamin D levels and incident type 2 diabetes: A meta-analysis of prospective studies. Diabetes Care. 36(5): 1422-1428. doi:10.2337/dc12-0962

(25) Pittas, A., Chung, M., Trikalinos, T., Mitri, J., Brendel, M., Patel, K., Balk, E. (2010). Systematic review: Vitamin D and cardiometabolic outcomes. Annals of internal medicine. 152(5): 307-314.

(26) Baz-Hecht M., Goldfine A.B. (2010). The impact of vitamin D deficiency on diabetes and cardiovascular risk. Curr Opin Endocrinol Diabetes Obes. 17(2): 113-9. doi: 10.1097/MED.0b013e3283372859.

(27) Bischoff-Ferrari, H., Borchers, M., Gudat, F., Dürmüller, U., Stähelin, H., Dick, W. (2004). Vitamin D receptor expression in human muscle tissue decreases with age.Journal of Bone and Mineral Research. 19(2): 265-269.

doi:10.1359/jbmr.2004.19.2.265.

(28) Zeitz, U., Weber K., Soegiarto, D.S., Wolf, E., Balling, R., Erben, R.G. (2003). Impaired insulin secretory capacity in mice lacking a functional vitamin D receptor. The FASEB Journal. 17(3): 509-11 doi:10.1096/fj.02-0424fje.

(29) Holick, M. F. (2007). Vitamin D deficiency. New England Journal of Medicine. 357(3): 266-281. doi:10.1056/nejmra070553

(30) Reusch, J. E. ., Begum, N., Sussman, K. E., Draznin, B. (1991). Regulation of GLUT-4 Phosphorylation by Intracellular calcium in Adipocytes. Endocrinology. 129(6): 3269-3273. doi:10.1210/endo-129-6-3269.

(31) Borissova, A.M., Tankova, T., Kirilov, G., Dakovska, L., Kovacheva, R. (2003). The effect of vitamin D3 on insulin secretion and peripheral insulin sensitivity in type 2 diabetic patients. Int J Clin Pract. 57(4): 258-261.

(32) Baynes, K. C. R., Boucher, B. J., Feskens, E. J. M., Kromhout, D. (1997). Vitamin D, glucose tolerance and insulinaemia in elderly men. Diabetologia. 40(3): 344347. doi:10.1007/s001250050685. 
(33) Scragg, R., Sowers, M., Bell, C. (2004). Serum 25-Hydroxyvitamin D, diabetes, and ethnicity in the Third national health and nutrition examination survey. Diabetes Care. 27(12): 2813-2818. doi:10.2337/diacare.27.12.2813.

(34) Pittas, A. G., Harris, S. S., Stark, P. C., Dawson-Hughes, B. (2007). The effects of calcium and vitamin D Supplementation on blood glucose and markers of inflammation in Nondiabetic adults. Diabetes Care. 30(4): 980-986. doi:10.2337/dc061994.

(35) Manickam, B., Neagu, V., Kukreja, S., Barengolts, E. (2013). Relationship between Glycated hemoglobin and circulating 25-Hydroxyvitamin D concentration in African American and Caucasian American men. Endocrine Practice. 19(1): 73-80. doi:10.4158/ep12168.or.

(36) Coskun, H., Aydin, Y., Kutlucan, A., Yildirim, H., Kudas, O., Kir, S., Turgut, M. (2012). Vitamin D3 deficiency effect on the HbA1c in type 2 diabetic population, Endocrine Abstracts. 29: P733.

(37) Shanthi, B., Revathy, C., Devi, A. J. M., Parameshwari, P. J., Stephen, T. (2012). Serum 25(OH)D and Type 2 Diabetes Mellitus. Journal of Clinical and Diagnostic Research. 6(5): 774-776.

(38) Madar, A. A., Knutsen, K. V., Stene, L. C., Brekke, M., Meyer, H. E., Lagerløv, P. (2014). Effect of vitamin D3 supplementation on glycated hemoglobin (HbA1c), fructosamine, serum lipids, and body mass index: A randomized, doubleblinded, placebo-controlled trial among healthy immigrants living in Norway. BMJ Open Diabetes Research \& Care. 2(1), e000026. doi:10.1136/bmjdrc-2014-000026.

(39) Exebio, J. C., Zarini, G. G., Ajabshir, S., Antwi, J., \& Huffman, F. G. (2015). Validation of a sun exposure questionnaire among subjects with type 2 diabetes residing in south Florida. Journal of Immigrant and Minority Health. 18(1): 228-233. doi:10.1007/s10903-015-0163-7.

(40) Ajabshir, S., Exebio, J., Zarini, G., Nayer, A., McLean, M., Shaban, L., \& Huffman, F. (2014). Skin color and self-reported sun exposure scores are associated with serum 25-Hydroxyvitamin D concentrations in a multi-ethnic population living in south Florida.British Journal of Medicine and Medical Research, 4(34): 5312-5323. doi:10.9734/bjmmr/2014/10551.

(41) Cohen M.P., Hud. (1989). Production and characterization of monoclonal antibodies against human glycoalbumin. J Immunol Methods. 8;117(1): 121-129.

(42) Cohen M.P., Hud. (1989). Measurement of plasma glycoalbumin levels with a monoclonal antibody based ELISA. J Immunol Methods. 1;122(2): 279-283.

(43) Santos R.K.F., Brandão-Lima P.N., Tete R.M.D.D., Freire A.R.S., Pires L.V. (2017). Vitamin D ratio and glycaemic control in individuals with type 2 diabetes mellitus: A systematic review. Diabetes Metab Res Rev. doi: 10.1002/dmrr.2969. 
(44) Ryu O.H., Lee S., Yu J., Choi M.G., Yoo H.J., Mantero F. (2014). A prospective randomized controlled trial of the effects of vitamin D supplementation on long-term glycemic control in type 2 diabetes mellitus of Korea. Endocr J.61(2): 167-76.

(45) George PS, Pearson ER, Witham MD. (2012). Effect of vitamin D supplementation on glycaemic control and insulin resistance: a systematic review and meta-analysis. Diabet Med. 29: 142-150.

(46) Elkassaby S., Harrison L.C., Mazzitelli N., Wentworth J.M., Colman P.G., Spelman T., Fourlanos S. (2014). A randomised controlled trial of high dose vitamin D in recent-onset type 2 diabetes. Diabetes Res Clin Pract.106(3): 576-582. doi: 10.1016/j.diabres.2014.08.030.

(47) Mirhosseini N., Vatanparast H., Mazidi M., Kimball S.M. (2017). The Effect of Improved Serum 25-Hydroxyvitamin D Status on Glycemic Control in Diabetic Patients: A Meta-Analysis. J Clin Endocrinol Metab. 102(9): 3097-3110. doi: 10.1210/jc.2017-01024.

(48) Vimaleswaran K.S. Berry D.J., Lu C., Tikkanen E. , Pilz S., Hiraki L.T., CooperJ.D., Dastani Z., Li R., Houston D.K., Wood A.R., Michaëlsson K., Vandenput L., Zgaga L., Yerges-Armstrong L.M., McCarthy M.I., Dupuis J., Kaakinen M., Kleber M.E., Jameson K., Arden N., Raitakari O., Viikari J., Lohman K.K., Ferrucci L., Melhus H., Ingelsson E., Byberg L., Lind L., Lorentzon M., Salomaa V., Campbell H., Dunlop M., Mitchell B., Herzig K.H., Pouta A., Hartikainen A.L., Streeten E.A., Theodoratou E., Jula A., Wareham N.J., Ohlsson C., Frayling T.M., Kritchevsky S.B., Spector T.D., Richards J.B., Lehtimäki T., Ouwehand W.H., Kraft P., Cooper C., März W., Power C., Loos R.J., Wang T.J., Järvelin M.R., Whittaker J.C., Hingorani A.D., Hyppönen E. (2013). Genetic Investigation of Anthropometric Traits-GIANT Consortium . Causal relationship between obesity and vitamin D status: bi-directional Mendelian randomization analysis of multiple cohorts. PLoS Med. 10(2): e1001383.

(49) Veugelers P.J., Pham T.M., Ekwaru J.P. (2015). Optimal vitamin D supplementation doses that minimize the risk for both low and high serum 25hydroxyvitamin D concentrations in the general population. Nutrients.7(12): 1018910208.

(50) Buhary B.M., Almohareb O., Aljohani N., Alrajhi S., Elkaissi S., Sherbeeni A, Almaghamsi A., Abdulhamid Khan S.,Almalkia M.H. (2017). Association of Glycosylated Hemoglobin Levels With Vitamin D Status. J Clin Med Res. 9(12): 10131018. doi: 10.14740/jocmr3227w.

(51) Kimballa S. M., Emery J. C. H.,Lewanczuk R. Z. (2017). Effect of a vitamin and mineral supplementation on glycemic status: Results from a community-based program. Journal of Clinical \& Translational Endocrinology. 


\section{CHAPTER V: SUMMARY AND CONCLUSIONS}

The results of the present study showed that pro-inflammatory dietary intakes may be associated with increased risk of hypo-insulinemia and incidence of higher SBP among individuals with type 2 diabetes and vitamin D deficiency/insufficiency. Furthermore, we showed daily oral supplementation with higher doses of vitamin D, $4000 \mathrm{IU}$ and $6000 \mathrm{IU} /$ day compared to the recommended dose of $600 \mathrm{IU} / \mathrm{day}$, for 6 months may improve oxidative stress status among a group of individuals with type 2 diabetes and vitamin D deficiency/insufficiency. Serum 8-OHdG may be a predictive biomarker of DNA/RNA damage among individuals with type 2 diabetes. Our results showed no improvements in 8-OHDdG after 3 months of supplementation with vitamin $\mathrm{D}$ among individuals with vitamin D deficiency/insufficiency. This may suggest that longer supplementation durations than 3 months should be considered for interventions among individuals with vitamin D insufficiency/deficiency. We did not find significant changes in sun exposure during the 6 month period of this study. This study suggests daily supplementation with higher doses of vitamin D3, 4000 IU and 6000 IU/day compared to the recommended dose of $600 \mathrm{IU} /$ day, may have further beneficial effects on health status of individuals with type 2 diabetes. Vitamin D supplementation for 3 months may decrease the GA\% among individuals with type 2. This study showed that GA\% change pattern followed 25OHD change pattern inversely: As 25OHD increased from baseline to 3 months, GA\% decreased. When 25OHD remained unchanged from 3 months to 6 months, GA\% did not change significantly. Based on the present study`s results, GA\% may be a more sensitive biomarker for oxidative/glycemic changes in individuals with type 2 diabetes and hypovitaminosis D. 
In summary, daily oral supplementation with higher doses of vitamin D, $4000 \mathrm{IU}$ and $6000 \mathrm{IU} /$ day compared to the recommended dose of $600 \mathrm{IU} / \mathrm{day}$, and antiinflammatory dietary intakes may have beneficial effects on health status of individuals with type 2 diabetes and vitamin D deficiency/insufficiency. The results of this study may serve as a basis for the future nutrition interventions to improve the dietary inflammatory intake and health status of individuals with type 2 diabetes. Larger studies with longer durations among different racial and ethnic groups with and without diabetes may help to confirm the benefits of vitamin D3 supplementation and anti-inflammatory dietary patterns on oxidative and glycemic health outcomes. 
Appendix 1: Consent Form 


\title{
FIU]
}

ADLLT CONSENT TO PARTICIPATE IN A RESEARCH STUDY

\author{
"The Effect of Vitamin D Supplementation on Cardioyascular Risk Factors among Hispanies and \\ African Americans with Type 2 diabetes"
}

\section{PURPOSE OF THE STUDY}

You are being asked to participate in a research study. The purpose of this study is to determine the effect of supplemental vitamin D intake on cardiovascular risk factors in Hispanics and African Americans with typc 2 diabetes.

\section{NUMBER OF STUDY PARTICIPANTS}

If you decide to be in this study, you will be one of 120 people in this research study.

\section{DURATION OF THE STUDY}

Your participation will require one (1) visit evcry 3 months and each visit may last up to 3 hours. You will be asked to participate in an initial blood collection screening. Depending on your yitamin D level, you will be contacted either to continue in the study or you will be told that you do not qualify after your first visit. If you qualify for the study, you will be required to make a total of 4 visits to the human nutrition lab, during the study period.

\section{PROCEDURES}

If you agree to be in the study, the following procedures will be done:

1. You will provide information on your gender, age, level of education, year of diagnosis of diabetes, medication use, and smoking.

2. You will answer questions about your mood, sun exposure habits and dictary intakes.

3. Your skin color will be measured by a hand-held device. This will be painless.

4. A certified phlebotomist will draw your blood (approximately four tablespoons of blood or $15 \mathrm{ml}$ ). Blood will be drawn from your arm. You will also provide a urine sample.

5. You will be required to take Vitamin D at a dose of $4000 \mathrm{IU} /$ day or 6000IU/day for 6 months.

6. You will take $4000 \mathrm{IU} /$ day if you are one of the first 60 participants and $6000 \mathrm{IU} /$ day if you are among the next 60 participants.

\section{RISKS AND/OR DISCOMFORTS}

The following risks may be associated with your participation in this study: First, soreness, redness or possible infection of the area in front of elbow joint from where blood will be drawn. A certified phlebotomist will be using sterile and standard procedures. Therefore, risks of soreness, redness or infection may be extremely rare. Second, you may experience very mild dizziness that is reversible within few minutes without any effects. Taking high doses of Vitamin D may cause signs of toxicity such as nausea, vomiting, excess thirst, excess urination, weakness and nervousness. You will be requircd to immediately report to the PI or the study team if you experience any of these issues. Study team will regularly monitor you at all visits for signs of toxicity. If you show signs of toxicity due to vitamin D, you will be withdrawn from the study. 


\section{FIU 10}

\section{BENEFITS}

The following benefits may be associated with your participation in this study:

- You will receive your blood test, diet analysis results and be able to ask questions about Diabetes and the study.

- Vitamin D may improve your bone density.

\section{ALTERNATIVES}

You may choose not to participate in the study or withdraw from the study at anytime without any consequences.

\section{CONFIDENTIALITY}

The records of this study will be kept private and will be protected to the fullest extent provided by law. In any sort of report we might publish, we will not include any information that will make it possible to identify a subject. Research records will be stored securely and only the research team will have access to the records. The U.S. Department of Health and Human Services (DHHS) and/or the Food and Drug Administration (FDA) may request copies of your records to review them. Your records may also be reviewed for audit purposes by authorized University or other agents who will be bound by the same provisions of confidentiality. A description of this clinical trial will be available on http://www.ClinicalTrials.gov, as required by US Law. This web site will not include information that can identify you. At most, the web site will include a summary of the results. You can search this website at anytime.

\section{COMPENSATION \& COSTS}

You will receive a payment of twenty $(\$ 20)$ dollars for your participation on the first visit. If you qualify for the study, you will receive a payment of twenty $(\$ 20)$ dollars on your second visit and forty $(\$ 40)$ dollars each on the third and fourth visit. You will not be responsible for any costs to participate in this study.

\section{MEDICAL TREATMENT}

Routinely, FIU, its agents, or its employees do not compensate for or provide free care for human subjects in the event that any injury results from participation in a research project. If you become ill or injured as a direct result of participating in this study, contact your regular medical provider. If you have insurance, your insurance company may or may not pay for these costs. If you do not have insurance, or if your insurance company refuses to pay, you will be billed. Funds to compensate for pain, expenses, lost wages and other damages caused by injury are not routinely available. If you show symptoms of physical or mental illness, you will be referred to your physician with your permission.

\section{RIGHT TO DECLINE OR WITHDRAW}

Your participation in this study is voluntary. You are free to participate in the study or withdraw your consent at any time during the study. Your withdrawal or lack of participation will not affect any benefits to which you are otherwise entitled. The investigator reserves the right to withdraw you from the study without your consent at such time that they feel is in the best interest of the study participant. 


\section{FIU]}

\section{RESEARCHER CONTACT INFORMATION}

If you have any questions about the purpose, procedures, or any other issues relating to this research study you may contact Dr. Fatma G. Huffman at HLS I room 435, (305) 348-3788, huffmanf@fiu.edu.

\section{IRB CONTACT INFORMATION}

If you would like to talk with someone about your rights of being a subject in this research study or about ethical issues with this research study you may contact Dr. Patricia Price, the Chairperson of the FIU Institutional Review Board (IRB) at 305-348-261 8 or 305-348-2494.

\section{PARTICIPANT AGREEMENT}

I have read the information in this consent form and agree to participate in this study. I have had a chance to ask any questions I have about this study, and they have been answered for me. I understand that I am entitled to a copy of this form after it has been read and signed.

Signature of Participant

Printed Name of Participant

Signature of Person Obtaining Consent
Date

Date 


\section{FIU /}

\section{CONSENTIMIENTO PARA PARTICIPAR EN UN ESTUDIO DE INVESTIGACION \\ "EI Efecto de la Suplementación con Vitamina D en los Fuctores de Riesgo de Enfermedad Cardiovascular en Hispanos y Afro-Americanos con Diabetes Tipo 2"}

\section{PROPOSITO DEL ESTUDIO}

Usted ha sido invitado para participar en un estudio de investigación. El propósito del estudio es detcrminar el efecto de la suplementación con vitamina $D$ en factores de riesgo cardiovasculares en Hispanos y AfroAmericanos con diabetes tipo 2.

\section{NUMERO DE PARTICIPANTES EN EL ESTUDIO}

Si usted participa en este estudio, será una de las 120 personas en este estudio de investigación.

\section{DURACION DEL ESTUDIO}

Su participación requerirá una (1) visita cada 3 meses y duraran alrededor de 3 horas cada una. Usted proveerá una muestra de sangre para selección. Dependiendo de sus niveles de vitamina $D$ en sangre usted será contactado para continuar en el estudio o será retirado del mismo. Si usted califica para el estudio, usted tendrá que hacer un total de 4 visitas al laboratorio de nutrición humana.

\section{PROCEDIMIENTOS}

Si usted acepta participar en este estudio, los siguientes procedimientos serán realizados:

1. Usted proveerá información sobre su género, edad, nivel educacional, año de diagnostico de diabetes, medicación usada, y habito de fumar;

2. Usted responderá preguntas sobre sus sentimientos, hábitos de exposición al sol e ingesta de alimentos;

3. Su color de piel será medido por un instrumento manual. Esto será indoloro;

4. Un flebotomista certificado le sacara sangre (aproximadamente 4 cucharadas de sangre o $15 \mathrm{ml}$ ). La sangre será obtenida de su brazo. Usted proveerá una muestra de orina

5. Usted tendrá que tomar $4000 I U$ o $6000 \mathrm{IU}$ de vitamina $\mathrm{D}$ al día por 6 meses.

6. Usted tomara $4000 \mathrm{UL} /$ dia si usted es uno de los 60 primeros participantes y $6000 \mathrm{UL} /$ dia is usted esta dentro de los siguientes 60 participantes.

\section{RIESGOS Y/O MOLESTIAS}

Los siguientes riesgos pueden ser asociados con su participación en el estudio: primero, dolor, enrojecimiento o posible infección del área enfrente del codo de donde la sangre fue obtenida. Un flebotomista certificado usara procedimientos estériles y estándares, por lo tanto, el riesgo de dolor, enrojecimiento o infección es muy raro. Segundo, usted puede experimentar un ligero mareo, el cual desaparecerá en unos pocos minutos sin ningún efecto. Tomar altas dosis de vitamina $\mathrm{D}$ puede causar síntomas de intoxicación como nausea, vomito, excesiva sed, excesiva micción, debilidad y nerviosismo. Usted tendrá que reportarse inmediatamente al PI o al equipo de investigación si usted sufriera de alguno de estos síntomas. El equipo de investigación estará constantemente monitoreando algún signo de intoxicación que usted presente. Si usted presenta signos de intoxicación causados por la vitamina $\mathrm{D}$, usted podría ser retirado del estudio.

\section{BENEFICIOS}

Los siguientes beneficios pueden ser asociados con su participación en este estudio:

- Usted recibirá los resultados de su análisis de sangre, dieta y podrá hacer preguntas referentes a la diabetes.

- La vitamina D puede mejorar su densidad ósea 


\title{
Fii]/
}

\begin{abstract}
Aliternativas
Usted puede escoger no participar en el estudio o retirarse del estudio en cualquier momento sin ninguna consecuencia.
\end{abstract}

\section{CONFIDENCIALIDAD}

Los archivos de este estudio scrán privados y protegidos por la ley. En cualquicr reporte que nosotros publiquemos, no incluiremos ninguna información que haga posible identificar a un sujeto. Los archivos serán guardados en forma asegura y solo el equipo de investigación tendrá acceso a ellos. El Departamento de Salud y Scrvicios Humanos de los Estados Unidos (DHHS) y/o la Administración de Alimentos y Drogas (FDA) pueden pedir copias de sus archivos para revisarlos. Sus archivos pueden ser también revisados para propósitos de auditoría por agentes autorizados de la Universidad u otros agentes quc seguirán las mismas reglas de confidencialidad. Una descripción de este estudio clínico estará disponible en http://www.ClinicalTrials.gov, según lo requiere la ley. Esta página web no incluirá información que lo pueda identificar. A lo sumo, la página web incluirá un resumen de los resultados. Usted puede acceder a esta página web en cualquier momento.

\section{COMPENSACION Y COSTOS}

Usted recibirá un pago de veinte $(\$ 20)$ dólares por su participación en la primera visita. Si usted califica para el resto del estudio, recibirá un pago de veinte $(\$ 20)$ dólares en su segunda visita y cuarenta $(\$ 40)$ dólares por la tercera y cuarta visita. Usted no será responsable de ningún costo por participar en este estudio.

\section{TRATAMIENTO MEDICO}

Rutinariamente, FIU, sus agentes, o sus empleados no compensan o proveen cuidado gratis a sujetos en el evento de que una lesión resulte de su participación en cl proyecto de investigación. Si usted resulta enfermo o lesionado como resultado directo de su participación en el estudio, contacte a su médico. Si usted tiene seguro, su compañía de seguros puede o no pagar por estos costos. Si usted no tiene seguro, o si su compafía de seguros se niega a pagar, usted será facturado. Fondos para compensar por dolor, gastos, pérdida de salario y otros daños causados por lesión no están disponibles habitualmente. Si usted muestra sintomas de enfermedad física o mental, será referido a su médico con su consentimiento.

\section{DERECHO DE DECLINAR O RETIRARSE}

Su participación en el estudio es voluntaria. Usted es libre de participar en el estudio o de retirar su consentimiento en cualquier momento durante el estudio. Su retiro o falta de participación no afectara ningún beneficio para los cuales tenga derecho. Los investigadores se reservan el derecho de removerlo del estudio sin su consentimicnto en el momento que ellos lo crean necesario.

\section{INFORMACION DE CONTACTO DEL INVESTIGADOR}

Si tiene alguna pregunta acerca del propósito, procedimiento, u otro tema relacionado a esta investigación, puede contactar a Dr: Fatma G. Huffman en HLS I oficina 435, (305) 348-3788, huffmanf@fiu.edu.

\section{INFORMACION DE CONTACTO DEL IRIS}

Si usted desea hablar con alguien acerca de sus derechos como participante en este estudio o acerca de temas éticos relacionados con el estudio, puede contactar a Dr. Patricia Price, Directora del Comité de Revisión Institucional de la FIU (IRB) al 305-348-2618 o 305-348-2494. 


\section{FIU}

ACUERDO DEL PARTICIPANTE

Yo he leído la información en esta forma de consentimiento y estoy de acuerdo en participar en el estudio. Yo he tenido la opción de hacer preguntas acerca del estudio y han sido respondidas. Yo entiendo que tengo derecho a una copia de esta forma después de haberla leído y firmado.

Firma del Participante

Fecha

Nombre del Participante

Firma de la Persona que Obtiene el Consentimiento

Fecha 
Appendix 2: Short Food Frequency Questionnaire 
This form asks about your usual eating habits over the past year.

First: For each food listed, mark the column to show how often, on average, you ate the food during the past year

Please BE CAREFUL which column you put your answer in.

Second: Mark whether your usual serving size is small, medium, or large. Please DO NOT OMIT serving size.

\section{Additional Comments:}

Please DO NOT SKIP any foods, if you never eat a food, mark "Never ar less that once per month."

A small serving is one-half the medium serving size shown or less.

A large serving is about one-and-a-haif times the medium serving size shown or more.

Sample: This person ate medium serving of rice about twice per month and never ate squash.

\begin{tabular}{|c|c|c|c|c|c|c|c|c|c|c|c|c|c|}
\hline \multirow[b]{3}{*}{ Type of food } & \multicolumn{8}{|c|}{ How Often } & \multicolumn{5}{|c|}{ How Much } \\
\hline & $\begin{array}{c}\text { Never or } \\
\text { Less than } \\
\text { Once }\end{array}$ & 1 per & $2 \cdot 3$ per & 1 per & 2 per & $3-4$ per & 5-6 per & 1 por & $2+$ per & Mediu in & & $\begin{array}{l}\text { Your } \\
\text { Servin } \\
\text { Size }\end{array}$ & \\
\hline & per Month & Month & Month & Week & Week & Week & Week & Dxy & Day & Serving & $s$ & M & $L$ \\
\hline Rice & & & $x$ & & & & & & & $3 / 4$ cup & & $x$ & \\
\hline $\begin{array}{l}\text { Winter squas hi } \\
\text { baked squash }\end{array}$ & $x$ & & & & & & & & & $1 / 2$ cup & & & \\
\hline
\end{tabular}

\begin{tabular}{|c|c|c|c|c|c|c|c|c|c|c|c|c|c|}
\hline Type of Beverage & $\begin{array}{l}\text { Never or } \\
\text { Less than } \\
\text { Once } \\
\text { per Month }\end{array}$ & $\begin{array}{l}1 \mathrm{per} \\
\text { Month }\end{array}$ & $\begin{array}{l}2.3 \text { per } \\
\text { Month }\end{array}$ & $\begin{array}{l}1 \text { per } \\
\text { Week }\end{array}$ & $\begin{array}{l}2 \text { per } \\
\text { Week }\end{array}$ & $\begin{array}{l}34 \text { per } \\
\text { Week }\end{array}$ & $\begin{array}{l}5.6 \text { per } \\
\text { Week }\end{array}$ & $\begin{array}{l}1 \text { per } \\
\text { Day }\end{array}$ & $\begin{array}{c}2.3 \text { per } \\
\text { Day }\end{array}$ & $\begin{array}{l}\text { Medium } \\
\text { Serving }\end{array}$ & s & $\begin{array}{l}\text { h } \\
\text { Your } \\
\text { Serving } \\
\text { Size } \\
\text { M }\end{array}$ & $\mathrm{L}$ \\
\hline $\begin{array}{l}\text { Whole milk and } \\
\text { bev rrages with } \\
\text { whole milk (not } \\
\text { including creagls) }\end{array}$ & & & & & & & & & & 802 glass & & & \\
\hline $\begin{array}{l}\text { 2\% milk and } \\
\text { beverage } \\
\text { Win 2\% milk (not } \\
\text { inclucing cereall) }\end{array}$ & & & & & & & & & & $80 z$ glass & & & \\
\hline $\begin{array}{l}\text { Skim mik, } 1 \% \text { milk } \\
\text { or buttermilk (not } \\
\text { inclucing on cereal) }\end{array}$ & & & & & & & & & & $80 z$ glass & & & \\
\hline Malk in corflee or tea & & & & & & & & & & 1 ables poon & & & \\
\hline
\end{tabular}




\begin{tabular}{|c|c|c|c|c|c|c|c|c|c|c|c|c|c|}
\hline Type of food & $\begin{array}{l}\text { Never or } \\
\text { Less than } \\
\text { Once } \\
\text { per Month }\end{array}$ & $\begin{array}{l}1 \text { per } \\
\text { Month }\end{array}$ & $\begin{array}{l}2-3 \text { per } \\
\text { Month }\end{array}$ & $\begin{array}{l}1 \text { per } \\
\text { Week }\end{array}$ & $\begin{array}{l}2 \text { per } \\
\text { Week }\end{array}$ & $\begin{array}{l}3-4 \text { per } \\
\text { Week }\end{array}$ & $\begin{array}{l}\text { 5-6 per } \\
\text { Waek }\end{array}$ & $\begin{array}{l}1 \text { per } \\
\text { Day }\end{array}$ & $\begin{array}{c}2+\text { per } \\
\text { Day }\end{array}$ & $\begin{array}{l}\text { Medium } \\
\text { Serving }\end{array}$ & ow I & $\begin{array}{l}\text { Your } \\
\text { endn } \\
\text { Size } \\
\text { M }\end{array}$ & $\mathbf{L}$ \\
\hline Broccoll & & & & & & & & & & $1 / 2$ cup & & & \\
\hline $\begin{array}{l}\text { Mustard greens, } \\
\text { urnip greens, } \\
\text { collarc greens }\end{array}$ & & & & & & & & & & 1/2 cup & & & \\
\hline $\begin{array}{l}\text { Spaghett, } \\
\text { lasagna, other } \\
\text { paste wlth } \\
\text { omaxo sauce }\end{array}$ & & & & & & & & & & 1 cup & & & \\
\hline $\begin{array}{l}\text { Mixed dishes with } \\
\text { cheese (such as } \\
\text { macaroni and } \\
\text { cheesa) }\end{array}$ & & & & & & & & & & 1 cup & & & \\
\hline $\begin{array}{l}\text { Cheese and } \\
\text { cheese spreads } \\
\text { (inclucing on } \\
\text { sandwiches, } \\
\text { burgers, taccs; } \\
\text { and nachos; } \\
\text { not including } \\
\text { cotage cheese) }\end{array}$ & & & & & & & & & & $\begin{array}{c}2 \text { strices } \\
\text { or } \\
2 \mathrm{Oz}\end{array}$ & & & \\
\hline $\begin{array}{l}\text { Whise bread } \\
\text { (including } \\
\text { sardiwlches, } \\
\text { bagoss, burger } \\
\text { folls, French or } \\
\text { talian bread) }\end{array}$ & & & & & & & & & & 2 silces & & & \\
\hline $\begin{array}{l}\text { Dark bread, } \\
\text { such as wheat, } \\
\text { rye, pumper- } \\
\text { rickel (including } \\
\text { sandwiches) }\end{array}$ & & & & & & & & & & 2 slices & & & \\
\hline $\begin{array}{l}\text { Biscuits or } \\
\text { muffins } \\
\text { (inclucing } \\
\text { test foods) }\end{array}$ & & & & & & & & & & $\begin{array}{l}1 \text { medium } \\
\text { piece }\end{array}$ & & & \\
\hline ce croam & & & & & & & & & & $\begin{array}{c}1 \text { scoop or } \\
1 / 2 \text { cup }\end{array}$ & & & \\
\hline $\begin{array}{l}\text { Yogutst, frozen } \\
\text { yogurt }\end{array}$ & & & & & & & & & & 1 cup & & & \\
\hline Milk on cereal & & & & & & & & & & $1 / 2$ cup & & & \\
\hline
\end{tabular}




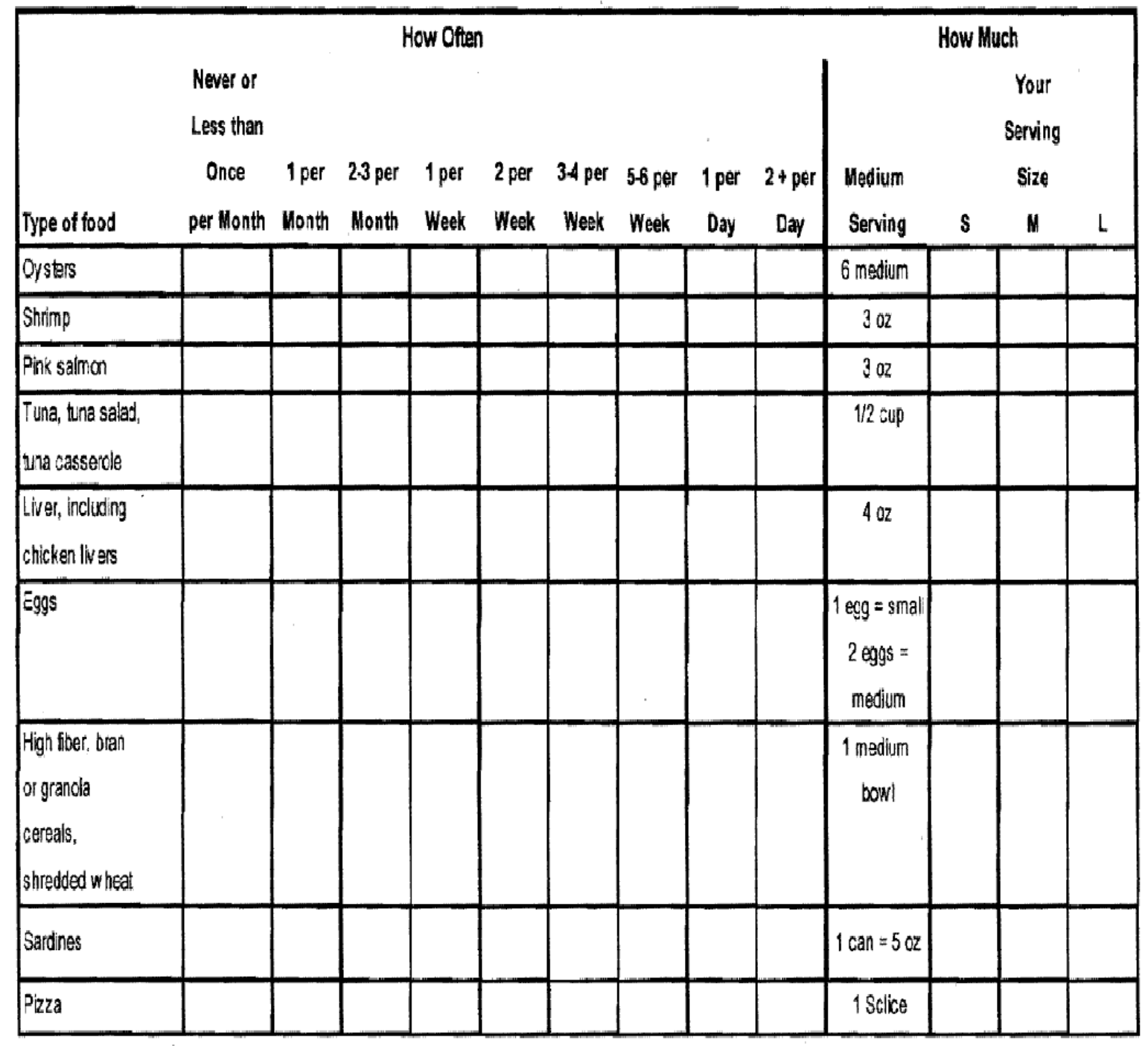


Appendix 3: Skin Color and Anthropometrics Record Form 


\section{Anthropometries, Blood Pressure \& skin color (screening/baseline/3months/6months)}

Weight:

pounds

Height: inches

BMI:

Waist circumference 1 ..cms

Waist circumference 2 cms

Average Waist Circumference: $\mathrm{cms}$

Blood Pressure 1:

Systolic $\mathrm{mm} \mathrm{Ig}$

Diastolic. . $\mathrm{mm} \mathrm{Hg}$

\section{Blood Pressure 2:}

Systolic $\mathrm{mm} \mathrm{Hg}$

Diastolic $\mathrm{mm} \mathrm{Hg}$

\section{Average Blood Pressures:}

Average Systolic: . $\mathrm{mm} \mathrm{Hg}$

Average Diastolic: $m m ~ H g$

\section{Skin color I:}

Forearm:

Upper arm:

Stomach:

Skin color 2:

Forcarm:

Upper arm:

Stomach:

Average Skin Color:

Forearm:

Upper arm:

Stomach:

Average difference: 
Appendix 4: Demographic Questionnaire 
Please answer each of the questions by filling in the blanks with the correct answer or by choosing the single best answer.

Q1. Please indicate your age in years

Q2. Male $\square 1 \quad$ Female $\square$ 2

Q3. How much schooling did you have?

$\square$ 1. $8^{\text {th }}$ grade or less

$\square$ 2. Some high school

$\square$ 3. High school diploma or GED

$\square$ 4. At least some college

Q4. Do you use tobacco? No $\square$ ? Yes $\square$ 2

Q4a. Please indicate your tobacco use

$\square_{1}$ Cigarettes $\square_{2}$ Cigar $\square_{3}$ Pipe $\square_{4}$ Chewing

Q4b. How many cigarettes do you smoke each day on average?

$\square_{1} \quad 1-6 \quad \square=\quad 7-12 \quad \square_{3} \quad 13$ or more

Q5. How many drinks of alcohol ( $12 \mathrm{oz}$ beer, $5 \mathrm{oz}$ wine, $1 \mathrm{oz}$ hard liquor) do you drink each week on average?

$\square 1$ None $\quad \square_{2} \quad 1-2 \quad \square_{3} \quad 3-7 \quad \square_{4} \quad 8-14 \quad \square_{5} \quad 15-21 \quad \square 6 \quad 22$ or more

Q6. Please indicate any of the following types of medications that you take

$\square$. Cholesterol-lowering

$\square$ z Blood-sugar regulating (not including insulin)

$\square$ Hypertensive medication

$\square 4$ Anti-depressants

$\square$ Pain killers

$\square 5$ Aspirin

Q7. What year were you first diagnosed with diabetes? $19 . . . . . . . . . . .$.

Q8. What is your marital status? $\square_{1}$ Married $\square 2$ Single $\square_{3}$ Divorced $\square{ }_{4}$ Widawed Q9. Do you currently have a job? $\square_{1}$ No $\quad \square_{2}$ Yes $\square_{3}$ l am disabled

Q10. How many years have you been living in the US?

Q11. Do you currently have health insurance? $\square 1$ No $\square \square_{2}$ Yes 
Appendix 5: Compliance and Adverse Events Form 
3 months visit date:

Baseline visit date:

No of days between visits (a):

PILL COUNT

Pills dispensed during last visit: $\quad$ Number of pilis taken (b):

Adherence b/a:

On time $\square \quad$ Late $\square \quad$ Compliant: Yes/ No

Adverse Events Log

Date of event:

Date reported to IRB:

Notes about the event:

Remarks/Comments about the visit

Hospitalization: Yes/No

Surgery: Yes/ No

6TH MONTH VISIT

6months visit date:

3 months visit date:

No of days between visits (a):

Pill count

Pilis dispensed during last visit: $\quad$ Number of pills taken (b):

Adherence b/a:

On time $\square \quad$ Late $\square \quad$ Compliant: Yes/ No

\section{Adverse Events Log}

Date of event:

Date reported to IRB:

Notes about the event:

Type of visit: 6 months

Type of visit: 6 months


VITA

\section{SAHAR AJABSHIR}

2006-2010 B.Sc., Cell Molecular Biology and Biochemistry, Azad University of Mashhad, Mashhad, Iran

2011-2013 M.Sc., Dietetics and Nutrition, Florida International University, United States

\section{PUBLICATIONS}

Validation of a Sun Exposure Questionnaire Among Subjects with Type 2 Diabetes Residing in South Florida. Joel C. Exebio, Gustavo G. Zarini, Sahar Ajabshir, Janet Antwi, Fatma G. Huffman. Journal of Immigrant and Minority Health. Jan 2015. DOI 10.1007/s10903-015-0163-7

Lifestyle Behaviors and Self-Rated Health: The Living for Health Program. Gustavo G. Zarini, Joan A. Vaccaro, Maria A. Canossa Terris, Joel C. Exebio, Laura Tokayer, Janet Antwi, Sahar Ajabshir, Amanpreet Cheema, and Fatma G. Huffman. Journal of Environmental and Public Health Volume 2014, Article ID 315042, 9 pages, http://dx.doi.org/10.1155/2014/315042

Skin Color and Self-reported Sun Exposure Scores are Associated with Serum 25Hydroxyvitamin D Concentrations in a Multi-ethnic Population Living in South Florida. Sahar Ajabshir, Joel Exebio, Gustavo Zarini, Ali Nayer, Michael McLean, Lemia Shaban, Fatma Huffman. British Journal of Medicine and Medica Research. 4(34): 53125323, July 2014

Use of Homeostatic Model Assessment Indexes for the Identification of Metabolic Syndrome and Insulin Resistance among Cuban-Americans: A Cross Sectional Study. Joel Exebio, Sahar Ajabshir, Gustavo Zarini, Lemia Shaban, Fatma Huffman. British Journal of Medicine and Medica Research. 4(26): 4455-4469, June 2014

Ethnic Differences in Insulin Resistance, Adiponectin Levels and Abdominal Obesity: Haitian Americans and African Americans, with and without Type 2 Diabetes Mellitus. Amanpreet K Cheema, Gustavo Zarini, Joel Exebio, Sahar Ajabshir, Lemia Shaban, Joan Anne Vaccaro and Fatma G. Huffman. British Journal of Medicine and Medica Research. 4(26): 4455-4469, June 2014 
The effects of vitamin D on the renin-angiotensin system. Sahar Ajabshir, Arif Asif, Ali Nayer. J Nephropathol. 2014; 3(2): 41-43

The association of depression and perceived stress with beta cell function between African and Haitian Americans with and without type 2 diabetes. Fatma G. Huffman, Maria Vallasciani, Joan A. Vaccaro, Joel C. Exebio, Gustavo G. Zarini, Ali Nayer, Sahar Ajabshir. Journal of Diabetes Mellitus, 2013; 3:4

Perceived stress and self-rated health of Haitian and African Americans with and without type 2 diabetes. Fatma G. Huffman, Joan A. Vaccaro, Sahar Ajabshir, Gustavo G. Zarini, Joel Exebio, Zisca Dixon. J Res Med Sci, 2013; 18(3): 198-204

Relationship of omega-3 on C-reactive protein and homocysteine in Haitian and African Americans with and without type 2 diabetes. Fatma G. Huffman, Joan A. Vaccaro, Joel C. Exebio, Sahar Abajshir, Gustavo G. Zarini, Lamya H. Shaban. J Nutr Food Sci 2013; 3:1

Intelligent Health Card. S. Ajabshir, J. Chamani. Science Cultivation Journal 2011; 1:7277

Innovation Management, Sahar Ajabshir. Innovation Festival of Azad University of Mashhad, Mashhad, Iran- March 2009

Association of Serum 25-hydroxyvitamin D, Quantitative Insulin Sensitivity Check Index (QUICKI) and Homeostatic Model Assessment Indexes of Insulin Resistance (HOMA1-IR and HOMA2-IR) Among Three Ethnic Groups. S. Ajabshir, J. Exebio, G. Zarini, F. Huffman. FASEB J, 2017

Effect of Vitamin D3 Supplementation on Blood Pressure in Hispanics with Type 2 Diabetes. Gustavo G. Zarini, Joel Exebio, Joan Vaccaro, Michael McLean, Sahar Ajabshir, Fatma G. Huffman. FASEB J, 2017

Homeostatic Model Assessment Index 1 and 2 Are Associated with Serum 25Hydroxyvitamin D among Haitians and African-Americans Living in South Florida. S. Ajabshir, J. Exebio, G. Zarini, J. Voccaro, F. Huffman. FASEB J, 2016

The Effect of Vitamin D Supplementation on Blood Lipids in Minorities with Type 2 Diabetes. J. Exebio, S. Ajabshir, G. Zarini, F. Huffman. FASEB J, 2016

High Density Lipoprotein Cholesterol to Total Cholesterol Ratio Is Associated with Index of Central Obesity in a Young Multi-ethnic Group Living in South Florida. F.G. Huffman, S. Ajabshir, T. Li, J. Exebio, G. Zarini. FASEB J, 2016 